
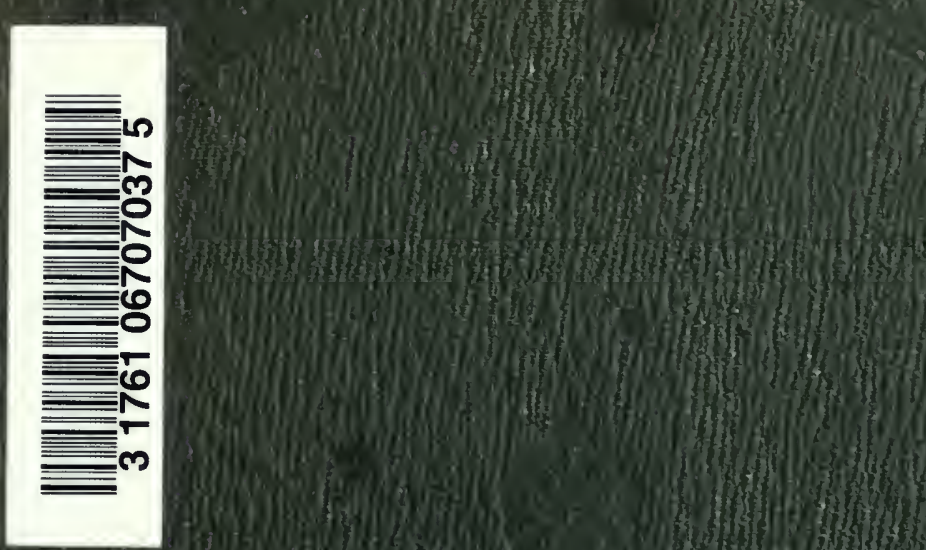


\section{NEW EDITIONS OF STANDARD WORKS.}

1. PROU'I ON THE NATURE AND TREATMENT OF STOMACH AND RENAL. DISEASES. Fifth Edition. 8vo. 20 s.

2. IVILLIAMS' PRINCIPLES OF MEDICINE; Couprehending General Pathology axd Teerapeutics. Second Edition. 8vo. 14s.

3. COOPER ON DISLOCATIONS AND FraCtures. New Edition. Edited by BraNsBy Cooper. 8vo. 20 s.

4. COOPER ON THE STRUCTURE AND DISEASES OF THE TESTIS. With 24 highly-finished Coloured Plates. Second Edition. 21.10 .

5. LAWRENCE'S TREATISE ON RUPTURES. Fifth Edition. 8vo. $16 s$.

6. HOPE ON DISEASES OF THE HEART AND GREAT VESSELS. Fourth Edition. Post 8vo. 10s. 6d.

7. CARPENTER'S PRINCIPLES OF GENERAL AND COMPARATIVE PHYSIOLOGY. Third Edition. 8ro.

8. CARPENTER'S PRINCIPLES OF HUMAN PHYSIOLOGY. Third Edition. 8vo. 21 s.

9. ADDISON ON HEALTHY AND DISEASED STRUCTURE. 8 ro. $12 s$.

10. BIRD ON URINARY DEPOSITS; their Diagnosis, Pathology, ANd Therapeutical indications. Third Edition. Post 8 vo.

11. RAMSBO'HAM'S PRINCIPLES AND PRACTICE OF OBSTETRIC MEDICINE AND SURGERY. Second Eḍition. 8vo. 22s.

12. BUDD ON DISEASES OF THF LIVER. 8ro. $14 s$.

13. WILSON ON DISEASES OF THE SKIN. Second Edition. 8ro. $12 s$. The same Work, with Exgravings on Steel, accurately Coloured. 8vo. $28 s$.

14. HENNEN'S PRINCIPLES OF MILITARY SURGERY. Third Edition. 8vo. 16 s.

15. BENNET ON INFLAMMATION, ULCERATION, AND INDURATION OF THE NECK OF THE UTERUS. Second Edition. 8vo. $12 s$.

16. PARKER'S MODERN TREATMENT OF SYPHILITIC DISEASES. Second Edition. Post 8vo. 6s. 6d.

17. LEE'S CLINICAL MIDIVIFERY; coMprising Histories of Difficult, Preternatural, and Complicated labour. Second Edition. Fcap. 8 ro. 5.5.

18. Gaipdner ON GOUT; its History, its Causes, and its Cure. Post 8vo. 6s.

19. LISTON'S PRACTICAL SURGERY. Fourth Edition. Svo. $22 s$.

20. HALL'S PRACTICAL OBSERVATIONS AND SUGGESTIONS IN MEdiciNe. First and Second Series. Post 8vo. 8s. $6 d$. each.

21. CONOLLY ON THE CONSTRUCTION AND GOVERNMENT OF LUNATIC ASYLUNIS. Post 8vo. 6.8 .

22. DRUITT'S SURGEON'S VADE-MECUM. Fifth Edition. Fcap. Sro. 12s. $6 d$.

23. 'TILT ON DISEASES OF MENSTRUATION, AND OVARIAN INFLAMMATION. Post 8 vo. $6 s$.

24. JONES ON ANIMAL CHEMISTRY IN ITS RELATION TO STONIACH AND RENAL DISEASES. 8vo. 68 . 


\section{WORKS ON CHEMISTRY.}

BOWMAN'S INTRODUCTION TO CHEMISTRY; with numerous Engravirigs on Wood. Fcap. $8 \mathrm{vo} .6 s, 6 d$.

BOWMAN'S HAND-BOOK OF MEDICAL CHEMISTRY. With numerous Engravings on Wòd. Fcap. 8ro. 6s. 6d.

FRESENIUS' INSTRUCTION IN CHEMICAL ANALYSIS.

QUALITATIVE. Third Edition. 8vo. 9s.

QUANTITATIVE. 8vo. $14 s$.

FOIVNES' CHEMISTRY, AS EXEMPLIFYING THE WISDOM AND BENEFICENCE OF GOD. Second Edition. Fcap. 8vo. 4s. $6 d$.

GRIFFITHS' CHEMISTRY OF 'THE FOUR SEASONS. With Engravings on Wood. Post 8vo. cloth, 10s. 6d.

PROUT'S CHEMISTRY, METEOROLOGY, AND THE FUNC'TIONS OF DIGESTION. Third Edition. 8vo. $15 s$.

\section{CHURCHILL'S MANUALS.}

Fcap. 8vo. clotll, 12s, 6d, each Volume.

AGGREGATE SALE 43,500 COPIES.

ANATOMY.-ErasuUs IViLson, F. R.S.

CHEMISTRY.-Dr. FownEs, F.R.S.

MATERIA MEDICA.-Dr. Royle, F.R.S.

MEDICAL JURISPR UDENCE.-Dr. TAYLOR, F. P.S.

NATURAL PHILOSOPHY.-Dr. G. Bird, F. R.S.

OPHTHALMIC MEDICINE.-WhaRTON JONES, F.R.S.

PHysiologY.-Dr. Carpenter, F. li.S.

POISONS.-Dr. TAYlon, F.R.S.

SURGERY.-Mr. FERgusson, F.R.S.

\section{THREE SPLENDIDLY ILLUSTRATED WORKS.}

PATHOLOGY OF THE HUMAN EYE. Illustrated in a Series of Colovren Plates, from Original Drawings. By John Daleymple, F.R.S., F.R.C.S. Fasciculus I. to VI. Imperial quarto. 20s, each.

SURGICAL ANATOMY. A Series of Dissections, illustrating the Principal Regions of the Human Body. By Josepr Maclise, F,R.C.S. Fasciculus I. to VII. Imperial folio, $5 s$, each.

PORTRAITS OF SKIN IDSEASES. By Erasmus IVILSON, F.R.S. Fasciculus I. to VIII. 20s, each. 
Digitized by the Internet Archive in 2007 with funding from Microsoft Corporation 


\section{THE PHILOSOPHY}

OF

\section{I T A L M O T I O N.}

$\mathrm{BY}$

CHARLES BLAND RADCLIFFE, M.B.

Licentate of the royal college of physicians;

LECTURER ON Vegetable PHYSIOLOGY AND bOtANY AT THE WESTMINGTER HOSPITAL, ETC. ETC.

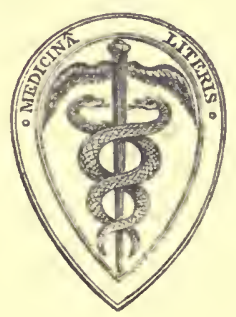

LONDON :

JOHN CHURCHILL, PRINCES STREET, SOHO.

M DCCCLI. 



\section{CONTENTS.}

CHAPTER I.

Preliminary considerations Respecting Vital motion . $\begin{array}{r}\text { pag } \\ 1\end{array}$

\section{CHAPTER II.}

OF VITAL MOVEMENTS.

A. Of vital movements in vessels and cells . . 10

\section{SeCtion I.}

OF VITAL MovemeNtS IN THE VeSSELS, CELLS, AND INTERcellular passages of the plant . . . . . . . 11

I. In the laticiferous vessels (cyclosis) . . . . . 14

II. In simple cells, (including the phenomena of "rotation"). . . . . . . . . 20

III. In the plant generally (circulation of the sap). . 27

\section{SECTION II.}

Of vital movements in the Vessels AND Cells of animal bodies . . . . . . . . . . . . . 32

I. In capillary vessels . . . . . . . . . 33

II. In cells . . . . . . . . . . . . . . 49

\section{CHAPTER III.}

B. Of Vital Movements SUCH AS ARE SEEN IN THE IRRITABLE TUMOURS OF THE SENSITIVE PLANT, IN THE COATS OF THE ALIMENTARY CANAL, AND IN VOLUNTARY MUSCLES . . . . . . . . . 52 


\section{SECTION I.}

IN THE IRRITABLE TUMOURS OF THE SENSITIVE PLANT. • 52

\section{SECTION II.}

IN THE COATS OF THE ALMMENTARY CANAL AND IN VOLUNTARY MUSCLES . . . . . . . . . . 56

I. In the coats of the alimentary canal, \&c. . . . 62

II. In the voluntary muscles : . . . . . . . 71

\section{CHAPTER IV.}

C. Of vital movements in the heart . . . . . 106.

\section{CHAPTER V.}

OF THE NERVOUS INFLUENCE AS AN AGENT IN VITAL MOVEMENT . . . . . . . . . . . . 126

\section{CHAPTER VI.}

OF THE ACTION OF MIND IN VITAL MOVEMENT . . . 128 


\section{P R E F A C E.}

IN a work lately published under the title of "Proteus; or, the Law of Nature," I have endeavoured to realize that unity, or $\tau \grave{o} \hat{\varepsilon} \nu$, which is said to ensoul the diversities of things, and bind them together in one. I have traced this principle in plant and animal, not merely as a vague generality, but as pervading the entire structure-from a simple organ to a perfect organism, and from the complicated nervous, vascular, or osseous systems, to the more rudimentary parts of the economy. I have traced, also, the same principle into inorganic bodies;-so that in relation to form, we may conclude that there is one archetypal law in all created things, whether animate or inanimate. Heat, light, chemical affinity, electricity, motion, and other physical agencies, have also been found to be connected with each other, and with the more recondite vital influences, as correlative aspects of one central force; so that the unity of creation is reflected in force as well as form. And finally, this principle 
has seemed to be absolute, for on proceeding onwards it. is seen to be impossible to separate form from force, and to regard the one as a mere lifeless image, or the other as a mere "naked essence." .

But it may be objected that all these ideas are mere philosophical abstractions, and that this unity of nature is not a practical truth to be realized in the problems of every-day physiology. If there be this oneness of which you speak, it may be asked, how is it that the body is obedient to a law which is totally different to anything we find in inorganic nature? Will it explain the hitherto inexplicable capillary movements of the blood? - will it solve the oftperplexed, and still unread riddle of muscular action? -will it tell us why the heart continues its mysterious beatings? - will it give the clue to a hundred acts and movements which are distinctive of life, and which we are obliged to refer to an incomprehensible and potent essence which is shut up in every living body?-for, except it will help to do these things, the doctrine is of no practical value. An objection like this is just and right, for no one can be expected to receive an opinion which is based merely on transcendental facts and arguments, especially when it is belied (or seems to be) by his own daily experience. 
Let us encounter, then, this objection on the grounds that are here indicated, and inquire whether the phenomena of vital motion will not receive light and interpretation from the doctrine they seem to contradict. Remembering the arguments for a common law, let us not seek the explanation in the body alone in which the movements are manifested, but in a wider range of causes. Let us treat unity as a reality and not as a fiction, and wait patiently for the result. If we do this, every phenomenon will be found to point to this truth; and this truth, on the other hand, by enlarging our ideas to receive the comprehensiveness of nature, will enable us to advance far towards the explanation of vital motion. If we do this, the movements of blood or other nutrient fluids in vessels independently of any cardiac impulse, the action of muscle, the beating of the heart, and many other mysteries of life, will no longer perplex us, for each will interpret the other, and all will refer to a common law-cosmical_one.

4, Henrietta-street, Cavendish-square.

January 1st, 1851. 


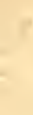

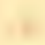

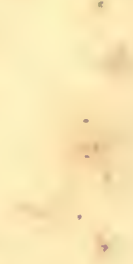

$\therefore \quad+$ $0+\infty$
$+\infty$

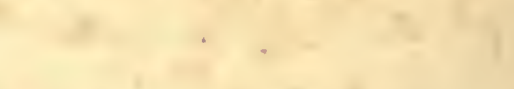

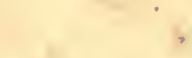

$+\infty$

$+$

?.:

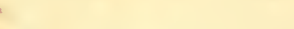

. +1 i $\therefore$,

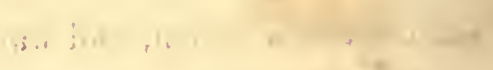

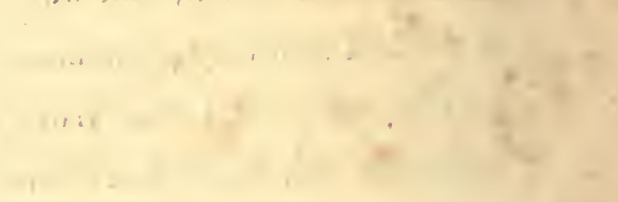

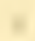

$+1$

$+7$

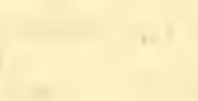

$+$

a 
'THE'

\section{PHILOSOPHY OF VITAL MOTION.}

\section{CHAPTER I.}

\section{PRELIMINARY CONSIDERATIONS RESPECTING} .VITAL MOTION.

IN spring the seed of the sensitive plant becomes the seat of active life, and the sapling emerges from the shelter in which it had slept during the cold season; in summer the foliage is unfolded; in autumn the verdure and freshness are lost; and in winter the plant is bare and dead. At the return of spring the buds receive new life and awake from their dormant condition; in summer the branches are reclothed with leaves and blossoms; in autumn the vital energies decline; and in winter the plant is again reduced to a naked and lifeless skeleton. Year by year these phenomena succeed each other in the same order and with the same regularity, so that the vitality would seem to ebb and flow in direct relation to the varying intensity of the sunbeams. At daybreak, also, the 
leaves recover from the closed and pendent condition in which they are found at night, and-if not disturbed in any manner-they remain erect and unfolded until evening, when they again close and droop; and these alternations recur in this order so long as the characteristic sensitiveness is retained. In both cases, indeed, there is a manifest connexion between the phenomena and certain changes in the relative positions of the earth and sun, the one referring to the annual, and the other to the diurnal revolution; and hence it may be argued that the vital movements of the sensitive plant are due to the joint operation of cosmical force, and of an innate principle which belongs to the individual organism.

The egg of the lizard, like the seed of which we have spoken, exhibits no signs of development unless it be quickened and fostered by external agents; and the same aid is necessary after the animal has escaped from the shell. In the perfect state there is a sensitive and intelligent principle by which the actions are regulated and governed, but this does not supersede the foreign powers which acted upon the egg. It is a constant rule, indeed, for this animal to be active and full of life in warm weather, and to hybernate in cold - the periods of animation and torpidity being in exact correspondence with the summer and winter; and it is equally constant for the same animal, when in its active state, to wake throughout the day and to 
sleep throughout the night; - and hence we may argue that the vivifying rays of the sun are essential to the continuance as well as to the commencement of existence, and that the vital movements of the lizard depend, not merely upon a source and spring of action that is peculiar to the creature itself, but also upon a more general and comprehensive agent, which affects at one and the same time the entire realm of nature.

As in the sensitive plant and lizard, so in other plants and animals, the vital movements are found to refer partly to internal and partly to external agencies. In some cases there may be greater energy in the forces which reside within the organism; in others the influence of surrounding nature may be more powerful; but in every case the two classes of agencies are invariably associated.

In order, therefore, to arrive at any satisfactory knowledge of vital motion, it is necessary to examine it in relation to cosmical as well as to organic force,or rather in relation to the forces which originate within and without the organism-for we find, on the one hand, that cosmical force pervades the organism and constitutes part of its vitality, and, on the other, that organic force is not restricted to the limits of the body. Before we enter upon any special and systematic enquiries, however, it may be well to endeavour to obtain some preliminary information upon the mode in which the bodily structures are affected by some of 
the more ordinary varieties of what may be called extra-organic force, in contradistinction to that which,

* originating within the body, may be called intraorganic. And this shall be the subject of our present chapter.

As we might anticipate, the parts of the plant or animal which respond most readily to extraorganic agents, are those which are simple and rudimentary in their character; for in the higher textures, such as muscle, the influence of this class of agents is greatly masked by the workings of inherent vitality. In the simple tissues, however, there is no obscurity.

In the sensitive plant, for example the cellular cushions which move the leaves are found to expand under the influence of light and warmth, and to contract on the withdrawal of these agents; and with few exceptions, and these but apparent, the same law is observable in all similar organs.

The simpler fabrics of animal bodies, which are furthest removed from the control of the nervous system, and in this respect most nearly allied to the tissues of the plant, are also found to move in obedience to an external impulse. The subcutaneous areolar web is shrunk and puckered in winter, so as to give rise to the appearance called "cutis anserina," 
and it is relaxed or expanded in summer. When exposed to cold, also, the dartos contracts in a very remarkable manner, and an opposite condition is induced by the operation of warmth. And so likewise in the vascular coats of erectile tissue.

These instances furnish different points of view, from which we may regard all the principal forms of rudimentary tissue. The irritable tumours of the sensitive plant consist chiefly of cells which do not differ from the ordinary cells of plants. Areolar tissue is composed of fibrils of various sizes, which are formed from the same material as the primary cells, and which material appears to be absolutely identical in plant and animal. The tunic of the dartos is only another form of areolar web, in which there is a preponderance of certain thicker fibres, that are present everywhere in less abundance; and between these fibres and those which enter into the composition of the vascular coats, there is a direct and immediate gradation. Each form, indeed, is transitional to the other, and the whole constitute a group that includes all structures subordinate to true muscle. It is of moment, therefore, that we find these tissues to contract when exposed to cold, and to pass into an opposite state under the influence of warmth, inasmuch as this action must be supposed to be common to all the rudimentary tissues of the economy. In this way, 
then, we obtain evidence of the operation of external agents in the phenomena of vital motion, and learn at the same time the mode of action, so far at least as that force is concerned which is most intimately wedded to motion-namely, heat.

This result is in harmony with that which marks the operation of the same agent in inanimate bodies, for these contract or expand according to the presence or absence of heat: and yet there is an important difference in the midst of this seeming analogy. It is found, indeed, that there is a much greater alteration of volume in organic solids, under trifling changes of temperature, than in any other bodies. Under no higher degree of heat than what is expressed by the term warmth, the fibrils of the areolar covering of the body are greatly elongated, provided they were previously in a contracted state; and in the fibres of the dartos and erectile tissue, the former length may be doubled. In inorganic solids, on the contrary, the change, under these circumstances, would be almost inappreciable; and even in fluids, which are apt to undergo greater changes than solids, and are very sensible to the motive power of heat, as may be seen in the mounting or falling of the liquid in the tube of the thermometer, we are acquainted with no instances where the change is in 
any way commensurate with that which is witnessed in these organic solids.

Notwithstanding this peculiarity, however, it is evident that the simple vital movements of which we speak are connected with, and in some degree determined by, ordinary heat, and on further examination we find no reason to doubt this conclusion.

It is found, indeed, that various inorganic solids are affected differently by heat, some being acted upon to a much greater extent than others: and this is sufficient to show that there may be a still further difference in organic substances, without any departure from the mere physical character of the phenomenon.

It may be observed, also, that the solids in question are composed of several elements, as oxygen, hydrogen, nitrogen, and carbon, which for the most part remain gaseous when in an uncombined state, and of which the mutual affinity is so feeble that they readily pass into an aëriform condition, - and hence it may be supposed that such solids will undergo a greater change of volume under the action of heat than an inorganic substance, in which the constitution is simple and the molecular affinity more stable. And for the same reason it need be no ground of wonder that the change should be greater than in water, or in any other fluid whose particles do not tend to 
remain gaseous under the ordinary condition of the atmosphere.

The hygroscopic property of organic substances, which is illustrated in the expansion or contraction of the belts of sea-wrack which occasionally serve as hygrometers, or in the shortening or lengthening of a lady's ringlets, according to the moisture of the atmosphere-is another circunstance which may in part account for the changes of volume in these tissues. It is probable that the heat which determines the evaporation of water from the earth operates, remotely, in preparing these bodies to receive a portion of this fluid within their interstices; but whatever the explanation may be, the phenomenon is of a physical character, inasmuch as it is exhibited when the subjects of it are removed altogether from the operations of vitality. This hygroscopic property, therefore, is another reason why the remarkable changes of volume in the rudimentary tissues of the organism, under slight changes of temperature, may be nothing more than the natural and physical consequence of the constitution of these tissues.

Such would appear to be some general facts in connexion with the operation of one form of external agent, in some of the simpler phenomena of vital movement. They show that the motions in the tissues of the plant and animal, of which mention has been made, may be referred in part to causes that are 
not within the pale of life; and also that the movements themselves, in so far as they are related to heat, are analogous to those which are brought about by the same agent in inorganic substances, any apparent difference being only one that may be accounted for by the mere physical constitution of the tissue. 


\section{CHAPTER II.}

\section{OF VITAL MOVEMENTS.}

THESE phenomena may be arranged under three heads:- Under the first, are those which are seen in vessels and cells; under the second, all such movements as occur in the irritable tumours of the sensitive plant, in the coats of the alimentary canal, and in the voluntary muscles; and under the third, the rhythmical beatings of the heart. We shall speak of the several varieties of vital motion according to this arrangement, and then add some separate considerations on the influence of the nerves and mind in these phenomena.

\section{A. OF VITAL MOVEMENTS IN VESSELS $A N D$ CELLS.}

These movements are less complex in the plant than in the animal, for here they are not confused by the cardiac impulse; and it is in the plant, therefore, that we institute our first inquiries. 


\section{Section I.}

OF VITAL MOVEMENTS IN THE VESSELS, CELLS, AND

INTERCELLULAR PASSAGES OF THE PLANT.

\section{Preliminary Considerations.}

In plants, the sap exhibits very positive motion, but there is no true circulation. There is a general movement which belongs to the plant as a whole, and to which all parts contribute; and there is a special movement, which is itself divided into two varieties, the one belonging to the laticiferous vessels, and the other to certain single cells.

The plan of the general movements of the sap would seem to vary at different times and places. When examined during the summer, the main current is found to pass from the roots, through the fibres and ducts of the newly-formed woody zones of the stem, to the upper surface of the leaves. It then tends towards the lower surface of the leaf, and thence, in a downward direction, through the fibrous structures of the bark, passing at the same time inwardly and horizontally through the tissues which form the medullary rays. "Very little of the elaborated sap reaches the roots, from which the motion commenced; and none of it, except that small quantity which mixes with the ascending current, is again transmitted through the system." The movement is not confined to any special tissue, but it seems to pervade indiscriminately the 
intercellular passages as well as the cavities of the cells, and to pass without difficulty through organic membranes, except these be thickened and altered by solid deposits. During the winter, however, or, at any rate, in times of severe frost, (as we learn from M. Biot,) the sap of the same plant flows chiefly from the branches towards the roots, so that at these times the former organs would seem to exercise the office which generally belongs to the latter. In plants, also, where the roots are sparingly developed, and infixed in arid and moving sand, or in parasites, whose dry, aërial roots are every-way unfitted to the function of absorption, it is clear that the fluids necessary to the wants of the economy must find entrance by other channels. In the lower cellular plants, also, which are adherent to dry and barren rocks, the surface which exercises the function of absorption is that which corresponds to the aërial system of more perfect plants. It would appear, therefore, that the stem and root, with their several organs respectively, may be the channel of absorption, a varying degree of importance being assigned to either in different plants; and this we may understand to be possible, from the law of analogy which has been already set forth in another work. It would appear, also, that there are periodical changes in the same plant, so that no one plan can be considered as constant - a supposition which is the more probable from the fact, that the sap infiltrates 
through the textures generally, like a stream through a porous rock, and not in fixed and definite channels.

The movement of the elaborated sap or latex in the laticiferous vessels, to which the name of cyclosis is given, has been fully investigated by Professor Schultz. It is the counterpart of the capillary circulation in the higher animals in the earlier periods of their fœetal history, or of that which remains permanently in some of the rudimentary entozoid forms; that is to say, it is not a single and constant stream, proceeding and returning to and from a common fixed centre or heart, but a complex movement, consisting of many distinct currents directed to and from certain independent centres, the positions of which are subject to continual change. This is the plan observable in the vascular area of animal bodies prior to the formation of the heart, and therefore there is nothing special and peculiar in the phenomena of cyclosis.

The second special movement of the sap, or rotation, is that which is observed in the contents of certain cells, and the phenomena are always limited to one of these rudimentary bodies. The law is not constant, and there are great and manifest variations, not only in different plants, but even in contiguous cells of the same plant. In one instance, the movement is directed along one wall of the cavity, and in a contrary direction down the other side, the line of the current being in accordance with the longitudinal axis of the cell: 
in another instance it follows a spiral course in a transverse direction: in a third it is vague, and to all appearance unobservant of any particular law.

In attempting to detect the causes of these several movements, we propose to commence our task with the study of the phenomena of cyclosis, for here we secure an intermediate position between the vague and imperfectly-understood movements confined to individual cells, and that more complicated circulation of the sap which extends to the entire plant.

\section{OF THE MOVEMENTS IN THE MILK VESSELS OF THE PLANT (CyClosis).}

In this, as in every phenomenon of vital movement, we have to seek for the efficient cause in agents which proceed from surrounding objects, and in agents which reside within the organism.

1. Of extra-organic force as the agent in the phenomena of cyclosis.

On watching the movements of the sap in the laticiferous vessels, Dr. Lindley found them to cease in a low temperature, and to recommence when the plant was carried into a warm room; and in this fact we have evidence of a partial dependence upon the influence we designate as heat. Let us begin our examination, then, by inquiring into the manner in 
which this physical agent may be concerned in these changes; and to this end, let us divest ourselves of those ideas of mysterious and unknown powers with which the explanation is presumed to be connected, and at the same time banish the notion that the causes of vital movement must, of necessity, be different from those which determine motion in inanimate bodies, while we consider, on ordinary principles, the necessary effects of heat under these circumstances.

Motion is one of the effects of heat in ordinary matter, repulsion of the particles marking the communication, and attraction the withdrawal, of the influence. If the body acted upon be arranged in a tubular form, an alteration in the capacity of the cavity must result, the calibre being diminished or extended, as the case may be. Such, also, may be presumed to be the effect of heat in a vessel composed of the simpler organic fabrics, for we have already seen that the particles of these tissues are affected like those of inorganic bodies.

Let it be supposed, then, that a latex vessel is acted upon by heat, and what, we may ask, will be the consequences. The vessel, as we have already seen, is composed of matter possessed of a remarkable susceptibility to movement under slight alterations of heat, much greater in degree than that which belongs to water, or blood, or the allied fluids, and therefore 
we suppose that the expansion of the latex will not be commensurate with the change experienced by the coats of the vessel; and hence, the primary operation of heat upon the vessel will be the production of a vacuum between the coats and the contents.

The operation of heat, therefore, may be the cause of the primary act of absorption, for to fill the vacuum which is thus formed, it is evident that there must be a rushing inwards of aëriform or watery fluids from neighbouring parts - a phenomenon readily permitted by the porosity, which is one of the properties of organic membrane-and thus the filling of the shrunk and empty laticiferous web, on the return of spring, may be nothing more than the necessary effect of the increased warmth of the season.

It does not appear, however, by what means the solar heat can be concerned in the production of the focal movements by which the latex is agitated, for this agency operates uniformly and equally upon all portions of the web. Nor in the construction of the vessels themselves does there appear to be any peculiarity which could localize the operation, inasmuch as the focal points are subject to change, and not confined to any fixed and permanent positions. At this stage of our inquiry, also, we do not find any aid in the physical agencies which are correlative of heatnamely, light, electricity, and the rest-and therefore we leave our present point of view, and proceed to 
study the phenomena of cyclosis in relation to the agents, which reside within the organism.

2. Of intra-organic force as the agent in the phenomena of cyclosis.

In addition to vital and peculiar principles, we find within the organism the several forces of ordinary matter-namely, heat, chemical affinity, electricity, and the rest. Of these agents, at this stage of our inquiry, heat is the only one whose effects are tangible and intelligible, and therefore we leave the others in abeyance for the present.

We know from the history of the animal economy that the production of organic heat will be commensurate with the molecular changes of the nutrient fluid, and the solid textures in relation to this fluid; and hence we may argue that the quantity of latex present in any part of the laticiferous web, will be a fitting measure of the capacity of that part for the production of heat. A greater amount of this influence, we may argue, will be extricated where the vessels are dilated and congested with sap, (vasa expansa,) than in the places where the vascular calibre is contracted, and the contents evacuated (vasa contracta).

The variable sizes of the laticiferous tubes, which is characteristic of the system, may therefore be the cause of some irregularities in the origination and 
operation of organic heat. Where indeed a vessel is more dilated, there we may suppose molecular changes, which will necessitate a further dilatation, by which additional quantities of fluid will be attracted from neighbouring parts; for although changes take place cotemporaneously in vessels which are contracted and comparatively empty, yet these lesser phenomena will be absorbed and counteracted by the greater. For the same reason, also, that the more expanded portions should, in the first instance, be the seat of a more vigorous extrication of heat and consequent expansion, by which currents are determined towards them, so also we must grant the possession of the same faculty when they have become more expanded by absorption. Once set up indeed, the process of expansion must go on in these parts, for anything we know to the contrary, either until a sufficient resistance is opposed by the pressure of neighbouring parts, or until the vessel is ruptured_for the coats will be less able to resist the distending force as the expansion progresses.

The stage of contraction in the laticiferous web which supervenes upon dilatation would seem to argue the abstraction or suspension of force, and such may be the case. This will appear if we leave those focal centres which have attained their maximum degree of enlargement, and cast our eyes upon other portions of the same system of ressels. There we find irregularity in the sizes of the tubes: and hence we may begin 
again as at first; and as the absorbing power of the original centres is suspended we may argue that the vessels which are most dilated at the time of suspension, will in their turn take upon themselves a faculty of expansion and become centres of attraction. These secondary centres will expand at the expense of the neighbouring vessels: and this process will go on (as in the first instance) until a barrier is opposed to further progress by external resistance. Cotemporaneously with the cessation of the flow of latex to these points a third order of centres will be established in other parts of the web where the vessels are largest, and there being no impediment to their enlargement, they will go on dilating, until, as in the former instances, the efficient cause is balanced by external resistance. A fourth order of centres will succeed the third, and a fifth be superadded upon the fourth, and so on in an unending series,_- the position of the new centres in each case being in those portions of the vascular web which are most dilated when the old centres cease to enlarge.

In the absorption produced by the expansion of these fugitive hearts we find a cause which will tend to empty all congested portions of the vascular web, and by this means we may partially account for the supervention of the stage of contraction upon that of dilatation. A second cause may also be found in the changes which have taken place in the contents of 
the dilated centres, for these contents may be supposed to be impoverished by having subserved to the nutritive wants of the part, and to have become on this account far less fitted to the performance of those molecular changes which originate heat: and hence the stage of contraction may be in part due to a direct diminution of the local monifestation of organic heat.

Cther agencies, without doubt, have some share in the determination of these phenomena, as we shall see in the sequel; but in the operation of heat, we findas it seems-the first step in the explanation of the primary absorption of the latex into the contracted vessels, and of the subsequent oscillation of this fluid to and from certain focal centres, while at the same time we are able to account, by the same means, for the change of position in the centres themselves.

\section{OF THE MOVEMENTS IN SIMPLE CELLS, AND THE PHENOMENA OF "ROTATION."}

1. Of extra-organic force as the agent in these movements.

The functions of the laticiferous vessel and the common cell are called into action at the same time, and the season which determines or suspends the vascular changes determines and suspends also the growth and internal movements of the cell. 
Whatever may be the cause of the appearance of the primary germs or nuclei in the organic fluids, we know that their molecular constitution is closely allied to the substance which forms the coats of cells and vessels, and also that heat is necessary to their future development. In these bodies, therefore, we may argue that expansion is inevitable under the operation of the last-named agent, and thus it is possible to conceive that the enlargement of growth may be no mysterious property but only the natural result of the operation of heat upon the substance. Even the formation of the cavity, by which the originally solid nucleus is converted into a hollow vesicle, may also be a part of the same process, for under the operation of an expansile force the particles of these minute fabrics will tend outwards from the centre.

When the cell is once formed we may readily understand that heat may be the cause of further development, for the material of which it is constituted will be acted upon like the coats of the laticiferous vessel. The process of rupturing which takes place in many of the free cells of organic fluids may also be the natural consequence of unrestrained expansion, and this result would probably be constant if in many cases the process were not kept within bounds by collateral pressure, as is the case in the cellular elements of solid tissues.

In the coats of simple cells there do not appear to 
be any periodical changes corresponding to those witnessed in the milk-vessels; but, at the same time, there is a fact which may be construed to indicate the existence of obscure changes in some measure analogous. The concentric layers which occupy the interior of many cells would seem indeed to refer to periodical alterations, which may be understood to be possible enough. We may suppose, indeed, a cell to submit to a state of contraction after having attained to its maximum state of dilatation, partly because its contents have been abstracted by neighbouring cells which are in process of development; and partly because the same contents are less fitted to the generation of heat after having subserved in some measure to the nutritive wants of the part. And further, we may suppose a second state of expansion during a period of comparative inactivity in neighbouring parts, which itself might result in contraction when the contents were wasted by nutrition, or wanted for the growth of other cells.

Under similar circumstances, also, the same processes might be repeated a number of times. In each case we may suppose the formation of one of the concentric layers, which line the interior of the cavity, to mark the epoch of nutrition, activity, and dilatation; and in this way the layers may be regarded as relics which give evidence of slow periodical changes in these cells, analogous, in some degree, to the more realized 
movements of the fugitive hearts of the laticiferous web of vessels.

These remarks upon the phenomena of cell growth, are intended to serve rather as suggestions than as explanations; but while we would be careful not to assign to them an importance they do not deserve, we must be equally on our guard not to scout the idea that physical agents are concerned in these changes. Heat is undoubtedly concerned, and largely so, and it is to be remembered that the changes in the organic substance accord with the natural law of action of this agent in inorganic substances.

The phenomena of cell-growth point also to the influence of light as well as heat. This agency is necessary to the free formation of the granules of starch: thus potatoes grown in orchards thickly crowded with trees, are always more watery and less rich in amylaceous matter than those cultivated in the open fields. The growth of the layers which impart hardness to wood requires a free exposure to the influence of light; and for this reason the timber grown in dense forests is never so firm and hard as that which has been freely exposed to the sun. The granules of the substance allied to starch, which impart colour to plants, depend for their formation upon the same foreign power. The growth of the entire plant is also influenced by light, and thus the trunk and its branches 
are always more perfectly developed than the root and rootlets.

In all these changes light seems to determine the formation of additional nuclei or centres of growth, and to be the prime mover of the act of nutrition. As heat stands related to development, so light appears to be connected with genesis : how and by what means is not easy to decide, but still we may obtain much information if we study the fact attentively. Light, it may be said, involves a certain clearness of the atmosphere and absence from clouds, which is favourable to evaporation and radiation; and under these circumstances it may be supposed that the organic fluid in which the nuclei originate tends rapidly to give off its more watery portions. This process proceeds until at last the remaining fluid is no longer able to retain the organic matter in solution, and hence perhaps the appearance of the solid particles. In this way the formation of nuclei in the organic fluid, and of crystals in an ordinary chemical solution, are both favoured by the operation of light, for a state of atmosphere is involved in the presence of this agent which would bring about the necessary evaporation of the solvent.

I am not prepared to deny that light has a special action upon growth, for it is directly concerned in the changes of the photographic process; but at the same time it is to be borne in mind that this agent is cor- 
relative with physical motion, heat, chemical affinity, and electricity. Instead of having any distinct and independent mode of action, therefore, light is rather to be regarded as a condition of one and the same action,--higher in character, perhaps, than heat, but still related to this and the other physical agents, just as the several prismatic colours in light are related to each other, all being varying aspects of one central principle.

It is difficult indeed to imagine any real difference in the mode of operation of the several physical agents foreign to the body; and it is more consistent with the spirit of philosophy to seek in secondary causes for the explanation of any apparent differences. Instead of supposing light to have any special action upon the organism, it is better, therefore, to regard this influence as expressive of that condition of the atmosphere most favourable to evaporation and radiation, and most likely to bring about that degree of inspissation in the organic fluids which naturally results in the deposition of solids that were previously in a state of fluidity.

The phenomena of "rotation" refer also to the agencies concerned in the free discharge of the other functions of nutrition; and here, likewise, it is possible to meet with a partial explanation without having recourse to the unintelligible mystery of vital power. Let it be supposed indeed that the cell (itself acted 
upon by external agents) reacts inductively upon the floating nuclei contained within it, and it may be imagined that one of the consequences of the action will be the communication of a motion to these nuclei, such as is witnessed in a constrained and modified manner in the various forms of electromotory machines. These intercellular movements may be in part explained in this way, for there is no doubt of the existence of a tangential force in connexion with electricity, which under some circumstances is sufficient to communicate to the body acted upon a direct, and, as it were, orbital movement around the body which is the principal source and spring of action.

At the present stage of our inquiry we may only hope to obtain presumptive arguments, for those which furnish demonstration and conviction have to be reared by a tedious cumulative process, which will not be complete until all the phenomena of vital movement have passed under consideration. At the same time it is necessary to place a check upon ourselves, lest we be blinded by our prejudices, and to keep the judgment cool and collected while we weigh the evidence which will gradually come under notice.

2. Of intra-organic force as the agent in cellular movements.

As in the phenomena of cyclosis, it is probable that in this case there are internal physical agencies which 
originate and operate in the same manner. In the plant, however, the power which enkindles and fosters life proceeds in great part from without; and it is not until we ascend to animal bodies that the inherent life of the creature assumes any great degree of prominence. In the laticiferous movement, which approaches most nearly to the capillary circulation of animals, there is, it is true, the distinct trace of internal power; and so, also, it may be argued, in the molecular movements of "rotation," and in cells which exhibit laminated deposits; but in all these cases the organic and foreign forces operate in the same manner, and are analogous in character; and it is not necessary to attempt to determine what precise degree of importance belongs to either.

The evidences, moreover, of the operation of any vital principle in the vegetable economy are too obscure to allow satisfactory and advantageous investigation, and it is better, therefore, to leave the contested topic in complete abeyance until we arrive at the more marked problems of animal life.

\section{OF THE GENERAL MOVEMENTS OF THE SAP.}

This question is much more simple than it appears to be: and if we take care to suspend the operation of certain unfounded prejudices which appertain to it, we shall find that the general movements of the sap 
are determined by the very same agents which bring about the special movements of the cell and latex vessel.

1. Of extra-organic force as the agent in this movement.

A statement of M. Biot, quoted by Dr. Lindley, affords a true clue to the discovery of the secret action of these forces. According to this observer, there is an abundant exudation of sap from the spongioles in frosty weather, which continues until a thaw supervenes, when it gives place to an opposite process of absorption, of which the vigour and activity is directly related to the degree of warmth and heat. In other words, there are changes which seem to show that the tissues of the plant contract when exposed to the influence of cold, and expand when heated, just as any inorganic substance; the waters being expelled from or absorbed into the porous textures, according to circumstances.

The powerful upward current of the sap, during the warm weather, would also seem to point to the same order of changes, and to meet with its explanation in them; for at this time the trunk and branches, with their several appendages, will be expanded by the heat, and vacua produced, into which fluids may be supposed to rush. The agent, also, which produces the expansion will vaporize a large quantity of these 
fluids, and the vapours, passing off into the atmosphere, will leave their former spaces to be filled from the same sources; and hence (the condition of the atmosphere being such as to favour evaporation and radiation) the same agent which causes the primary rush of fluids from the earth will provide for the continuance, and convert the rush into a continuous current.

The downward movement of the sap during the colder months of winter, when the temperature of the air is too low to produce any considerable expansion in the tissues of the aërial system of the plant, and when, for the same reason, the evaporation of fluids will be retarded, would seem also to be of similar significance; for at this time we may suppose the underground portions of the plant to be relatively warmer and more expanded than the aerial; and, consequently, on the same principles we may account for the change of current which has taken place.

Other powers may, and do, operate in these movements; but the actual exudation and absorption of sap from the roots, witnessed by Biot, on the supervention and cessation of a frost, together with the changes in the main current which characterize the circulation of the plant in summer and winter,-all point to heat as a grand and important agent.

In the circulation of the plant it has been already stated that the fluids move indifferently through the cells and vessels, or through the insterstitial spaces, 
and that no part is specially concerned in the process. Each cell, as it would appear, aids in the production of the general current; and this, therefore, is compounded of an infinite number of minor currents. The sap, indeed, may be said to rise as through a porous rock; and the analogy would be nearly perfect, if we could imagine the component crystals to be hollow and porous, and the stream to filter through their cavities as well as in the interstices. That the leaves or spongioles have no special power in determining these movements, though at times these are the main entrances to fluid, is evident from the changes in the main current of the sap which take place in winter and summer; for whatever function seems to belong to the leaf at one time is transferred to the rootlet at the other, so that the function of either, in relation to the absorption or exhalation of fluid cannot be regarded as absolute. In the arguments, also, which show the essential unity of the various parts of the plant, which have been set forth elsewhere, there is a strong reason for the belief in the possibility of a change of function in these parts.

The entire subject however is very imperfect, and many new observations must be made before it can be fully known. At the same time, it is sufficiently clear that the phenomena of the general circulation

" "Proteus; or, the Law of Nature." London: J. Churchill, 1850. Pages 9, \&c. 
in the plant are not always definitely and absolutely the same; and from what is known, it may be argued that the changes which take place are due to the operation of causes analogous to those which determine changes in the centres of the laticiferous vessel. In particular, the statement of Biot is very clear as to the existence of general expansion under the influence of heat, and of contraction under the opposite condition of cold; and hence we may infer that these effects will always follow when the plant is subjected to these agents.

2. Of intra-organic force as an agent in the general movement of the sap.

The evidence which appertains to this division of our subject, above what has been cited in connexion with the cell and latex vessel, is very obscure and imperfect; and to enter upon it would involve the discussion of questions which will be more advantageously considered when we speak of vascular movements in animal bodies. As, however, the general movement of the sap is in great part the aggregate expression of the cellular and vascular movements, we may argue that the influence of intra-organic force will be the same as in the cell and latex-vessel,_-and as to the rest, we must be content to reason from analogy, from what we shall find hereafter in auimal bodies. 


\section{SECTION II.}

OF VITAL MOVEMENTS IN THE VESSELS AND CELLS

OF ANIMAL BODIES.

In creatures which remain at the foot of the scale of existence, and in the early transitional phases of beings which ultimately attain to a higher grade, the vascular movements are in every respect similar to those of the laticiferous system in the plant; but in more perfect states the plan is greatly altered, and instead of the ever-changing centres, and the oscillatory currents connected with them, there is a single heart and a perfect circulation. In this movement the heart is undoubtedly the prime agent, but it is not less true, that the vessels, and especially the smaller ones, possess an important complementary power, - and this it is our present purpose to investigate.

The cellular movements of animal bodies are, in many respects, similar to those of plants, but in addition to these is one that is exhibited in certain processes to which the name of cilia is given, and which has attracted considerable attention in these days of microscopic investigation. All these demand attention in proper order. 


\section{OF MOVEMENTS IN the CAPILLARY vessels.}

1. Of extra-organic force as the agent in these movements.

The changes in the life of hybernating animals are the grand test of the operation of these forces upon the vascular system, for this strange faculty is to be referred simply to the conditions in which the life is passed, and not to any peculiarity in the nature of this life. A common squirrel, for example, which hybernates in high northern latitudes no longer does so if it be removed to a warm climate; but he returns to his old habit if again restored to his former home: and this is the common experience of all creatures which exhibit these phenomena. Nor is there any peculiarity in the organization of these animals, except perhaps a greater delicacy of constitution;-for of several animals to all appearance precisely similar, some are found subject to periodical torpidity, and others not, -and so we may argue that their strange susceptibility to the influence of forces foreign to the organism is merely an exaggerated expression of a sensibility which pervades animate nature.

The manner in which the vessels are affected by these forces may be illustrated by other facts. If, for example, the hand be held to the fire it becomes flushed with blood, and this condition may increase 
until a high degree of inflammatory action is kindled in the part;-but if, on the contrary, it be plunged into iced water, the circulation is suspended, and the vessels shrink so completely that the bloodless tissues resemble blanched wax. An effect, in some respects similar, may also be noticed in the skin of persons in whom the circulatory powers are feeble, and the appearance sallow and bloodless during the winter, but who lose their sallowness and become roseate and blooming on the occurrence of summer. In other words it may be said that, in each of these cases, the coats of the vessels expand or contract as heat is imparted or withdrawn.

So far as we are able to judge, this alteration in capacity would seem to extend to all vessels generally, and to be prolonged in duration, and not to be transient and limited to certain points as in the laticiferous system of the plant. The exercise of force in this case, as it would appear, is designed to preserve the vessels as open channels, so as to remove as much as possible any resistance which might impede the action of the heart. In the lower grades of existence, however, the case is different, and also in the earlier periods of the fotal history of the higher animals, while the heart is as yet a feeble instrument in the propulsion of the nutrient plasm, for under these circumstances the vessels do actually possess a proper power of movement analogous to the focal 
powers of the latex vessels:- and in the higher animal when the circulation flags and the heart beats faintly and irregularly, it is interesting to observe that the blood no longer moves in a continuous stream in one direction in the capillaries, but oscillates irregularly to and from certain points, in such a manner as to show a tendency to the revival of those numerous centres of action, which had been absorbed and superseded by the heart.

2. Of intra-organic force as the agent in the capillary movements.

In vegetables the vascular movements are mainly dependent upon the agency of extrinsic force, but in animals the case is altered, and the internal or organic powers gain the ascendancy, except in the hybernating class, where perhaps the influence of the two is nearly balanced.

The internal or organic force may be divided into two principal forms, and each of these will demand separate consideration. The first is connected with the mysterious operations of the nervous system; and the other, which is less vague and indefinite in its character, in the expression of the several molecular changes which constitute the functions of nutrition; respiration, and secretion. 
(a.) Of the nervous influence as an agent in the capillary movements.

It is not our purpose to consider the abstract properties of the nervous system, and the high and mystical communion between it and the intelligence of man, but simply to examine the physical relation which exists between this system as matter and the rest of the organism.

The physical mode in which the nervous influence affects the capillary vessels-for there is such a tangible mode of action-may be ascertained without any difficulty. When, for instance, the mind is paralysed by fear, the skin becomes pale and blanched, in consequence of the shrinking of its vessels; and not only so, but if the bodily frame be fragile and delicate, the deadening influence extends to the heart, and a state of syncope or entire suspension of circulation is the result: when, on the other hand, the frame thrills under the excitement of joy, and the nervous power is exuberant, the countenance becomes radiant, the skin is suffused with blood, and the heart beats with increased vigour. These phenomena afford a twofold illustration of the importance of the nervous principle as an "agent of life," and of the nature of the agency physically considered.

As evidenced in the capillary vessels, therefore, the effects of an exuberant or deficient supply of nervous 
influence are identical with those which attend the communication or withdrawal of that physical agent with which we have been already occupied, - so identical, indeed, that we naturally inquire whether the higher and mystical force does not operate through, and by means of, this ordinary agent. Independently of any unintelligible theories on the subject, it would appear that the peculiar nature of the nervous system, and the relation which this system holds to the rest of the organism, would authorize such a conjecture. The composition is of cells and fibres, constructed upon a common type, and moulded from a common plasm, with the other parts of the body; and structurally, therefore, there is no sufficient reason to suppose speciality of attributes. Nerve and ganglion, also, dissolve away under the ordinary destructive agencies which act upon the body, and change into new chemical compounds, identical in nature and history with the compounds which result from the disintegration of the rest of the organism. Viewing the question, therefore, in connexion with genesis, as in the act of nutrition elsewhere, a certain amount of ordinary physical force must attend the formation of nervous matter : and viewing it in connexion with destruction or disintegration, or, in other words, in relation to the respiratory function, the chemical affinity, which is here in active play, is but another name for the same force. A proportionate destruction of tissue is 
also involved in the development of nervous influence; and in this respect, as in other varieties of force, the nervous influence may be regarded as the exponent of a certain condition of change in matter.

For these reasons it must be admitted that ordinar'y physical agencies constitute a part, at least, of nervous power; nay, more, - that the degree of the one is commensurate with that of the others. It is impossible, moreover, to conceive the idea of ordinary force being present and inoperative; and it can scarcely be imagined that the nervous power which is superadded to the more commonplace agents should have a different law of action, otherwise the one might negative the other. Whatever difference of essence, reason and experience argue a community of operation; for, so far as the capillary vessels are concerned, the effects of an insufficient or excessive supply of nervous influence are similar to those which attend equivalent alterations in the intensity of ordinary force. Such, indeed, are the facts already cited in connexion with the history of fear and joy as to allow it to be supposed that the nerves act upon the capillaries_not by the sur-addition of any new agency, but by means of that which is already in operation,-by that, namely, which is the necessary exponent of the molecular changes in the material part of the nervous substance.

The metaphysical arguments which concern the 
relation between physical and vital force have been set forth elsewhere, and to these we must refer the student for the other arguments which bear upon this subject. At present, however, we have only to do with physiological facts and considerations; and these, we may observe, are of such a character as to allow us to suppose an intimate relation between the nervous influence, physically considered, and the ordinary force of matter, - so intimate, indeed, that the former may be regarded as a mere modification of the latter, not essential to the functions of vegetables, or of the lowest tribes of animate existence, but superadded in order to intensify the vitality of higher and more favoured creatures. It remains to be seen whether a subsequent examination of the phenomena of vital motions will bear out this conjecture, and the judgment must be suspended until the special modes of the operation of force upon the heart and the muscular system generally have been passed in review.

(b.) Of the organic force, not of a nervous character, as an agent in the capillary movements of animal bodies.

The force here referred to is of a twofold nature: on the one hand, it is the exponent of the changes which constitute the function of nutrition; and on the other, it marks the molecular movements of respiration. 
The operation of the force originating in nutrition may be seen in the phenomena of capillary circulation, if we contrast the opposite conditions of inflammation and anæmia. The abstract idea of inflammation consists, as it were, in the emancipation of some of the smaller vessels from their subservience to the heart-in the return to an early type of circulation -and in the establishment of an unnatural focus of movement, to which an undue afflux of blood is determined. In this state the vessels exhibit. the highest degree of vitality, and are fully distended with blood; while, at the same time, the increased manifestation of heat shows that this condition is attended with an inordinate amount of common force. In anæmia, on the contrary, where the watery blood is insufficient to the fit discharge of the function of nutrition, the capillaries are shrunk and exsanguine; and this condition is always accompanied with an absence of the natural degree of animal heat. Contrasting, therefore, the history of inflammation with the opposite state of anæmia, we may, without the assumption of any unintelligible agency, explain the peculiar condition of the vessels at the time, as the natural consequence of the degree of ordinary force resulting in the nutrient changes, to which at the time the vessels are subjected.

The history of the function of respiration is written in such plain terms, that it can scarcely be doubted 
that the accompanying force, which is its exponent, is ordinary and mechanical in its characters. The essence of this function consists in the formation of water and carbonic acid by the union of the oxygen of the atmosphere with certain hydrogen and carbon constituents of the organism; and, as the volume of the products is less than that of the constituent elements, it follows that the extrication of a certain amount of heat must attend their formation; and hence there can be no doubt that the force operating upon the vessels may be ordinary force. And that such is its nature may be ascertained, if the subject be fully analyzed.

What, it may be asked, is the true and essential character of the function of respiration? On a first glance at the physical and chemical nature of the act, without any reference to ulterior consequences, it would not seem to differ widely from the ordinary processes of combustion and decay. The atmosphere acts in the same way in each case, and the products which mark the action are similar; and except a mere question of degree, the only difference would appear to be, that in the one case the dissolution of the bodily fabrics is slow and gradual, and masked by the deposition of new matter in the function of nutrition, while in the other the disorganization is more rapid, and altogether undisguised by the counteracting function.

The parallelism of the acts of decay and respiration 
appears also when we attend minutely to the history of the latter function. If we are to estimate the vigour of the respiratory changes by the amount of the gaseous products which are given off, it is found that this vigour is directly proportionate to the feebleness of the vitality of the organism, becoming more and more marked as the vitality flags, and by insensible degrees blending at death into the signs of common decay. The plant, also, lives less intensely at night than during the day, and at this time the greater amount of carbonic acid exhaled is the evidence of increased freedom in the respiratory changes; and in autumn, when the powers of vegetation are sickening, the quantity of the same gas is greater than during the summer. In animal bodies, also, the products of expiration are greater in winter than in summer; and in tropical regions, where the powers of the system are fortified by a free exposure to the sun, the deepened colour of the skin may be an argument in favour of a certain decomposition of carbonic acid, under the influence of light, and of a deposition of carbonaceous matter in some degree analogous to that which takes place in the chlorophyllous cells of plants. Again, in the depression of putrid and eruptive fevers, the exhalation of gases from the pulmonary organs is much greater than in health.

The conclusion from these facts is that the process of respiration is resisted by the vitality of the organism, 
and it would seem that the chief difference between this process and that of decay consists partly in the degree of this resistance, and partly in the destruction being masked in the one case by the repairs of nutrition. There is no difference in the essential nature and products of the acts, but simply in the conditions in which they take place in the economy.

Viewed in this relation, the force connected with the process of respiration must be considered, in great part at least, as physical and mechanical in its character,-for it is difficult to attach the idea of vitality to a change, so closely allied to combustion and putrefactive disorganization: and the more so, as the effects upon the capillaries may be explained by this means. The dilated condition of the vessels, when the function of respiration is vigorous, may be regarded indeed as the natural consequence of the free extrication of heat, which must take place under these circumstances, and the shrunk and contracted condition when the process flags, as an equally necessary consequence of the diminished supply of the same agent.*

* The function of respiration, allied as it is to the processes of decay and combustion, is essentially destructive to the organism; and if certain circumstances did not exist, by which it was kept within bounds, the body would soon kindle up into fever or actual flame. The distinctive gaseous product, moreover, is highly poisonous in its character, and hence a second reason why the function would be inimical to the wellbeing of the creature unless properly restrained and checked. It may be interesting, 
The phenomena of capillary movement in perfect organisms appear to point to a common law in the operation of force, and this equally, whatever may be the nature of the force. Except in a very rudimentary

therefore, to pause a moment and investigate the antagonizing influences which prevent and correct these several evils.

The history of respiration appears to imply that this function is most vigorous in the absence of light. In plants, for example, the formation of carbonic acid is nearly suspended during the day, or at any rate is much less marked than at night. In animals these results are obscured by many circumstances, but here also, all other things being equal, the same facts are observable. In that form of force, therefore, which is accompanied with the sensation of light, we find, as it would seem, a condition unfavourable to the formation of carbonic acid, and light, on this account, may be supposed to be unpropitious to the act of respiration. Light, moreover, is not merely unfavourable to the formation of carbonic acid, but it is entirely inimical to this process, for the history of regetation affords sufficient and ample proof that this gas is actually decomposed under the influence of this agent. And thus it would appear, that the conditions unfavourable to the act of respiration are those which restore the equilibrium of the atmosphere by destroying the poisonous gas which is the product of the act.

The actual mode in which light prevents the formation, or effects the decomposition of carbonic acid, is but very imperfectly understood. The belief is, that the gas in question, though poisonous to animals, is a necessary element of food to plants : it is supposed that the latter are enabled to assimilate this gaseous food under the influence of light, and in this way to preserve the air in the requisite degree of purity. It is an apparent fallacy, however, to imagine that plants are the agents solely concerned in the process of atmospheric depuration. The difference between animal and vegetable is one of degree and not of kind, and though all parts of the creation 
condition of the vessels, or else at times when the heart flags there is no evidence of the existence of any power in these vessels which could aid in the circulation by rhythmical contractions and dilatations; but

are bound up as a common whole in mutual subserviency each to the other, each part is nevertheless a complete entity in itself, and not merely a complementary appendage to another.

It may well be doubted, indeed, that plants are the sole agents endowed with the power of destroying carbonic acid. If it were so we might imagine (what is not the case) that the quantities of this gas present in the atmosphere would be greater in proportion as the forests disappear before the progress of civilization. In India and China also it may well be doubted whether the vegetable covering of the soil is sufficient to render the air fit for healthy breath. And in the colder realms of the north, where the vegetable carpet is so scantily spread that mighty hordes of animals are compelled to migrate year by year into more southern regions, the insufficiency of the regetation to the proper purification of the atmosphere is very apparent: and so also in the ocean, for the scanty fields of seaweeds can scarcely be proportionate to the wants of the countless creatures which breathe in the waters.

And if the vegetable world be insufficient to the task of purifying the air and waters, where are we to turn in order to find the co-operating agencies? It may not be to the realm of animate nature, for here, though under certain circumstances there may be evidence of a partial decomposition of carbonic acid; yet, at all times, a larger amount of this gas will be generated than can by any possibility be decomposed. It is to the inorganic world, therefore, that we are obliged to turn, and that here are to be found the complementary agencies for which we seek, appears for a threefold reason.

In the first place: the stability of the atmosphere is an argument that the cause of this stability rests in an agency which 
there is evidence of a general dilatation under the operation of force, by which these vessels are preserved as open channels for the current which flows from the heart. We may imagine circumstances which would

remains constant and unchanging. This fact seems to point beyond the kingdom of life ; for, if the forms of vegetation were solely concerned in maintaining this equilibrium, it might be supposed that the quantity of carbonic acid present in the air would be greater in winter than in summer.

In the second place : it may be supposed that inorganic bodies, under certain circumstances, are endowed with a catalytic power, by virtue of which they are enabled, without any manifest change in themselves, to effect changes in other bodies, and lience it may be argued, without any improbable assumption, that the phenomenon of light is expressive of a condition in certain inorganic as well as in certain organic substances, by which the formation of carbonic acid is prevented and its decomposition effected.

In the third place: the history of sulphuretted hydrogen, (which gas is a joint product with carbonic acid in the process of decay, and not uncommonly also in respiration,) furnishes a strong argument that inorganic bodies are actually concerned in this depuratory office. Both these gases present many points of relationship, and they are closely allied in origin, in properties, in the poisonous effects upon the system, and also in the mode in which they are affected by light, for this agent is unfavourable to their origin and fatal to their existence; and therefore it is allowable to seek some explanation of the action of light in the one case by what is more clearly seen in the other. What, then, it may be asked, is the class of bodies employed in the destruction of the sulphuretted hydrogen which is continually passing off into the atmosphere? As is the case with carbonic acid, it cannot be supposed that this gas is absorbed as food by regetable structures, neither can it be supposed to be in any way sub- 
induce an undue and partial expansion in certain vascular tubes, and then suppose as the consequence of this an increased afflux of blood, which again, by its own peculiar molecular changes, would keep up and

servient to the wants of the animal system, for to animal and vegetable it is a direct and deadly poison. We are obliged to admit, therefore, that inorganic bodies are concerned in the decomposition of this gas-for agents must be employed to conquer the affinities of its component elements; and as this is the case here, so also we may argue, in relation to carbonic acid, that inorganic bodies under the influence of light are endowed with a similar depuratory office.

As to the identical bodies which may be concerned in the removal of carbonic acid and other poisonous gases from the atmosphere, we may infer, from the history of spongy platinum, that these are the porous rocks and earths. We know that the peculiar properties of the metal are chiefly owing to the infinite extension of surface by which the substance to be acted upon is brought into intimate contact with the agent, and therefore a similar property may, without any improbability, be claimed for other mineral bodies in which this condition exists. And hence we may see new proofs of design and beauty in the world around us. The porous rocks, when lighted by the sunbeams, may be intended to filter and purify the air as well as the waters, and so made to serve a purpose which could not be answered by crystalline solids like marble or granite. The belt of sand which encircles the sea may also have a similar office, and the activity of its several particles be increasèd perhaps by the continual washings of the tides. And, finally, the boundless deserts of torrid climes may have some relation to the exuberant life of other parts of the same regions, and instead of being wild and dreary desolations, they may be important means by which the atmosphere is purified, and health secured to man, and beast, and plant. 
exaggerate the original expansion, and so give rise to the phenomena of inflammation; but under ordinary circumstances, the "capillary power" is so ruled, that all parts are affected equally, the office being to destroy the contraction of the vessel, which would counteract the action of the heart, and not to determine the flow of blood to one part rather than another.

The mode of capillary action may indeed be illustrated by the circumstances which favour the injection of the vessels, which is necessary for anatomical purposes, and the illustration is perfectly legitimate. The fluid, as we know, passes from the syringe into the minutest vessel with great readiness, so long as the animal continues warm, or when the warmth is restored by immersion in the warm bath, but the contrary is the result when the animal is cold. In the one case the operation succeeds, as it would appear, because the passages present little or no resistance to the force of the syringe-in the other it fails, on account of that contracted state which has taken place in the vascular tunics, and in the tissues generally, when the body has become cold. No other explanation is admissible than that which refers to physical agents-for life has ceased;-nor is any other needed, for all the phenomena may be accounted for by the changes which must take place in the coats of the vessels, under varying degrees of temperature.

So also, we may argue of the natural circulation, if 
the heart be substituted for the syringe, and we may suppose that the blood moves sluggishly when the vessels are contracted, and rapidly when this cause of resistance is overcome, and the calibre expanded, - and that the so-called capillary power is directed to the removal of impediments to the action of the heart, and not an inherent heart-like faculty of action.

\section{OF THE CELluLAR MOVEMENTS IN ANIMAL} BODIES.

Great attention has been paid to the anatomical peculiarities of cells, and to their modes of growth, but this has been almost altogether without reference to efficient causes. Indeed, in this case, as in many others in physiology, these important considerations have been neglected on the ground that they referred to some principle whose operations were in no degree cognisable to the reason.

On comparing, however, the analogous sections in the history of the plant and the animal, we find many reasons to suppose that the cells in each case are acted upon by the same agents, and in the same manner. In the animal, external warmth is necessary to growth, as is evident from the history of nutrition in hybernating animals, for in them the process of growth is arrested during winter. Light, also, is necessary, as we may see particularly in the effects of this agent in determining the free development of the blood and the 
coloured cells of the epidermis. On the other hand, the history of plethora, when contrasted with the opposite effects of anæmia, may serve to show that free nutrition is associated with an abundant development of organic force.

It would appear, also, that there are phenomena in animal bodies which seem analogous to "rotation" (of the vaguer sort,) and that these are referrible, in part at least, to physical agencies. Dr. Addison, indeed, pointed out some time ago the existence of moving molecules in many forms of free cells, as in those of mucus, pus, and lymph, and also in the colourless cells of the blood; and I have heard him state, that after watching these movements until they had ceased, he has repeatedly seen them renewed and made as brisk as ever by accidentally placing the watch-glass in which the fluid had been contained upon the warm mantelpiece. It would thus appear that the process of cooling after removal from the body had arrested their movement, and that they were renewable by warmth, and in this manner we may detect further proofs of the continued operation of these agents.

It appears, also, that the movements of "vibratile cilia" continue so long as the supporting cells retain their integrity and are acted upon by warmth, and that they cease in opposite conditions; and this being the case we may obtain some light as to the cause of these singular phenomena. To find any proof of ex- 
ternal agencies, indeed, is to make a discovery by which we are relieved from supposing the existence of any mysterious intelligence in this organic rudiment, by the workings of which the cilia are moved; and when we escape from this notion, then there is no difficulty in supposing a continued series of inductive charges and discharges between the ciliate-cell and any other bodies which may have a share in this action, and in this way the vibration of the cilia may be considered as the intelligible sign of these charges and discharges. 


\section{CHAPTER III.}

B. OF VITAL MOVEMENTS SUCH AS ARE SEEN IN THE IRRITABLE TUMOURS OF THE SENSITIVE PLANT, IN THE COATS OF THE ALIMENTARY CANAL, AND IN VOLUNTARY MUSCLES.

These phenomena are arranged in two sections, according as they belong to the animal or vegetable kingdom of nature; and this division furnishes the primary heads of the present chapter.

\section{Section I.}

OF MOVEMENTS SUCH AS ARE SEEN IN THE IRRITABLE TUMOURS OF THE SENSITIVE PLANT.

1. Of extra-organic force as the agent in these movements.

Like all other phenomena of plant-life, these movements point rather to extrinsic than to inherent agents, when they are examined in relation to their efficient 
causes. In the Mimosa sensitiva, for example, where the life of the plant is quickened into its highest intensity, the vital motion is distinctly referrible to those associated influences which proceed from the sun. The leaves open and expand in the morning, and become raised on their footstalks; and in the evening they again close and droop: or, in other words, the irritable tissues pass into a state equivalent to expansion under the operation of light and warmth, and return to the contracted condition when these influences are withdrawn. They are in fact acted upon in the same manner as the rudimentary structures with which we were concerned in the first chapter.

The sudden contraction when the plant is touched would seem to point to an external agent, and to meet its explanation without the assumption of any mystical and inherent principle. The first question in this matter concerns the nature of the agent, and then we have to inquire whether there is an abstraction or a communication of influence when the contact is made. The agent, whatever it is, must be physical in its character, for it may be connected with an inorganic instrument, and therefore we have to choose which of the several correlated expressions of physical force is the one concerned. It is not heat, or light, or chemical affinity, because there may be no evidence of the presence of these in the instrument;-it is not the mere communication of ordinary motion, for the results are 
peculiar;-and if not these, we have to ask if it be electricity? That it may be so we may argue for many reasons, but especially from the history of the blade electrometer, where the metal leaflets are seen to diverge on the communication of the influence which they are intended to measure, and to collapse when touched-phenomena so singular that we are led to ask if the instrument is not a coarse and clumsy imitation of the leaf of the sensitive plant. It is not diffcult to suppose indeed that this leaf, of whose extreme susceptibility to motion we have evidence, may be a natural electrometer, and also that it may become charged with electricity, for it is acted upon by light and heat and other forces, with which electricity is associated as a correlative agent. It is also difficult to believe otherwise than that something has been abstracted, and not communicated, when the plant is touched, for we have evidence in the undisturbed natural changes of the plant that contraction is consentaneous with the withdrawal of the diurnal stimulus, while at the same time the possibility of an instantaneous abstraction, and the production of similar results, is evident in the movement of the common electrometer, so that this very fact of sudden contraction is a strong argument in favour of the force concerned being of the nature of electricity.

In this manner we may fancy the sensitive plant to be an exquisitely delicate natural electrometer adapted 
to measure changes which are far beyond the perceptions of the common instrument of this name.

The phenomena of motion in other irritable plants are of a similar character, and with few exceptions, the contraction occurs at night, or at times of contact with any foreign body, while the opposite condition of expansion is cotemporaneous with the day. The difference in other cases is, that the movements are not susceptible of rapid alterations, and merely respond slowly to the sun, but still the general law is the same, and leaves and flowers open in the day, and close at night. There are some flowers, however, whose movements seem to obey a different law, and to open at night; but these it must be observed do not close in the day, in the same sense that the leaflets of the sensitive plant do, but wither; and therefore the difference may be accounted for by a greater sensibility in these plants, the nocturnal stimulus being sufficient to awaken life, while, on the other hand, the full beams of the sun may be said to scorch and destroy the mobile textures. Indeed, in some cases it may appear that the plants which exhibit these exceptional peculiarities are those which have been brought from climes less genial than ours, to whose days our nights may be nearly equivalent, and it is possible, if the phenomena of motion were observed in their own homes that these would cease to differ from others. 
Under any circumstances the general phenomena of motion in plants conform to the law which rules in the sensitive plant, and as to the rest; it may be doubted whether there are any exceptional cases that are truly so.

2. Of intra-organic force as the agent in these movements.

Of these agents we have little knowledge, but there is reason to believe from the history of other movements of the plant, with which we have already been occupied, that they are of comparatively trifling importance. At present, indeed, we must be content to understand that the agency of extra-organic force is sufficient to account, in some measure at least, for the phenomena under consideration, and we must leave the darker and more mysterious operations of vitality until we can study the clearer manifestations which occur in animal bodies.

\section{Section II.}

OF VITAL MOVEMENTS SUCII AS ARE SEEN IN THE COATS OF THE ALIMENTARY CANAL, AND IN VOLUNTARY MUSCLES.

\section{Preliminary Considerations.}

In relation to these phenomena there are two initial considerations which demand our attention. The first is,- that all modes and forms of the contractile 
state are related to each other,- -that the mode to which the term irritability is applied, where the contraction is sudden and transitory, and the mode called tonicity, where the contraction is gradual and its duration indeterminate, are but varieties of the same state. This opinion has been gaining many supporters of late, and it is advocated in one of the most recent and important text-books of physiology.*

The second and more important of these considerations is, that the state opposed to muscular contraction is something more than mere passive relaxation.

This view has been advocated by more than one writer, and it is distinctly enunciated in the works of Bichât. In regard to the voluntary muscles, however, the opinion of this physiologist is somewhat obscure, for he speaks of these muscles being restored to the state in which they were previous to contraction by the action of the antagonist muscles. But at the same time, he cites some facts which show the presence of a positive power of extension:-thus, he speaks of the contraction and subsequent dilatation of a muscle after its removal from the body, when there can be no extraneous traction, and of the convulsive movements of a similar character which may be seen in divided muscles when these have been

* Physiological Anatomy and Physiology of Man: Todd and Bowman, vol. ii. p. 172-1845. 
exposed during surgical operations; and he further instances, as of similar significance, the existence of certain hysteric convulsions in which all the muscles are hard and expanded, so that those which (from the position of the part) ought to be relaxed, are as firm and unyielding as those which ought to be contracted.

In relation to the involuntary muscles the existence of a twofold mode of action is very apparent, and it is found that there is a power of expansion in these structures altogether independent of extraneous force. In some degree the contents of the viscera-in whose walls these muscles are seated-may oppose and partly counteract the state of contraction, (and in the absence of all antagonist fibres in the muscles themselves, this is the only extraneous power which could be productive of this result, ) but any counteraction of this character is more than doubtful. Be this as it may, however, Bichât's arguments show that there is something more than this in the relaxation of these muscles.

In the first place, this conclusion is necessary from the fact, that the walls of the alimentary canal alternately contract and dilate, when the contents are artificially removed, or when the passage is emptied. In the second place, a similar conclusion is necessary from the fact, that alternate and rhythmical changes of an analogous character may be observed in the heart and 
neighbouring great vessels when completely evacuated of their contents. It is also observed, that on irritating a heart with the point of a knife, or any other instrument, the first change was the production of dilatation; and further, as showing the activity of this state, it is said that the force of the diastole as felt by grasping the heart, and the force of the systolic contraction as felt by placing the fingers in the ventricular cavities, are equally great so far as may be judged by this coarse experiment. This fact had been observed before Bichât's day, and it has been since corroborated by Cruvelhier, and other observers of considerable authority.

In each system of muscular structures it would appear therefore that there are two modes of motion, one of contraction, and another of an opposite character. And to show the definitiveness of the idea which Bichât possessed in relation to the latter mode, he concludes his remarks on this important subject by hinting at some analogy between this quasi-state of expansion, and that more conspicuous movement of this character which is seen in the iris and in the several forms of erectile tissue.

The actual nature of this twofold change, however, is only to be understood after a careful and particular examination of the individual phenomena of muscular action; but before we proceed to this there 
are still two preliminary considerations which deserve attention as well calculated to facilitate our future inquiries.

It may be supposed, in the first place, that the mystery of muscular action will receive some explanation from the history of the fibrine dissolved in the blood, for this substance is analogous, in essential particulars, to that which occurs in muscular tissue. Now the history of the two is indeed parallel in some respects. As to the fibrine of the blood, it is found to remain in a fluid condition during life, and to solidify after death, so that we may properly argue that the latter in relation to the former is the passive state, and that the influence of life-be this what it may-is exerted in counteracting the state of solidity. In the fibrine of muscular tissue there is also a twofold condition, and from the solidification which takes place after death we may argue that there is during life, if not a condition of fluidity, a quasi-softness approaching to this state. In addition to the solidification which supervenes upon death, there is also another form which occurs during life, and the question is as to what is the meaning of this. Is it, we may ask, in any way related to the phenomenon which occurs in the fibrine of blood and muscle after death? If it is, then the inference will be that muscular contraction in relation to the opposite condition is a phenomenon which, like the coagulation of 
the blood, is determined by the withdrawal and not by the communication of a stimulus.

It may be presumed, in the next place, that the dartos will contribute towards the knowledge of muscular action, for this tunic is closely allied to true muscle both in structure and function. In the dartos, moreover, there are few nerves and vessels, and therefore the phenomena of irritability may be supposed to be simple and intelligible, and not complicated by those agencies which obscure the secret action of true muscle. Here, indeed, it seems as if the problem of mobility were stated in the simplest terms, and the result made known as clearly as possible. What these are we may learn in the first chapter, where it is shown that the state of contraction is associated with the operation of cold, and the state of relaxation with the presence of warmth. Contraction, indeed, in relation to the antagonistic phase of relaxation, is seen to be a phenomenon connected with the withdrawal, and not with the communication of a stimulus. The true connexion of contraction in the dartos with the analogous phase of muscular activity cannot now be determined, but if it is such as may be presumed from the anatomical relation of the two structures, the result is very significant,-and the more so as it harmonises with what is deduced from the changes in fibrine.

Under any circumstances the histories of the dartos 
and of the fibrine of the blood cannot be altogether without relation to the mystery of muscular action, and it is necessary that the deductions which have arisen during their consideration be borne in mind in the inquiries upon which we now enter.

\section{OF MOVEMENTS SUCH AS ARE SEEN IN THE COATS OF THE ALIMENTARY CANAL.}

"Wherever the striated structure occurs, we witness an aptitude for quick, energetic, and rapidly repeated movements; while, where it is deficient, they are sluggish, progressive, and more sustained." * Now the non-striated muscles, which belong to the system of organic life, are much more sparingly supplied with nerves and bloodvessels than the striated muscles of the voluntary system; and as the phenomenon of contraction is most conspicuous in the variety most sparingly supplied with nerves and vessels, it would seem to be a legitimate inference that the nervous and vascular influence, be this what it may, is intended to counteract, rather than to induce, contraction. But let us examine the subject in detail.

* Todd and Bowman, op. cit. vol. i. p. 185. 
1. Of intra-organic force as the agent in these movements.

(a.) Of the nervous influence as an agent.

In a state of fear, when the blanched skin, the faltering heart, and the occurrence of fainting, show how greatly the supply of nervous force has been repressed, the condition of the organic muscles is one of contraction. The pallor of the countenance and the smallness of the pulse is a sufficient proof that this is the case in the fibrous tissues which enter into the walls of the vessels. In parts, also, where the muscular fibre is more developed, as in the coats of the several visceral cavities, the result is the same; and thus, during the continuance of fear, there is a tendency to contract and expel their contents-a fact which is equally apparent in the alimentary canal, in the bladder, and in the uterus. In the first instance, it may be supposed that fear operates by inducing a state of paralysis in a sphincter muscle; but in the bladder and uterus no doubt of this nature can exist, inasmuch as the openings of these organs are destitute of sphincter fibres. Moreover, in the case of the alimentary canal, it must be observed that the tendency to evacuation, under the operation of fear, involves a powerful and sudden contraction of the coats; for the mere paralysis of the outlet, which is 
itself supposititious, is not sufficient to account for the results.

In maniacal frenzy, on the other hand, where there is a superabundant generation of nervous force, the results would seem to be entirely opposed to those which have just been considered. The hot and reddened skin, and the full pulse, necessitate, indeed, a distended state in the fibrous elements of the vascular coats; and the obstinate constipation of the bowels, and the retention of urine, which are such frequent symptoms of this condition, are facts which argue the existence of a state opposed to contraction in the walls of the viscera concerned.

(b.) Of the organic forces, not of a nervous character, as agents in the movements under consideration.

The influence of the blood upon the coats of the small vessels, and consequently upon the muscular fibres contained in these coats, has been considered in the last chapter; and it has been seen that this influence, whatever it may be, does not give rise to contraction. Wherever the blood possessed peculiarly stimulating properties, whether in consequence of a formation from rich pabulum, or as the result of perfect oxygenation, on these occasions the vessels are freely distended; and, on the contrary, whenever the blood is pale and watery, and the respiration 
faulty, then the vessels are shrunken and collapsed. In so far, therefore, as concerns the muscular tissue present in the coats of these vessels, it is evident that the state of contraction is not induced by the stimulant properties of the blood.

In nature and office the bloodvessel is very intimately related to the alimentary canal; and hence it may be expected that the influence of the food and the blood, upon the passages with which they are severally related, will present many points of correspondence and analogy. And such indeed is the fact.

The food is said to stimulate contraction in the coats of the alimentary canal; but let us examine what is involved in this supposition. If a morsel acts in this manner, how is it, we may ask, that the act of contraction does not prevent its admission into the gullet; or if by chance it be admitted, how is it that it is not immovably fixed there? There is no physical necessity that the muscular acts should follow in a certain and definite order; for, in the ordinary peristaltic movements, an impulse which passed in one direction at first may the next moment be entirely reversed. Again; in the movements of the gullet in the cow, or in any other ruminant animal, we have a simple proof of this fact; for, during the process of rumination, the morsel is seen to ascend and descend alternately, where the gullet lies superficially at the side of the neck. There is no reason, therefore, so 
far as we may perceive, why the food should pass in one direction rather than another, or why the act of contraction, which is supposed to be excited by the food, should, in the natural course of things, be behind, and not before the morsel.

The entire history of the assimilative function, however, is at variance with the idea that the food induces contraction in the alimentary canal: indeed the constant lesson is that the food remains within the digestive apparatus so long as any molecular changes are unaccomplished, and that expulsion takes place, and the effete matter is expelled, only when these changes are at an end. The ingestion of food into the stomach does not cause this organ to contract, nor does any contraction interrupt the process of digestion; and it is only when the gastric juices have effected their office and the food is dissolved, that the contraction takes place, by which the food is transposed to the duodenum. In the small intestines, the food remains during the continuance of the processes of ulterior digestion, and it is transmitted onwards, only when these are at an end And lastly, there is no contraction in the large intestines, until the digestive changes are completed. So long, therefore, as there are any evidences of the continuance of molecular changes, by which the food could act as a stimulus to the muscles of the alimentary canal, so 
long is there an absence of contraction in these muscles.

Nor can the germ be supposed to excite contraction in the uterus,- - for if so, how is it that these phenomena are deferred to the close of the period of gestation? The fact is, that the uterus has grown and expanded, so as to adapt itself to the increased size of its contents, so long as the mother was able to provide food for the development of her offspring, without prejudicing the supply necessary for her own system; but when this bound is passed, and the foetus has attained to such a magnitude as to become a source of exhaustion to the mother, then the walls of the uterus begin to contract. The immediate effects of this change will be to constrict the vessels connected with the placenta, and to lower in a proportionate degree the vitality of the fœetus, by this check upon its respiration. And this lowering of the vitality of the fœetus may be supposed to give rise to further contraction in the uterus,-for if during the previous nine months, the increase of the womb has been proportionate to the increasing vitality of the fœtus, and to all appearance consequent upon this increase, so we may infer that contraction will be commensurate with the decrease. By this uterine contraction, the placental vessels will suffer constriction, and the vitality of the fortus be proportionately reduced, while this reduction will 
react upon the uterus, and cause further contraction, further constriction of the placental vessels, and further depression of the life of the foetus, - and this latter change, reacting upon the uterus, will bring about the same train of results. And thus it must be, that when once the disposition to contraction is set up in the uterus, whether this be from the fotus having attained to a size disproportionate to the powers of the mother, or from any other and accidental cause, the necessary consequence will be an ever increasing contraction, until the completion of birth. The history of gestation, therefore, so far as we can see, would seem to justify the conclusion, that the contractions of the uterus are owing to the withdrawal of that influence which the living and growing fotus exerts upon this organ.

A similar objection opposes the notion that the urine stimulates contraction in the bladder; for if so, how is it that the organ fills with the secretion? On the contrary, contraction takes place when an impediment is opposed to the further admission of urine by the mechanical resistance of the coats of the bladder, or by the antagonizing pressure of neighbouring parts, and it is rather in harmony with the facts of the case, to suppose that this phenomenon is occasioned by the want, and not by the direct operation of a stimulus.

So far, therefore, we find no reason to suppose that the changes in these muscles differ from those which 
are seen in the coats of vessels. There is no evidence as yet of the introduction of any new and mystical agent in these movements, and the effects of the nervous influence, so far as we may at present see, are strictly analogous to those which mark the operation of the forces, which have their origin in the various molecular changes of the organism.

2. Of extra-organic force as the agent in the movements under consideration.

In the rudimentary forms of organic muscle which occur in the coats of bloodvessels, facts have already been stated which show that the state of contraction is consequent upon the abstraction of heat. In the higher forms of these structures, however, the influence of external heat is greatly masked by the operation of the organic forces; but at the same time there are facts which show that contraction is produced here, as in the simpler tissues, by the operation of external cold. Such a fact is the action of the intestines, which is very apt to happen in delicate persons on a draught of cold water.

The influence of light, as a special agent, is well seen in the iris, which may be said to represent an intermediate structure, connecting the simpler variety of organic muscle found in the coats of vessels with that more perfect form, which occurs in the 
hollow abdominal viscera; and here it may be said, that the state of contraction is expressive of the absence or dimunition of force. It was the opinion of Bichât, that the closure of the pupil was occasioned, not by the contraction of the mere rim, but by the general dilatation of the iris; and if this be true, then the absence of light induces contraction, and its presence, dilatation, or whatever else we may agree to call this state. And under any circumstances, there is quite as much probability in this opinion as in the hypothesis which at present prevails on this subject.

Electricity, also, is directly concerned in these phenomena, but it is difficult to estimate its mode of operation, until we are able to study it in connexion with the voluntary muscles. The facts which more especially point to this agency, are those contractions which happen in the coats of the alimentary canal, when these are touched by any foreign body, and which movements are said to be stimulated by the contact. As in the case of the sensitive plant, however, it may be argued with an equal share of probability, that something has been abstracted in this case, and that the contraction is the result of this abstraction; and as in all those cases which have already come under consideration, the phenomena of contraction are connected with the withdrawal of force, so also in these facts we may find a strong argu- 
ment in favour of there having been an actual abstraction, and not a communication of force on the contact of any foreign body. And if there has been such an abstraction, then the fact points to electricity, for this is the only known agent which could be abstracted in this instantaneous manner.

This question, however, is intimately connected with the phenomena of muscular action in the system of animal life, and its solution must be deferred until we can consider this subject.

\section{OF MOVEMENTS IN THE VOLUNTARY MUSCLES.}

The muscles of this system are chiefly distinguished by the ready manner in which they are affected by the nerves; and under this head the relation of nervous influence to muscular action will be a very important subject of inquiry.

1. Of intra-organic force as the agent in these movements.

(a.) Of the nervous influence as an agent.

Comparative anatomy furnishes a fundamental objection to the idea that nervous influence is necessary to the state of contraction in the voluntary muscles, for it is found that this phenomenon is more vigorous and perfect in reptiles, and in animals whose 
nervous system is rudimentary, than in creatures more elevated in the scale of being, and better furnished with nervous organs. Instead of being necessary to contraction, therefore, it would rather appear that nervous influence is concerned in the counteraction of this state; its office being to induce those transient relaxations which are necessary to that rapidity of muscular action which is distinctive of the higher animals.

The dictates of comparative anatomy are also supported and elucidated, when we study those phenomena of disease which betoken a suppression of nervous power; for in these cases muscular contraction is a frequent symptom.

The spasm which is characteristic of ramollissement of the brain is an important argument against the idea that nervous influence determines a state of muscular contraction by the impartation of a stimulus. In this disease there is atrophy of the cerebral substance, and partial paralysis of the sentient and motive energy; and therefore the spasm, in so far as it may refer to the nervous system for its cause, must be supposed to be symptomatic of diminished, and not of exalted innervation. It is, indeed, as if man was degraded in the scale of being to a point where his muscular acts became long and energetic as in reptiles -and for the same reason.

The ordinary tremulous movements of old age, or 
the more marked shakings of paralysis agitans, (both of which involve an unusual disposition to contraction in the muscular system,) are connected with a period in which the nervous power is rapidly on the wane, and often with a state of brain in some degree analogous to the disease last mentioned.

The causes of convulsive diseases are still very obscure, but in many cases there is reason to believe them associated with signs of debility, and not of strength. This doctrine was very ably advocated by Dr. Todd in the Lumleian lectures, delivered at the College of Physicians during the past and present years, on which occasion it was shown that the muscles were often flaccid and pale, and not firm and of a deep red colour as in health, and the brain much more white and bloodless than natural. This latter condition-pallor of the brain_was particularly in. sisted upon as a common sign in epilepsy; and hence, in this disease, which is the worst of the class, we may argue defective innervation, for it is well known that the nervous activity is proportionate to the vascularity of the brain.

The grand and conclusive argument, however, in favour of this view, is to be found in the general spasm of the body which succeeds the departure of life. In this case the phenomenon cannot be owing to increased innervation, for it does not occur until all signs of activity are withdrawn. Nor is this 
rigid spasm a transient state connected with the last flicker of life (as some suppose), but it endures, untiring and unrelaxing, until the fibres break up in the ruin of final decay. Like the coagulation of the blood, it is the consequence of an abstraction from the influence of life, whatever the influence may be.

The connexion of muscular contraction with a diminished supply of nervous force niay also be seen in certain conditions of the system in which there is great prostration.

The subsultus and convulsive jerkings, of extreme typhoid depression, are connected with a state of the nervous system, in some respects similar to that which supervenes gradually in old age, and gives rise to the tremulous shakings of this period.

In cholera, also, the spasm which begins in the involuntary muscles, and gradually extends to those which are subject to the will, goes hand in hand with collapse; and he who has stood by the bedside of patients in the last epidemic, and regarded the blue and icy skin, the shrunken countenance, and the hopeless prostration of mental and nervous energy, in extreme cases, and noticed the occurrence of fierce and untiring spasm along with this fearful depression, need have little difficulty (if he will remember these things) in dispossessing his mind of the idea that the spasms were owing to the operation of a vital stimulus. So far from supposing this, he will imagine, 
what was actually the case, that death was prematurely binding his victim, and that the cramp was a true rigor mortis in vitâ. In such a case, we may indeed suppose that the muscular contractions in many instances passed at once, and without any interval, into the rigidity of death; for though there is no direct evidence on the subject, yet it may be argued from analogy that it might be so. Indeed, in cases of extreme typhoid depression, where the condition is very closely allied to malignant cholera, (as was pointed out by Dr. Billing, the subsultus and convulsive twitchings of the moribund state at once pass into rigor mortis when life has fled: and therefore a similar transition in cholera, where the subsultus is exaggerated into spasm, is not only possible, but even probable.

The fact that paralysis of motion is a most familiar consequence of the cutting off of nervous influence, is not a fatal objection to the view that muscular contraction is a negative phenomenon. In this case we must not deceive ourselves by supposing the possibility of contraction to be lost. Twitchings in the muscles, convulsion, and tonic spasm, are in fact not uncommon accompaniments of paralysis of motion; and there is most generally-and especially where the disease has been of long continuance-a certain rigidity, particularly in the flexors, by which the limbs are partly bent. The occurrence, also, of excito-motory con- 
tractions on irritation, and of rigor mortis, are facts which show that the muscles still preserve the power of contracting. There is no reason for supposing that the paralysed part is more relaxed than it was when the nerves retained their integrity; indeed, so far from this, the contrary may be argued from the atrophy and shrinking of the tissues, which date from the time of the lesion. It is the same also in regard to the paralysis of motion which has been induced experimentally by the division of nerves, or by the removal of nervous centres. Tonic rigidity of the muscles is a common consequence of violent destruction of the cerebro-spinal ganglia; and where this is not the result there is no reason whatever for supposing the muscles to be more relaxed than they were before the operation. The contractions which take place under the operation of galvanism, and after death, are sufficient proofs that there is still a possibility of contraction in the paralysed muscle. And, lastly, it is shown, in the last paper contributed by Matteucci to the Transactions of the Royal Society, that the contractions induced by galvanism in the hinder limbs of a frog, after the division of the spinal cord, are more powerful than in an animal of similar magnitude and strength in which the cord is intact: an observation which is calculated to show in a very strong light the non-necessity of an additional supply of nervous influence in the phenomena of contraction. 
We are able also to form some conjecture as to the reason why complete contraction should not be the inevitable consequence of the cutting off of nervous influence. We learn, indeed, on the authority of Longet and other experimental physiologists, that the irritability of a muscle continues for a much shorter time after the ligature of the artery, than after the division of the nerve; and we may infer, therefore, that so long as the circulation continues there may be a sufficient amount of vital activity to prevent contraction, notwithstanding a complete interruption in the supply of nervous influence. And this conclusion is the more probable when it is considered that the phenomenon of rigor mortis does actually occur in paralysed muscles when the circulation is suspended by death.

It need be no fatal objection, therefore, that paralysis of motion, instead of contraction, should at times mark the suspension of innervation; for a slight variation in the condition of the circulation may be sufficient to produce this difference in the result. Indeed, paralysis may after all be the first phase of convulsion. 
(b.) Of the organic force, not of a nervous character, as an agent in the movements of voluntary muscles.

$\Lambda$ free supply of blood is essential to muscular activity, and here also the freedom of the supply would seem to be related to the state most opposed to contraction. It has been shown by Mr. Bowman, that the number of capillaries in muscular tissue corresponds very closely to the number of elementary fibres, and "consequently the same amount of muscular tissue, arranged as a large number of small frbres, would be supplied with a larger absolute number of capillaries than if arranged as a small number of large fibres."* In the voluntary muscles, therefore, where the fibres are much more delicate and numerous than in the involuntary muscles, it follows that the supply of blood must be greater in the same ratio: and thus the system in which contraction is the most transient phenomenon, is found to receive the greatest supply of blood.

It is found, moreover, that voluntary contractions become more prolonged and enduring as the activity of the circulation in the muscles diminishes; and thus the manifestations of this form of irritability in

* Todd and Bowman, op. cit. vol. i. p. 107. 
mammals during a state of hybernation continues almost to the same length of time as in reptiles.

In sloths and lemurs, also, where the contractions of the limbs continue a long time with little fatigue, it would appear that this faculty is to be partially ascribed to a peculiar division of the principal arteries into a number of very small branches, by which means the current of blood is broken, and the supply rendered more defective than it would be if the main channel remained pervious.

A somewhat analogous fact to the one last cited is to be found in cases of aneurism after the chief supply of blood has been cut off by the ligature of the vessel; for there is a strong tendency to cramp of the limb until the collateral circulation is established.

The nature of the relation which exists between the circulation and muscular action, however, is exhibited with greater clearness in hæmorrhage than in any other case; and here it would appear that spasm is the direct consequence of loss of blood, the one being proportionate to the other:-thus, when an animal is bled to death by the butcher, it first passes into a state of extreme jactitation very like chorea, and then into epileptiform convulsions, which become more and more decided as death draws nearer. Now in this case it cannot be supposed that the convulsions are dependent upon the operation of a stimulus, for the generation of all organic force, whether nervous 
or otherwise, bears a strict relation to the supply of blood, and it must fail therefore as the hæmorrhage . progresses to a fatal termination. In no way indeed can we suppose the spasms of hæmorrhage to be the result of an exaltation in organic force.

On the contrary, the absence of a disposition to muscular contraction is a conspicuous phenomenon in cases where the normal supply of blood is exaggerated. Thus, for example, there is no unusual tendency to cramp in the congested and inflammatory condition of the parts in muscular rheumatism, as we might anticipate if the activity of these vessels was likely to excite contraction; but the reverse is the case, and the parts are swollen and immobile. In plethoric persons, also, where it may be supposed that the muscular tissues participate in the general state of vascular repletion, an indisposition or inaptitude to muscular action is a frequent phenomenon. It is known, also, that the circulation in a muscle is quickened during exercise; and, at the time when it ceases to respond to the will in consequence of fatigue, there is reason to believe that the vessels are most congested.

A further argument in favour of the previous views may be deduced from the action of blood upon the bloodvessels, for if these vessels expand or contract according to the communication or withdrawal of organic force, (and these results are general,) such we may argue 
to be the effects of the same force upon the rich vascular web in muscular tissue. A part of muscular contraction must therefore be consequent upon the abstraction of force from the vessels, and that the rest of the phenomenon is of a similar character we may argue from the affinity which exists between the fibrous elements of the coats of the vessels and true muscular fibre,-an affinity which affords a strong argument in favour of a common law of action in these fibres.

From these and similar facts it would appear that voluntary muscle is affected by the non-nervous varieties of organic force, in the same manner as the subordinate textures which were previously considered. The presence of the force-that is to saydetermines a state of dilatation in the subject of it;-the absence allows the opposite condition of contraction.

2. Of extra-organic force as the agent in the movements of voluntary muscles.

In the higher phenomena of muscular action the special powers of the organism have masked and superseded all others, but still we may detect the agency of foreign force, and perceive the sameness of its law of action. 
The connexion of the state of contraction with the direct operation of external cold may be illustrated by two familiar facts, which facts also are well calculated to show one cause at least why cold does not always produce this result. In the process of crimping, for example, the fisherman produces the contraction which imparts the requisite firmness to the flesh, by first gashing the sides of a fish with a knife, and then dashing them with cold water. In cases of amputation, also, where the blood oozes obstinately from the stump, the surgeon causes contraction in the muscles and vessels (and in this way arrests the hæmorrhage) by the application of a sponge soaked in cold water. In both these cases the contraction is attended with the escape of blood from the vessels, and.hence we may find a reason, perhaps, why contraction is not induced when the free movements of the blood are interfered with, whether by coagulation, by removal from the sphere of the circulation, or by any other means. We may conjecture further, that free mobility of the blood is necessary to muscular action, in the same way that it is to the changes which take place in erectile tissue, and that the filling or emptying of the vessels is as necessary in the one case as in the other. In other words, we may conjecture that the causes of muscular action operate upon the fibrous coats of the vessels, as well as upon the other fibrous textures. 
As an objection to the notion that the voluntary muscles may be made to contract by the direct operation of external cold, we must mention, however, a statement often made by physiologists, that heat is given out during the state of contraction. The fact upon which this opinion is founded is the small increase of temperature which takes place during violent exercise, as of the forearm in the act of sawing,- -and this fact is undeniable. The conclusion, however, is altogether gratuitous. In an act of this kind, indeed, it is not with mere muscular contraction that we have to do, but with an alternate series of contractions and dilatations; and it is quite as probable that the elevation of temperature is connected with the latter phenomena as with the former. Nay, it is more so:for when the limb is wearied and the action at an end, and when also the temperature is highest, the condition of the parts is much more nearly allied to relaxation than to any other state, while the fact that the increased heat continues for some time after the cessation of the contractions, shows that it is not to these that we must look for its immediate cause.

It is difficult to procure any direct evidence of the action of light upon the voluntary muscles, for this is so mixed up with other actions: but, at the same time, we may notice two circumstances which seem to bear upon the question. The first of these is 
the more frequent occurrence of spasmodic attacks at night than during the day time. The second is the pale and flaccid appearance of the muscles, which is a common condition in convulsive diseases - a fact which may possibly show that the absence of light (for light is infinitely concerned in healthy nutrition, ) has had something to do in inducing that state of muscular fibre in which there is a proneness to contraction.

The influence of electricity in muscular action is very marked, but the manner of operation is difficult and hard to be understood. If, however, we investigate the late discoveries in this department of science, and especially those of Matteucci, we find reason to believe that the action of electricity, when more fully known, will present no essential difference from that of the correlative agents with which we are already familiar.

It is an initial fact in these inquiries, and one that may very easily be tested, that there is in the muscles of an animal during life, and so long after death as the irritability continues, an electric current from the interior to the exterior of the muscles, and in the limbs, from the extremities towards the head. The latter current, which is particularly conspicuous in the hinder limbs of the frog, is of infinite importance in the interpretation of the influence of electricity in muscular action, and our first step must be to acquire 
an adequate idea of its existence and reality. In this there is no difficulty. We must take a number of the hind legs of the frog, amputated at the pelvis, and stripped of their skin, and arrange them in a series of wine-glasses half filled with water, each leg being bent over the edge of the two contiguous glasses in such a manner that the foot is immersed in one glass and the thigh in the other. A foot and thigh of different limbs are thus in every glass, except the terminal ones, in the one of which there is (as must needs be) only a foot, and in the other a thigh. On plunging the poles of a galvanometer into the water contained in the glasses which hold the extremities of this muscular pile, there is a contraction of all the limbs, and a divergence of the needle of the instrument in such a direction as to show that a current of electricity has passed from the feet towards the thigh. By adding or diminishing the number of limbs, the divergence of the needle may be increased or lessened, and thus it is found that the intensity of the current is proportionate to the size of the pile. It is found also that the muscular contractions cease after a time, and with them the divergence of the needle; and in this way we may satisfy ourselves that the development of the electricity is dependent upon the conditions which preserve the muscular irritability, and not upon the mere contact of the limbs as masses of inorganic matter. The nerves would seem to have little to do 
in this process, nor are they necessary to connect one limb with another, for it is found that a metal conductor, or pieces of moist paper, will answer this purpose quite as well, if not better; and in this way we may be more fully satisfied that the influence which is generated is electrical in its character.

In this experiment contraction is induced in the limbs which form the pile, and in them we might investigate the operation of the electric agent. It is better, however, to prepare an additional limb in the same way as the others, and to induce action by bringing it within the circuit. In this case also it is of no moment whether the nerve be left to serve as a conductor, or whether we use metal or moist paper for the purpose.

On considering the contractions in this limb when it is connected with the pile, they are found to take place at different times, according to the direction of the current. At first there is contraction both on making and breaking the circuit. If the current pass from the thigh towards the foot, there is a powerful contraction on completing the circuit, and a far slighter one on breaking it; but if the current pass in a contrary direction,-namely, from the foot to the thigh, there is a slight contraction on completing the circuit, and a powerful one on breaking it. There is a change, however, if we continue to transmit the electric influence, and eventually the slighter contrac- 
tions disappear, - there being only contraction on closure of the circuit when the current passes towards the foot, and on disruption when it passes towards the thigh.

Now these results are not altogether unintelligible, if we attentively consider all the premises. It may be granted, in the first place, that there is a current of electricity in the limb which is used to test the activity of the pile, in the same direction as in the limbs which compose the pile,-namely, from the foot towards the thigh. It may be granted, also, that by adding this limb to the pile in the proper manner, the activity of the electric current would be intensified; and if it were inverted so that the thigh were added to the thigh-instead of to the foot_extremity of the pile, it may be granted also that this mal-arrangement will neutralize to a certain extent the energy of the current, just as would be the case if we were to add a pair of plates to a galvanic battery, in such a manner that platinum faced platinum, or zinc zinc, instead of observing the natural order and causing the zinc and platinum to oppose each other. And further, it may be granted that the limb which is made the subject of the experiment is virtually a part of the pile, though it be only connected by conductors, and that it must neutralize or intensify the energy of the electric current, just as much as if it were more obviously a part of the pile. 
When, therefore, the electric influence from the pile is transmitted through the limb in question, from the thigh towards the foot, the direction must oppose the natural current of the limb; and in this case we must suppose that the intensity of the current will suffer diminution on the completion of the circuit. The powerful contraction, therefore, which takes place under these circumstances, if it be connected with the electricity at all, must be the consequence of the neutralization or diminution, and not of the intensification of the agent. Nor is it any objection to this view that a slight contraction should take place on the disruption of the circuit, as may be seen if we call to mind the nervous conformation of the limb with which we have to do. It is provided with a nerve of mixed fibres, of which some convey the peculiar influence with which they are charged from the thigh to the foot, and others in a contrary direction, from the foot to the thigh. During the passage of the electricity, therefore, we may suppose the nervous current (if we may so speak) to have been neutralized in the fibres which opposed the electric current, and to have been intensified in the others which coincided; for there is no doubt that there is an affinity and possibility of reaction between the two agents. There are fibres, therefore, as we may suppose, where the molecular activity would be stimulated during the passage of the electric current, and where the increased activity must 
cease on the breaking of the circuit; and hence the contraction which takes place at the time may be the natural consequence of this cessation. The slightness of the phenomenon argues the operation of a more partial agent than that which produced the more violent contraction when the circuit was closed. The short duration, also, favours the notion that it depends upon some change in the nerves; for when these cords cease to convey any motive influence to the muscles, we cease to have any contraction on the disruption of the circuit when the current passes towards the foot.

When, on the other hand, the influence of the pile is transmitted through the limb in a contrary direction,-namely, from the foot towards the thigh, and when, therefore, the proper current of the limb coincides with that of the pile, then the major contraction follows the breaking and not the completing of the circuit. Now, in this case, the electric tension must have been increased during the continuance of the current; for the limb forms a true additional element of the pile, and yet the principal contraction does not take place on the completion of the circuit, as we might expect if this phenomenon was the consequence of an impartation of the electric agent. Instead of this, it supervenes when the circuit is broken, and when there is a removal or partial neutralization of force. Nor is it any objection that there is on closure of the circuit the minor contraction, which disappears 
eventually; for in this instance, as in the other, we may argue that it is owing to a neutralization of motive influence in the nervous fibres, the molecular arrangement of which is opposed to the electric current; for all the arguments in favour of this view which were applicable then, are so now.

Granting, therefore, the existence of a definite electric current in this limb, and the nerve of mixed fibres, it seems necessary to suppose that there is a certain annihilation of electric influence whenever contraction takes place in these muscles.

In the original experiment of Galvani, also, in which contraction is excited in a frog's limb that is allowed to remain connected with the trunk only by the sciatic nerve, whenever the foot is brought in contact with the lumbar plexus, it is possible to meet with the same explanation. In this case, indeed, it is necessary to suppose that the electric current in the limb is neutralized when the opposite poles are brought in contact, whether this be by bending the limb upon itself, as Galvani did, or by employing a conductor of metal or moist paper.

The results of which we have been speaking are rendered more complicated, when the limb which is experimented upon is allowed to remain in connexion with the living animal by removing the pelvis without destroying the nerves. Under these circumstances the muscles of the loins contract powerfully at the 
time when the slight contractions take place in the limbs. These contractions, however, are accompanied with signs of pain and suffering, and Matteucci has shown that they are due to the reactions of the nervous centres, and not to the direct agency of electricity, for they cease when the nervous communication with the spinal cord is destroyed.

In all these experiments, where free electricity is used, it is immaterial whether it be procured from a metallic battery or from the muscular pile. In each case the effects are the same, and the contraction would seem to be coincident with the removal or neutralization of the agent.

There is some reason also for supposing that the operation of galvanism and of nervous influence harmonizes more closely than would appear at first sight. It seems, indeed, as if the galvanism gave rise to instant contraction when passed in the same direction as the motive nervous influence; but it must be remembered that we have found some reason to believe that the nervous influence is abstracted during contraction and not communicated,-and hence it may be necessary to change our ideas in relation to the transit of nervous fluid in the motor nerves, the current being to and not from the brain,- - that is to say, in the same direction as the natural electrical current. Be this as it may, however, it is not with nervous influence that we are concerned when speaking of the effects of elec- 
tricity upon the system, for we have no right to assume the identity of these forces. We have to do with eléctricity and electricity alone, and we have to study any peculiar constitution of the animal which may favour or oppose the operation of this force, and this being the case, we must conclude, for the reasons that have been given, that muscular contraction is consentaneous with the abstraction, and not with the communication of electricity.

These results are taken from the history of the frog, but there is no reason to suppose them confined to this animal; indeed, there is evidence (though much more obscure) of currents of natural electricity in other animals. It is found, also, where the question has been examined, that the muscles respond to electricity in the same manner as in the frog, and this is an inportant argument in favour of the same electrical constitution in the subject of the experiment as in the frog.

In connexion with this part of our subject, it is necessary to refer once more to another order of phenomena,_namely, the effects of mechanical irritation; but a passing allusion is sufficient after what has been said elsewhere. Previously it was argued that the contractions produced by any simple irritant were not proofs of the communication of a stimulus, and it was shown to be equally probable that a something had been abstracted, as that anything had been im- 
parted. Indeed, the presumption in favour of the latter hypothesis had the advantage, inasmuch as the state of contraction under other circumstances was seen to be expressive of a change of this character. In voluntary muscles, also, the same arguments hold good, for so far as we have gone we have been able to trace the operations of a common law of action; but here also are found other arguments in favour of the same view, in the presence of an actual electrical condition of the parts, the equilibrium of which may be disturbed by the contact of any foreign body.

Under these circumstances, it may be presumed that the effects of mechanical irritation are more intelligible on the presumption of a stimulus having been abstracted than the reverse; and from the known electrical condition of the part it may be said that there is a process of discharge at the instant of contact, just as is the case on touching a charged electrometer, and that the process of contraction in the one case is a phenomenon analogous to the collapse of the metal blades in the other.

That there is an actual discharge of this kind during mechanical irritation we may further argue from the intimate analogy which exists between a mass of muscle and the organ which produces free electricity in certain fishes, as the Torpedo and Gymnotus. Owen, Faraday, and Matteucci have all contributed important arguments in proof of this 
analogy. The organization and the mode of action alike present many similarities. There is nothing which favours or suspends muscular contraction which does not operate in the same manner upon the electrical discharge. It has been shown indeed, that when the fish is acted upon by galvanism, the discharge accompanies the closure of the circuit when the current passes along the nerve towards the electrical organ, and the disruption when passed in a contrary direction. On the strength of this analogy, therefore, we may reason as to the operation of mechanical irritation in muscle, and as we know that a discharge is produced by irritating the electric organ, we may infer that there is a similar, though less sensible discharge when a muscle is subjected to the same treatment.

The return of the muscle to the relaxed state after contraction, when the vascular and nervous systems retain their integrity, is readily ascribed to the great molecular changes which these involve. Under these circumstances the generation of force is as necessary and inevitable as in a galvanic apparatus where the plates and fluids are in contact; and it is easy to understand that the amount will be altogether immeasurable. When the muscle is detached from the body, and the flow of blood and nervous power arrested, it is still possible to suppose a free extrication of electricity, for the atmospheric influences will induce very perceptible changes. It is not, indeed, as 
if we had to do with a solid mineral, where under these circumstances the action would be inconsiderable, and where careful isolation is necessary to render it sensible, but it is rather with a galvanic apparatus in slow action, where there is large amount of sensible force, notwithstanding the immense quantities which steal off to the earth without any manifest trace.

It is not difficult, therefore, to account for the effects of mechanical irritation upon an electrical hypothesis, without having recourse to any other law than that which has been traced throughout these researches.

The phenomena of muscular motion, in relation to the chemical aspect of the general force of which heat, light, and electricity are correlative expressions, are mixed up with a large mass of dubious theoretical notions; but at the same time we may obtain some insight into this part of our subject from the action of oxygen and carbonic acid upon the respiratory organs, for while these gases are intimately concerned in the normal workings of life, they at the same time typify the two grand classes of chemical agents which depress or exalt the vitality of the system.

In respiration the air passages alternately dilate and become filled with air, and contract and expel their contents; and these changes are excited by certain vivifying properties of the atmosphere, which 
depend chiefly upon the presence of oxygen. It is difficult, however, to suppose that the contractions are. due to this presence. On the contrary, we find that the air effects an entrance, remains for some time, and is not expelled until a considerable quantity of the vital element has been absorbed and replaced by carbonic acid; and hence it would appear that the contractions (if due to the air at all) are rather to be ascribed to the last-named gas than to the oxygen. In opposition to this notion, however, we find that the respiratory passages of the fœtus remain in a contracted state in absence of any aëriform stimulus, and also that there is a similar condition in the adult, independently of any direct stimulant, when an attempt is made to inhale an irrespirable gas. When, therefore, we consider that the air passages, both before and after birth, may remain in a contracted state, in absence of any gaseous stimulant, and when we consider that they immediately take in vital air, and remain expanded until this is partly devitalized, the natural conclusion appears to be that the atmosphere produces, by virtue of its oxygen, a state the reverse of contraction, and that this expansion disappears when the efficient cause is removed by the requirements of respiration.

In objection to this view it may be said, that the lungs are filled or emptied in consequence of the movements of the walls of the chest, and that the seeming 
dilatation of the respiratory passages is occasioned by the descent of the atmosphere into the space which has been formed by the contraction of the diaphragm and thoracic muscles; but, if we reflect a moment, we may perceive that this explanation will not meet the whole requirements of the case. The consideration, indeed, that the chest cannot be filled with irrespirable air is sufficient to show that the efficient cause of inspiration is something more than mere atmospheric pressure. From the difficulty which is experienced under these circumstances, it seems almost as necessary that the air should possess certain qualities by which it could overcome the contracted state of the respiratory passages, as that the blood should possess certain properties in order to secure a free entrance into the bloodvessels. Indeed, the consideration that the blood exerts this action upon the vessel is a strong argument that the air acts upon the respiratory passages in the way we suppose,-for in each case the activity is mainly to be ascribed to the oxygen, and in each case the action is exerted upon an irritable tissue, which presents many grounds of affinity and analogy. Be this as it may, however, the necessity of oxygenated air to inspiration is a sufficient proof that there is an active dilatation of the respiratory passages, in addition to the passive distention which will result from the mere weight of the incumbent atmosphere.

When, therefore, we find that an expanded state of 
the muscular fibres of the tubes in question is associated with oxygenated air, and the contracted state with air in which the stimulant properties are replaced by others which are directly sedative, we may argue (and with some pretence of reason) that the contraction is not stimulated by the oxygen; and from the occurrence of contraction, independently of the presence of carbonic acid, we may argue also that this gas is not to be regarded as the efficient cause of this phenomenon. In this case, indeed, as in those with which we are already familiar, the contraction would seem to mark the want, and not the presence of the agent.

It is not intended to say that some gases have no positive action in inducing contraction. On the contrary, such a result is not unlikely to follow the continued inspiration of dilute sulphuretted hydrogen; for it would seem as if the action of this poison was to unsettle the unstable equilibrium of the organic solid, and favour the formation of a similar gas from the decomposed materials, - to favour, in other words, a putrefactive change of solids into gaseous matter, which must be attended with the lowering of organic heat. Under these circumstances, therefore, the contraction of muscular fibre may be the direct consequence of the operation of the gas; but under other circumstances, where the quantity of the poison is larger, and the respiration at once arrested, it is more 
easy to believe that the air passages remain contracted in consequence of the absence of a vital stimulusthe natural operation of which is to produce dilatation, than that they are stimulated to this state by any positive action of the gas. It is difficult, indeed, to suppose that the gas has produced contraction in passages into which it has not entered.

In relation to the effects of other chemical agents we know but little. We know, however, that in order to the proper mobility of muscle, the peculiar state and constitution of the fibre, in relation to moisture, must be preserved, and that in absence of this the mobility will be nullified. When a fibre is macerated in water it is found to become pulpy, changed in colour, and otherwise altered. It is no longer with a normal fibre that we have to do, and we must not reason as if it was so; and if, therefore, under these circumstances, the mobility be lost, we may argue that this result is the natural consequence of the altered constitution of the fibre. Alcoholic, alkaline, or acid solutions are also found to alter the quality of the fibre in a peculiar way. In speaking, therefore, of the effects of a solution of opium or any other drug, the effects of the menstruum are not to be forgotten; and as this has been the case in too many instances, it is necessary that more careful experiments be instituted before we can be satisfied that we possess a proper knowledge of the true action of these drugs.

H 2 
A word, however, may be said upon the two agents that especially concern muscular irritability,-viz., opium and strychnia. Now, we know very well that a tetanic state is very apt to happen in frogs that are poisoned by these drugs, and the question is as to the cause of these spasms. Are they stimulated? Against this view it may be said that opium produces direct depression of all the vital faculties, of which depression it is not unreasonable to suppose that the spasm may be one of the signs. And in relation to strychnia, it may be asked if it is not begging the question to say that it acts by stimulating the nerves. If spasm is the only proof, then all the previous arguments upon muscular action are against the conclusion; moreover, there is undoubted evidence of the existence of severe convulsive diseases in which there is no such irritation, and in which the system is torpid, and in every respect the reverse of-what is called-excitable.

The whole subject, however, is so obscure that we must be content to wait the results of future investigation. Meanwhile, however, we may contend that there is at least an equal amount of reason for the supposition that the muscular contraction, which is the result of the operation of chemical agencies, is the sign of a negation and not of a communication of force.

We have now studied the phenomena of muscular action in relation to every aspect of physical 
force save one, and in every case we have found contraction to mark the abstraction of a stimulus. The remaining question, however, opens out, or seems to do so, a serious objection to this view; for on studying the motion, which is the effect of the operation of force, and at the same time a correlated expression of force, it appears that the law of vital contraction in muscular tissues, is altogether different from that of ordinary contraction in inorganic bodies.

This objection is chiefly founded upon some experiments of M. Schwann, which were instituted for the purpose of testing the force of muscular contraction in different degrees of this state. In these researches, the experimenter employed a frog, and an apparatus consisting of three parts - a stage or platform, - a balance, with one arm free and the other connected with an ordinary scale,- - and a moveable pin, which might be placed over the balance-beam in such a manner as to prevent the ascending movements without interfering with those in a downward direction. The frog was prepared by dividing one of the ischiatic nerves, and the principal tendon of the same leg close by its attachment to the heel; and when this was done, the animal was secured upon the stage, with the divided tendon attached to the empty arm of the balance by a piece of string, and with the nerve drawn out and placed in such a manner that it could readily be 
brought in contact with the wires of a pair of galvanic plates.

This arrangement being completed, the wires of the battery were applied to the nerve, and the muscles made to contract; and having done this, the pin was placed so as to keep the balance-arm attached to the tendon at the depressed position to which it had been brought by the contraction.

The arm of the balance connected with the tendon being in the position to which it had been brought by the contraction, a small weight was added to the empty scale which depended from the other arm, and the wires again applied to the nerve. At this time, however, the muscle gave no evidence of contraction. The pin was then removed, and the galvanic current renewed: and on this occasion the beam was seen to ascend, and the muscle to exhibit signs of action after it had attained to a certain degree of extension. At the former state of contraction, therefore, M. Schwann concludes that the muscle was not able to move the weight, and that it did not acquire this power until it had become extended and relaxed to a certain degree. He notices, however, that the contractions which took place under these circumstances did not depress the beam as much as before.

The experimenter then fixed the balance-arm in the position to which it was brought in this second phase 
of contraction, and proceeded to notice the effects of an additional weight. He proceeded as before, and found a similar train of results. There were, indeed, no signs of action so long as the pin remained; but on removing this, the beam once more ascended, and the muscle began to contract, after a certain degree of extension. It was the same, also, in relation to the degree of contraction, for the beam was not depressed as much as when a lesser weight was in the scale.

From these experiments, M. Schwann concludes that the power of contraction is greater when the muscle is least contracted, and therefore (he argues) that the force of vital contraction cannot augment in an increasing ratio as the particles approximate, as would be the case if the law of attraction were of the same nature as that of gravity, or any other physical force.

It is difficult, however, to understand by what process of reasoning M. Schwann is led to this conclusion. In respect to the law of universal attraction, there is no doubt that bodies will move towards each other with an energy increasing in the ratio of the square of the distance, if these bodies are free to move; and such a law seems to be involved, of necessity, in the very idea of force. When, however, the bodies acted upon are not free to move, and a force of resistance is opposed to that of attraction, the case is entirely altered. Do away with resistance, and bodies will 
move towards each other with increasing velocity, according to a certain and definite law, until they merge into one; but concede the antagonistic force, and the results of the pure law of attraction are at once masked. That law, therefore, which M. Schwann requires in muscular contraction is impossible, except he could do away with the matter of the muscle, and all opposing force in other quarters.

Instead of being a valid objection, therefore, the experiment under consideration merely shows that the normal manifestations of the law of attraction in muscles, as in other bodies, is masked by a force of resistance; and hence the only value of the experiment is as a measure of the degree of this resistance. Alter, indeed, the manner in which the facts are stated, and the result is simply this-that a muscle contracts to a certain degree when it has a given weight to raise, to a greater degree when the weight is lessened, and to the greatest degree when the scale is emptied, and when the antagonizing influence is only that which is furnished by the substance of the muscle itself.

M. Schwann would have had reason for his conclusions, if he had found the muscle to contract to the same extent in each of these differing circumstances; but this was not the case, and the amount of shortening was always inversely proportionate to the resistance. There is less reason, also, for the arrival at 
this conclusion, when it is remembered that elastic bodies follow precisely the same law; and lastly, as another argument against his conclusions, it must be remembered that these movements are not nervous and vital, but the results of the workings of the galvanic force.

All, therefore, that we learn from this experiment is, that attraction and the antagonizing forces occupy an inverse relation to each other-and this is a truth of universal extent. The deductions of M. Schwann are altogether gratuitous, and so far from the experiment being an objection to the idea that vital and physical contraction are obedient to the same law, it furnishes evidence in favour of this view; by showing, that the force of attraction in each case is affected in the same manner by resistance.

In conclusion: we have reviewed the phenomena of voluntary muscular action in relation to the several correlated aspects of physical force, and from this examination it appears that the muscles are subject to each and all of these agents, as inorganic bodies are subject. Heat, light, electricity, and chemical agency are all correlative of motion, and this latter aspect of force, so far as we may judge, is not different from the motion which is correlative of these forces in inanimate nature. 
C. OF VITAL MOVEMENTS IN THE HEART.

\section{Preliminary Considerations.}

If we examine the heart, we find many reasons to believe that it is subject to the law which rules the rest of the muscular system.

The existence of the sigmoid valves at the outlets of the ventricular cavities, is a fact which testifies as to the existence of a power in the heart whose operation is to produce regurgitation of blood: and in those cases, where these valves have been altered by disease, so that the arterial openings are imperfectly closed, the stethoscope reveals to us the reality of such a regurgitation. Now it is certain, that the force by which the blood is made to rush back in this manner is not owing to the resilience of an elastic tissue seated in the walls of the ventricles, 
which tissue had been compressed during the systole, for no such structure is to be found: and therefore we are led to suppose that the ventricular diastole must be more nearly allied to dilatation than relaxation.

Again: the peculiar construction of the heart in insects, and other articulate animals, is in favour of the existence of a state of active dilatation in this organ. In these creatures, the heart lies in the general cavity of the body, and floats in the bloodlike liquid with which this cavity is filled. There are no venous trunks, but the blood at once finds entrance into the ventricle through simple valved slits. The heart, moreover, is not a dense muscular viscus, as in the higher animals, but it is a lax membranous tube, little, if at all, superior to the condition of an ordinary small vessel. Notwithstanding this peculiarity, however, the beats follow the characteristic rhythm. The action, in fact, is perfect with the conditions simplified. Here, for example, the diastole cannot be a state of mere relaxation originating in the operation of a vis-a-tergo, for in a heart without veins, and lodged, as it were, in an immense auricle where the blood moves in no definite current, there can be no such force. Here, moreover, the diastole cannot be the consequence of the resilience of elastic tissue, for the walls of the organ are lax and membranous. In such a heart, indeed, there can be no passive cause of 
dilatation, and hence it seems necessary to suppose that there must be something more than mere relaxation in the diastole.

Another argument in favour of the same conclusion may be found in a case of cardiac-hernia, recorded by Dr. Cruvelhier, in which it is stated that the hand which grasped the protruded heart was opened during the ventricular diastole, notwithstanding a considerable effort to the contrary on the part of the experimenter, - a fact which is altogether at variance with the idea that this state is one of mere relaxation.

These considerations are sufficient to prepare us to expect that the movements of the heart form no exception to other vital movements, and to make us doubt that the ventricular diastole is a condition of relaxation, marking fatigue or weariness after an act of mysterious and exhausting contraction. What, however, is the true nature of this state, and of the systole, will appear if we proceed to examine the heart in relation to its causes of action.

1. Of extra-organic force as the agent in the movements of the heart.

The effects of the agents which belong to this class are somewhat obscure, but they are most apparent in the rudimentary phases of life. Low in the scale of creation, in "exsanguine animals, such as the snail," we learn, on the authority of the great Harvey, that 
the rhythmical movements of the heart are suspended in winter, or else repeated so slowly as to escape the attention of an ordinary observer, and the organ itself so shrunk and contracted as to be little more than an ordinary vessel, - a change which, when compared with the state in summer, would seem to argue that the heart has suffered contraction in consequence of the coldness and inclemency of the season.

The influence of extra-organic agents may also be seen in the heart of a chick, if a visit be paid to the hydro-incubating establishment of M. Cantello. The other day, for example, I had ocular demonstration of this, along with my friend Dr. William Addison. On opening an egg of the third day the heart was seen to pulsate regularly, and to continue to do so for some after the embryo was separated from the vascular area, and placed upon a slip of glass. When the heart became still, which it did in a few minutes, we found it possible to renew the action by placing the lower surface of the glass in light contact with the warm water which is used to hatch the eggs; and when it was still a second time the rhythm was renewable in the same manner. Indeed it was found possible by this application of warmth to revivify the heart when it ceased to act, until the organ and the rest of the gelatinous embryo were half dried up by exposure to the atmosphere. It was the same also with an embryo-chick of the sixth day, which was 
subjected to the same treatment. On examining the heart in these cases, after it had ceased to act, it was shrunken and collapsed, and the immediate operation of the heat seemed to induce the diastole; but owing to the minuteness and indistinctness of the parts it is not easy to speak positively upon this point. Be this as it may, however, the influence of extra-organic agents is clearly exhibited in these experiments.

The same influence is also seen in the heart of a cold-blooded animal—of a frog, for example; and here we may obtain a distant glimpse of the causes which induce the rhythm. It is well known that a heart of this kind will pulsate for some time after removal from the body, taking air into its cavities and expelling it again, as it might be blood,-the reactions between the air and the heart being the chief source of the force which is concerned in this action. Now, at first sight, we have no more reason to suppose that the air excites the systole than the diastole; but, if we reflect awhile, we find it easier to entertain the latter supposition than the former. There is no elastic tissue to restore the diastole by its resilience when the systole ceases, and on this account it is difficult to suppose that the air can find entrance, unless it possess some power by which it can resolve the contracted state. Moreover it may be supposed, that a certain generation of force must result from the combination of the atmospheric oxygen with the 
tissues with which it comes in contact. And, further, if the air finds entrance into the heart by this means, it follows that it will be less able to retain its position after a portion of its vivifying ingredients have been expended, as they must have been if the diastole is induced in this manner, and we may infer, therefore, that the systole will occur and expel the air, as the natural consequence of the altered and deteriorated quality of this air. But let the explanation be as it may, we may return to the original assertion, and say, that there is no more proof that the air excites the systole than the diastole. The question, however, is extremely complicated, and we must be content to deduce an indirect answer from the more evident operation of intra-organic agents.

2. Of intra-organic force as the agent in the heart's action.

(a.) Of the nervous influence as an agent.

The effects of fear upon the heart are very well marked, and these may serve as the first subject for inquiry. In this state the extreme pallor of the skin and the tendency to evacuation in the several visceral cavities, argue, as we have seen, an actual contraction in the rudimentary muscular structures, and it is the same also in the walls of the heart. When, for example, fear verges upon syncope, and the contrac- 
tions of the heart are very hurried, and when, at the same time, the paleness of the skin shows how small a quantity of blood is forced into the vessels, the only manner in which it is possible to account for the inconsistency of these phenomena, is to suppose that the walls of the ventricles have become contracted,for if these cavities preserved their natural dimensions, the increased number of systolic contractions must produce an equivalent distention of the vessels, by which the skin would become hot and flushed, instead of being, as it is, cold and pallid. And hence it may be presumed, that a state of contraction has been induced under the influence of fear, in the walls of the heart, as in other muscular structures.

In the natural action of the heart, also, there is strong presumptive evidence that the systole is cotemporaneous with an interruption in the supply of nervous influence, and not with any increased supply. We know, indeed, that the development of this agent is proportionate to the flow of blood to the sources of innervation; and hence we may conclude that this development must follow an intermittent law in animals provided with hearts. At the systole, indeed, a gush of blood will pass to the nervous organs and produce signs of activity in them; and as the distribution of force will be consentaneous with its production-for in subtlety this agent is analogous to electricity-it follows that the heart is most freely supplied with 
nervous force during the period of diastole; while, according to the same rule, the period of feeblest innervation will be during the systole, and the short space of rest immediately antecedent.

It may be objected, however, that the flow of blood in the capillaries is uniform and regular, and not intermittent, as is here supposed, and it is not to be denied that this objection is of great importance. At the same time it will be admitted that this uniformity is only comparative. Whatever, indeed, may be the case in muscular and firmer textures, it is difficult to imagine uniformity in the softer nervous structures, where the vessels are extremely delicate, and comparatively destitute of extraneous support. On the contrary, the powerful pulsatory movements of the brain that are consentient with the beats of the heart, and which are seen when a portion of the skull is removed, and felt in the throbbing torments of headache, are arguments in favour of some variations in the supply of blood-to the brain at least, such as might determine an intermittent development of nervous influence.

From the manner in which the blood is sent from the heart, therefore, we may infer that the development of nervous energy will be in corresponding intermittent gushes: and here we begin to catch a glimpse of the causes which operate upon the heart, and produce its mysterious rhythm. Let us suppose, 
indeed, the heart to pass from diastole into systole, and one of the effects will be the sending of a flood of blood to the sources of innervation. There this flood will excite a free development of nervous influence, which being directed to the heart through the proper channels will induce the state of diastole. In consequence of this change the arterial stream is cut off, and the blood sets in to the heart from the auricles and veins. The stoppage of the supply of blood arrests for the moment the free development of nervous energy, and hence one influence is withheld which induced the diastole, and the heart, therefore, returns to the systole. And so we get round the circle. The arterial stream again sets out in consequence of the systole,- - the blood causes the renewal of nervous energy,- - the nervous energy induces the diastole, and in this way, the blood being again withheld from the vessels, we arrive at the cause of that suppression of force which occasions the systole. And so, in a regular series, systole will give rise to diastole, and diastole be followed by systole, so long as the vascular and nervous systems retain their integrity.

No mention is here made of the share which the auricles have in the action of the heart, and it may be thought that this must be directly contradictory to that of which we have been speaking, inasmuch as the diastole of the auricle, and the systole of the ventricle, are cotemporaneous changes, and, vice versâ, the sys- 
tole of the auricle is related in point of time to the diastole of the ventricle. But a careful examination of the question is sufficient to disarm this difficulty.

It cannot be doubted that the auricles, as well as the ventricles, possess a proper power of contracting and dilating, but it is a fallacy to suppose that these states-at least in the rapid rhythmic order in which they occur-are distinct in themselves, and altogether independent of the movements which have taken place in the ventricles. There is good reason, indeed, to doubt the actuality of auricular-systole as a state of positive and independent contraction, and to suppose it to be, as it were, a pseudo-systole, consequent upon the sudden emptying of the auricle by the rapid diastole of the muscular ventricle. And to this opinion we are led by the anatomical peculiarities of the coats and cavities of the auricles. In the cavities, the absence of valves to prevent a reflux of blood into the veins, and the want of all evidence of any such reflux (except in patency of the auriculo-ventricular valves, where, indeed, the cavities of the auricles and ventricles are continuous), afford a strong argument against there being any true systole in the auricles. The history of these cavities also, as gathered from the records of comparative anatomy, tends to show that they are mere cisterns calculated to hold the blood necessary to the wants of the ventricles, rather than organs destined to aid in the circulation by systolic 
contractions. In the structure of the coats of the auricles, also, there is reason for the same conclusion. This is different from that of the ventricle, for though truly muscular, yet it is that unstriped variety which is more closely allied to what is found in the coats of the veins, than in voluntary muscle and the muscle of the ventricle. Now, in veins there is an absence of any rapid rhythmic changes, though there is a capacity for slower and more prolonged movements, and hence it may be doubted whether there are any rapid changes in the auricles. It is the same, also, in the coats of the alimentary canal, and hence another and confirmatory reason for the same conclusion. In relation to structure, indeed, the two cavities of the heart are widely different: on the one hand, the ventricles are composed of muscle which, from its striped character and close analogy to voluntary muscle, may be supposed to be extremely apt to rapid and energetic movements, especially under the agency of nervous influence; and on the other hand, the auricles, like the coats of the veins and alimentary canal, are composed of the unstriped variety of muscle,-and hence we may infer that their movements, like those of the veins and intestines, are slow and not likely to respond with readiness to a nervous stimulus.

In this manner, therefore, the problem of the heart's action may be greatly simplified, and we may find some reason why the auricle should contract at a time 
when, judging from the state of the ventricle, there is the freest innervation. In harmony with these considerations, we may suppose that the filling of the entire side of the heart is a single act, though it appears twofold. Owing indeed to the decided and rapid diastole of the ventricle, we may suppose the blood to be suddenly drawn away from the auricle, and not sent away; and so the apparent contraction of the auricle at this time may be collapse of the thin walls of the organ, instead of true and positive systole.

We may consider, in short, that the movements observable in the auricles are secondary and not primary. The systole we may consider as complementary to the arterial pulse, each phenomenon being dependent upon actions which take place in a remote seat-namely, in the ventricles. The diastole also we must regard as mainly dependent upon the general current of the blood, which, proceeding from the pulse and capillary power, flows onwards from the veins. There is indeed more confirmed activity in the auricles than in the neighbouring veins, but when the activity is compared with that of the ventricles, it becomes insignificant and scarcely appreciable. 
(b.) Of the organic force, not of a nervous character, as an agent in the action of the heart.

The immediate influence of the blood in this case is not readily illustrated; but it is not difficult to perceive that the present theories upon this subject are very unsatisfactory. That the blood does not stimulate contraction may be argued from the histories of the common bloodvessels and visceral cavities, which have been given in a former page, between which histories and that of the heart there is an intimate connexion,for whatever the differences in form and function when fully developed, they all spring from the same origin. To suppose that the blood excites contraction in the heart, moreover, is to create a difficulty which has already been insisted upon; for, if this were the case, how is it that the blood finds entrance into the organ?

There need, however, be no doubt upon this question if we institute once more a comparison between the opposite conditions of plethora and anæmia. In anæmia, for example, (especially in the variety which is associated with the consumptive habit of body, ) we find rapidity and smallness of the pulse, together with other signs of emptiness in the vascular system. There is in fact the same evidence of contraction in the ventricular cavities as was found in the state immediately antecedent to syncope, for as we argued in this case, a proportionate flood of blood must be sent into the 
vessels if these cavities were fully dilated. In plethora, on the contrary, the pulse is generally full and slow; and hence we should argue, in the first place, that the diastole is perfect, and a large quantity of blood taken into the heart at this time; and secondly, that the presence of the blood does not immediately and of necessity give rise to a systole. Comparing, indeed, the state of plethora with that of anæmia, the contrary would seem to be the fact,- and the rapid systole in the one case would seem to be ascribable to the small quantity of blood which is taken into the heart, together with its impoverished and watery quality; and the deferred systole, in the other case, to the presence of a larger quantity of richer and more genial blood. The effects, indeed, are analogous to those witnessed in the vessels under similar circumstances, and it must be admitted that the heart has a greater capacity of dilatation in plethora than in anæmia. And so clear in other respects is the significance of the same facts, that it seems as reasonable to suppose that the blood excites the vessels of erectile tissue to contraction, as that it has this influence upon the heart, which after all, is but one of many forms of bloodvessel.

It would appear, also, on further examination that the influence of the blood is an agent of extreme importance in determining the rhythmical action of the heart. At the ventricular systole the blood is distributed to the vessels, and among the rest to the 
coronary arteries: and this abundant supply of the vivifying stream cannot be without its influence upon the walls of the heart. We cannot suppose it to excite the systole, however, for the rush is absolutely simultaneous with the opposite condition,-namely, with the swelling out of the heart into the diastole. Moreover, there is a short pause before the supervention of the systole. The blood, in fact, rushes into the walls of the heart at the instant when the diastole commences, remains during the continuance of this state, and throughout the short pause which supervenes, - and hence the flood of new blood can scarcely be supposed to be the cause of the systole. There is no difficulty, however, in believing that it is one of the causes of the diastole. The very rushing into the vessels may contribute to this. The reaction, also, which takes place between the oxygen of the blood and the vascular coats, which we know to be one main cause of the capillary force, will co-operate with the arterial tension in producing the same result, for a definite extrication of force is the direct consequence of this reaction. When, therefore, we consider the rush of blood in the coronary arteries, and the attendant actions in the capillaries, we may easily understand that the pulse of blood in the vessels of the heart may be an important coagent with the pulse of nervous influence which takes place at the same time, in bringing about the diastole. But 
this is not all that concerns the action of the blood upon the heart: and on further examination we may find, in the same quarter, a reason why the systole should follow the diastole. The jet of blood in the coronary arteries is withheld, as we know, in consequence of the diastole, and hence the arterial tension must be less perfect. The blood, also, at the same time is passing, or has already passed, into the veins, and become deprived of its arterial character. It has in fact given up, in great measure, the principle which is the main stimulus of activity and life,namely, the oxygen; and therefore it is less fitted to sustain the diastole, than it was when freshly injected into the ressels. The arterial tension and capillary action are in fact reduced, if not removed; and hence we may conclude that as this tension and action was a canse of the diastole, so the removal will tend to bring about the systole, by allowing, that is to say, the heart to return to its former condition of contraction.

To this explanation it can scarcely be objected, that there is no intermittent variation in the quantity of blood contained in the walls of the heart. At each systole the blood is expelled from the cavities, and we can hardly suppose that this contraction should take place without expelling some of the blood in the walls as well. Indeed, if we watch the action of the heart in a frog, in which the sternum has been 
removed, without doing any injury to the vessels, we may be convinced of this; for at each diastole the organ becomes turgid with blood, not merely in the cavity, but in every vessel of the coats; while at the systole the walls are pale and the cavity emptied.

It is possible, also, that there may be a pulsatile generation of force in the pulmonary and some other tissues, where from the looseness of the structure, and the comparative absence of the pressure or support of surrounding parts, the flow of blood may be intermittent rather than continuous. Any pulses of vascular force originating in this way may react with the pulse of nervous influence (either through the nervous circle, or else by direct conduction through contiguous tissues), and with the pulses of vascular force belonging to the coronary system, in the induction of the diastole; while the common pause in the generation of force in all these quarters which is necessitated by the cessation of the jet of blood into the arterial system, may bring about the systole. It is possible, also, that the blood within the cavities of the heart, in so far as its surface is concerned, may act upon the lining membrane, just as it does upon the coats of the capillaries; but this action must be very insignificant when compared with the immense surface acted upon in the walls of the heart itself. Moreover, on the one side of the heart the cavities contain venous blood, and on the other side, 
arterial; and unless we had some common cause in operation (as we have in the general distribution of new blood through the coronaries) it is difficult to account for the simultaneous occurrence of diastole and systole in these two sides. It is an assumption without any proof, that the right side of the heart is more sensitive than the left, and that, by reason of this, it is able to respond to the feebler stimulus of venous blood: indeed this assumption is in opposition to the known law, that the acuteness of sensibility is in direct relation to the arterialized condition of the blood. We may conclude, therefore, that the action of the blood in exciting the heart, is exerted upon the vessels and fibres of the walls of the organ (and perhaps in certain additional reactions in the vessels elsewhere), rather upon the lining membrane of the cavities,-although we are not prevented from supposing that there is a certain and definite action of the same kind in the latter quarter.

In the action of the heart, therefore, we detect the harmonious co-operation of extra-organic and intraorganic agents, with which we are already familiar, but the theory is not complete except it will account for the presence of the rhythm in the heart, and the absence in all other muscular structures. Why it is present in the heart we may find on examination. The valvular construction of the organ may be one reason, for this necessitates a continual admission of fresh 
supplies of blood. By this arrangement it may be supposed that the fibre of the heart is placed in the conditions most favourable to the exaltation of its mobility,-for in other muscles we see that this faculty is directly proportionate to the free supply of oxygenated blood. A chief cause, however, may be supposed to be the intimate relation which exists between the heart and the blood, - a relation which is rather what it might be imagined to be in a structure intermediate between erectile tissue and muscle, than in ordinary muscle. This is not only seen in the phenomena which have been noticed as occurring in the heart of a frog during action, but also in the peculiar vascularity of any heart, when compared with the other muscles of the same animal. As contributing to the peculiarity of the action of the heart, we must also mention the shortness of the vessels, and the existence of the foramina thesbesii, all of which are favourable to the speedy entrance and escape of blood; and finally, we must notice the great variations in the quantities of blood contained in the walls and cavities of the heart. Now, on comparing voluntary with involuntary muscle, there is good reason to believe that the more abundant vascularity of the former is a chief cause of the greater readiness and rapidity of action; and for the same reason, therefore, we may suppose the heart to possess a greater mobility than either; hence there is no great difficulty in supposing 
that the heart is able to respond to the rhythmical variations of force which can be pointed out as acting upon the organ. On the other hand, the very reasuns which enable us to suppose that the heart may have a rhythmical action, prevent us from expecting this elsewhere. In other muscles, the more scanty supply of blood-vessels argues a duller mobility, and the absence of such marked variations in the contents of these vessels-the circulation in them being continuous rather than intermittent-argues also a feebler manifestation of the rhythmical variations of force. In other muscles, therefore, we have a feebler rhythm of force, and a duller capacity of responding to this rhythm; and therefore the comparative absence of the conditions which determine the rhythm of the heart may be the reason why such a rhythm is absent elsewhere.

In conclusion: the heart is subject to the laws which govern other mobile fabrics, and its history would seem to offer no exception to what has gone before. The systole refers to the common causes of contraction; the diastole to the common causes of dilatation. The rhythm also may be supposed to be nothing more than the obedience of a natural susceptibility to certain periodical variations in the supply of intra-organic force, the existence of which variations can be satisfactorily demonstrated. 


\section{CHAPTER V.}

\section{OF THE NERVOUS INFLUENCE AS AN AGENT} IN VITAL MOVEMENT.

In the preceding chapters, it has been found that nervous influence, and the other forces of organization agree in their mode of action, and that all these vital and physico-vital agencies co-operate harmoniously with the several varieties of extra-organic force,and hence we may infer, with very sufficient reason, that nervous influence is nothing more than a modification of cosmical force.

In another work, ${ }^{*}$ it has been shown that the nervous system is formed upon the same archetypal plan as the other parts of the body, and even of the body itself, and that the same plan is extended to what are called inanimate bodies; and in this unity of the material framework of things there is another

* See "Proteus," p. 65, \&c. 
reason for supposing the nervous influence to be a variety of cosmical force.

It has been shown, also, in the same work that all forms of physical and vital force are truly correlative: and hence a final argument in favour of the view that the nervous influence is a variety of cosmical force.

We are not taught, however, by these considerations to do away with the idea of nervous influence, though we regard it in this point of view, or to ascribe its workings to electricity, or heat, or light, any more than we should confound the existence of light, or heat, or electricity, and say that either of these agents was identical with the others. Correlation, in fact, involves the idea of unity, but it as distinctly retains that of difference. Nor are we to confound nervous influence with mind, for-if it be as we have said-it is clear that it can have no exclusive claim to be considered as identical with this essence.

The nervous influence, therefore, is to be regarded as one of several modes of cosmical force, which reacts harmoniously with all companion agencies, in the determination of vital movement. 


\section{CHAPTER VI.}

\section{OF THE ACTION OF MIND IN VITAL MOVEMENT.*}

Mind and body are associated in a mystical union, and the one cannot be understood without the other; but it will facilitate our inquiries, and enable us to attain with more readiness to some knowledge of the action of mind in vital movement, if we consider the mental principle as a distinct and separate entity, before we regard it as wedded to corporeity.

I.

In mind apart from body there are no traces of decay and perishability, nor is there any evidence of

* In its most comprehensive sense, the term " mind" signifies the composite essence which comprehends the several faculties of memory, imagination, instinct, understanding, reason, conscience, will-and in this full sense we must be supposed to use the term, mind. 
subjection to time and place, in the sense in which we understand the body to be subject.

1. The indelible record which is preserved by the memory of every conscions or unconscious act of the mind, may be taken as a proof that the mental essence is itself imperishable.

In the mind of every one there are certain images of past events, or actions, which continually obtrude upon the attention, and which appear in this way throughout a long life, without losing any of their distinctness and reality. There are images, also, which remain out of sight unless they are wanted, when they awake and issue from their hiding-places. And, along with these, there are other images which have escaped from the dominion of the will, and which would seem to have vanished into oblivion, if they did not appear occasionally in answer to certain sights or sounds which seem to exert a talismanic influence over them: thus, for example, the long-forgotten feelings and thoughts of boyhood may bestir themselves at the sight of a faded blossom that has been preserved among the pages of a school-book, - not languidly, but with the same tumult as they did on the holiday on which the flower was gathered, when ourselves and companions, the landscape and the sky, were full of life, and without shade or sadness; and in this way we find that this part of the past is not cancelled, although it had been hidden by the crowd of suc- 
ceeding days and years; or the moaning of wind in the casement may bring to remembrance the chamber, with all its darkness and loneliness, where we once listened to such a sound, as if it were instinct with supernatural meaning; and the involuntary shudder proves that time has been no more able to erase this passage from our history than the other. It is, indeed, the experience of every moment, that no impression can fall upon the senses, and no movement take place in our inner being, which does not awaken something that had been forgotten,- and we may well pause, therefore, before we conclude that the past is cancelled, because it does not reveal itself in obedience to the will.

The difference in the power of recollection in various people, and in the same person at different times, is another argument in favour of the indelibility of memory. We find this power to be most acute in cases where, and at times when, it is most in exercise. It fails under neglect, and is recovered by attention. Nor do we know of any limits which can be set to the perfectibility of this faculty; and hence we may reason that the memory is a blank in some particulars, not because it has treacherously refused to receive what ought to have been recorded, or that these records have become effaced, but simply because we have neglected to fortify the mental vision by which we read what is written. 
The phenomena of disease afford other arguments, which confirm and support this position The memory, for example, is suspended when the brain is pressed upon by the finger, and returns again when the pressure is removed; and hence we may argue, from this recovery, that the memory was not obliterated, but simply that its active manifestations were suspended. In like manner, also, we may account for the absence of memory in apoplectic and paralytic seizures; for in these cases the faculty returns as the effects of the disease wear away. In delirious excitement, on the other hand, the preternatural activity of the brain is often accompanied with a corresponding development of the memory; and these cases afford the strongest possible proof that nothing which has found its way into the mind is ever forgotten. In delirium there are many well-authenticated instances of persons talking in a language which they had known in their youth, but which they had completely forgotten before this particular illness, and which they forgot again, as completely as before, on recovery. Coleridge, also, has recorded a case where, in delirious fever, sentences were spoken in a language which was never understood, and where the sounds had been retained without any knowledge of their meaning; and so remarkable is this case, and so well calulated to show the indelibility of memorial impressions, that I copy it, and the comments which follow, as a most fitting 
illustration of our present problem. This case, says Coleridge, " occurred in a Catholic town in Germany, a year or two before my arrival in Göttingen, and had not then ceased to be a frequent subject of conversation. A young woman of four or five and twenty, who could neither read nor write, was seized with a nervous fever; during which, according to the asseverations of all the priests and monks of the neighbourhood, she became possessed, and, as it appeared, by a very learned devil. She continued incessantly talking Latin, Greek, and Hebrew, in very pompous tones, and with most distinct enunciation. This possession was rendered more probable by the known fact, that she was or had been an heretic. Voltaire humorously advises the devil to decline all acquaintance with medical men; and it would have been more to his reputation, if he had taken this advice in the present instance. The case had attracted the particular attention of a young physician, and by his statement many eminent physiologists and psychologists visited the town, and cross-examined the case on the spot. Sheets full of her ravings were taken down from her own mouth, and were found to consist of sentences, coherent and intelligible each for itself, but with little or no connexion with each other. Of the Hebrew, a small portion only could be traced to the Bible; the 
remainder seemed to be in the Rabicalin dialect. All trick or conspiracy was out of the question. Not only had the young woman ever been an harmless, simple creature, but she was evidently labouring under a nervous fever. In the town in which she had been resident for many years as a servant in different families, no solution presented itself. The young physician, however, determined to trace her past life step by step,-for the patient herself was incapable of returning a rational answer. $\mathrm{He}$ at length discovered a place where her parents had lived; travelled thither, found them dead, but an uncle surviving; and from him learnt that the patient had been charitably taken by an old Protestant pastor at nine years old, and had remained with him some years, even till the old man's death. Of this pastor the uncle knew nothing, but that he was a very good man. With great difficulty, and after much search, our young medical philosopher discovered a niece of the pastor's, who had lived with him as his housekeeper, and had inherited his effects. She remembered the girl; related that her venerable uncle had been too indulgent, and could not bear to hear the girl scolded; that she was willing to have kept her, but that after her patron's death, the girl herself refused to stay. Anxious inquiries were then, of course, made concerning the pastor's habits; and the solution of the problem was soon obtained. For it 
appeared that it had been the old man's custom, for years, to walk up and down a passage of his house into which the kitchen door opened, and to read to himself, with a loud voice, out of his favourite books. A considerable number of these were still in the niece's possession. She added that he was a very learned man, and a great Hebraist. Among the books were found a collection of Rabbinical writings, together with several of the Greek and Latin fathers; and the physician succeeded in identifying so many passages with those taken down at the young woman's bedside, that no doubt could remain in any rational mind concerning the true origin of the impressions made on her nervous system.

"This authenticated case," Coleridge proceeds to say, "furnishes both proof and instance that reliques of sensation may exist for an indefinite time in a latent state, in the very same order in which they were originally impressed; and as we cannot rationally suppose the feverish state of the brain to act in any other way than as a stimulus, this fact (and it would not be difficult to adduce several of the kind) contributes to make it even probable that all thoughts are in themselves imperishable; and that if the intelligent faculty should be rendered more comprehensive, it would require only a different and apportioned organization - the body celestial, instead of the body terrestrial-to bring before every 
human soul the collective experience of its whole past existence. And this-this, perchance, is the dread book of judgment, in whose mysterious hieroglyphics every idle word is recorded! Yea, in the very nature of a living spirit, it may be more possible that heaven and earth should pass away, than that a single acta single thought_-should be loosened or lost from that living chain of causes, to all whose links, conscious or unconscious, the free will-our only absolute self-is co-extensive and co-present."

Mind, therefore,-we may conclude from these considerations, - is an essence in which there is an absence of the signs of perishability which we are accustomed to regard as distinctive of the body. And this is one property of mind.

2. Nor is the mind subject to time in the ordinary sense of the word. On the contrary, it wanders continually from the present into the past, and from the past into the untried domains of futurity. Under the influence of mind, also, the present itself is of uncertain duration, and a day may become as a moment, and a moment as a day. The hours, for example, pass along and leave no impression when the spirit is free from care and anxiety, or a moment of anguish may be so preternaturally dilated that we can hardly believe what we have felt and suffered to have been confined to this short space of time. There is a hidden truth in the Arabian romance of the caliph 
who believed himself to have been sold as a slave, and to have suffered seven years' servitude during the instant that his head remained immersed in the bath; or in the story of Mahomet's ascent to the seventh heaven in the interval between the overturning of a water-jar and the escape of the contents, - for in both these stories is shadowed forth the superiority to the bounds of time which is a second property of mind.

3. The mind, also, is not subject to place. On the contrary, there is, as it were, an irradiation from one person to another, and it is difficult to define the limits of mental being.

We arrive at this conclusion from the arguments which show the correlation of physical and vital force -which arguments have been set forth elsewhere*but we may obtain direct as well as indirect evidence if we examine mental actions, (as words, ideas, feelings, or the more general movements of the frame,) or the faculties which are the motives and springs of these actious; for in every instance we may detect the operation of mind beyond the body whence it emanates.

An instance illustrative of the connexion of words with a foreign mental impulse, was told me the other day by a friend, as having fallen under his own notice

* See Proteus, or the Law of Nature, chap. ii. 
in an English family, at that time resident in Germany. As is not unusual under such circumstances, one of the younger children had acquired the power of speaking on ordinary matters in German or in English, without confusing the words or idioms; but, notwithstanding this double faculty, he was invariably obliged to reply in the language in which he was spoken to, if addressed by an adult. When, for example, he carried a message to the nursery-maid, who was a native villager without a knowledge of any language save her mother-tongue, he delivered it in German, though it had been received the moment previously in English; and hence we are led to imagine that his speech was ruled for the time by some influence proceeding from the maid-akin perhaps to that which, under other circumstances, might have awakened a smile in his countenance; for the child was too young to allow us to suppose any process of reasoning by which he had purposely selected from his vocabulary the words which were intelligible to her. And that this was the case appears from what took place on his return to the parlour. At this time he joined in the English conversation which was carried on, and he had no power of doing otherwise if he spoke at all: thus, if asked what Annchen had said, he answered in English as often as the question was proposed in English, and even though pressed to give the words he had heard in the nursery, he still 
continued to do the same, without seeming to be aware of the difference; but if the question was put to him in German, the answer was in German, there being in this case his same inability to reply in English, if wished to do so, as there had been when required to give a German answer to an English question. In this case, therefore, the words would seem to have been dictated by another person rather than by the mind of the speaker, and thus the tongue of the child may be said to test the actual presence of mind beyond the bodily limits in which the impulse originated.

In part, also, we may suppose an adult to have been affected in the same way, when, in conversation (as not unfrequently happens) he has been irresistibly led to give utterance to words which it would have been prudent to conceal from his companion, and which words, moreover, he had fully resolved to conceal. And so in all probability it is with all: for if we examine ourselves, we find it impossible to account for all the words we utter by referring them to the will for their origin.

It is the same, also, in relation to ideas, as may be seen in many ways. There is, however, a page in the "Sylva Sylvarum" which shows very clearly the influence of one mind in infixing an idea in another person, and this I shall quote as a better illustration than any I can furnish from my own experience:- 
"I related," says Lord Bacon, "one time to a Man that was Curious, and Vaine enough in these Things; That I saw a kinde of Juggler, that had a Paire of Cards, and would tell a Man what Card he thought. This Pretended Learned Man told mee; It was a mistaking in mee; For (said he) it was not the Knowledge of the Man's Thought, (for that is Proper to God,) but it was the Inforcing of a Thought upon him; and Binding his Imagination by a Stronger, that hee could Thinke no other Card. And thereupon he asked me a Question, or two, which I thought he did but cunningly, knowing before what used to be the Feats of the Juggler. Sir, (said hee,) doe you remember whether he told the Card, the Man thought, Himselfe, or bade Another to tell it. I answered, (as was true,) That he bade Another to tell it. Whereupon he said, so I thought: For (said he) Himself could not have put on so strong an Imagination; But by telling the other the Card, (who believed that the Juggler was some Strange Man, and could doe Strange Things,) that other Man caught a strong Imagination. I hearkened unto him, thinking for -Vanitie he spoke prettily. Then he asked me another Question: Saith he; Doe you remember whether he bade the Man thinke the Card first, and afterwards told the other Man in his eare, what he should thinke, Or else that he did whisper first in the Man's eare, that should tell the Card, telling that such a Man 
should thinke such a Card, and after bade the Man thinke a Card? I told him, as was true; That he did first whisper the Man in the Eare that such a Man should thinke such a Card: Upon this the Learned Man did much Exult and Please himself, saying; Loe you may see that my Opinion is right: For if the Man had thought first, his Thought had been Fixed; But the other Imagining first, bound his Thought. Which though it did somewhat sinke with me, yet I made it Lighter than I thought, and said; $I$ thought it was Confederacie, between the Juggler and the two Servants: Though (indeed) I had no Reason so to thinke: For they were both my Father's Servants: And hee had never plaid in the House before. The Juggler also did cause a Garter to be held up: And tooke upon him to know that such an One should pointe in such a Place of the Garter; As it should be neare so many Inches to the Longer End, and so many to the Shorter; And still he did it, by First Telling the Imaginer, and after Bidding the Actour thinke."

We cannot doubt that a weak and uncertain person may receive some of the energy in which he is deficient from one who is firmer than himself; and it is not less true that a man may acquire both resolution and imaginative power from the confidence of others;and therefore it is not impossible for the juggler to have received an increase of power sufficient to com- 
mand a clownish spirit by allying himself to another who lent himself implicitly to his purpose. Let the interpretation of this phenomenon be what it may, however, there is abundant evidence to show the influence of mind in determining an idea in another person, as we see in the ideas of childreu and students which are respectively stamped by parents and teachers.

The connexion of feelings with a foreign impulse is very obvious. A glance of the eye, or an expression of countenance, is sufficient to enkindle a corresponding feeling in the minds of others. An amiable person, for example, cannot be long in a room where there are children before his kindness is distinctly reflected in their manners or countenances; and a morose visitor, under the same circumstances, is sure to extinguish mirth and laughter. It would seem also as if there was something more in this influence than what we are pleased to regard as impressions through the senses, as we may argue from the frequent coincidence of thought when we are in company with a friend, although, there has been no turning of the head to read what is passing in his countenance. Both speak at once, and both know that they are about to express the same thing before a single word has been uttered. It is also an instance of the same more mysterious supra-sensational influence where one person is aware of the approach of another (a nut uncommon event with many) before 
the information of his arrival could have been communicated by the ordinary senses. The feelings, therefore, as well as ideas and words, betoken the operation of mind beyond the limits of the body where it originates.

In addition to these there are also other and more tangible signs which show the extra-corporeal operation of mind. In mesmerism, for example, one person is fascinated by another, and the tongue and all the muscles are removed from the dominion of consciousness and volition. In stammering we see how the disordered action is communicable from one child to another, or even from one adult to another; and it is the same also in more general convulsive affections, as hysteria and epilepsy. It is not to account for these phenomena by ascribing them to imitation, for the facts prove that the person is mastered by an involuntary impulse - an impulse, moreover, which does not originate with himself; for, before he witnessed the stamniering or convulsed person who was the occasion of his seizure, he may have been perfectly sound and healthy. It is the same also with the unthinking bravery of soldiers in action, who for the most part are absorbed, without any spontaneous effort, in the spirit of their captain. Whether in signs of depression or excitement, therefore, as exhibited in transient paralysis or involuntary action of the entire frame, or of part of the frame, there is sufficient proof 
of the immediate and positive influence of mind upon a second person.

We might show also the influence of one mind upon another in the motives and springs of mental action, as well as in the actions themselves, and many illustrations might be cited. But one will suffice. During the performance of Hamlet, for example, the will is resigned to the genius of the poet and his representative, and intellect, reason, imagination, and every faculty of the mind is affected in turn. With Hamlet himself the loftier and sterner thoughts of the soul are stirred into life, and we rise above humanity; with Ophelia the tenderer sentiments of nature come into play, and we suffer with her as she yields to her fate; with the Gravedigger we leave that which is high and endearing, and become ordinary menthe true gravediggers of soul. We change with the changes of the play, and because of these changes; and our mental faculties are undoubtedly ruled for the time by the outward impulse.

But it is idle to multiply instances to show the extra-corporeal presence of mind. It is the experience of every moment to feel and prove it. Imagination is constantly tinctured by the addition of foreign fancies. Conscience is not shut up to our own hearts, for her dictates are sensibly biased by association. In the strictest sense of the word, will is not our own, for this energy is continually influenced 
for good, and too often for evil, by our friends and neighbours. Every faculty of the mind, indeed, belies the idea of isolated and independent existence, and affords the evidence of an extra-corporeal presence, quite as distinct and real as that of heat and light beyond the limits of the glowing embers.

We arrive at the same conclusion, also, if we examine the mind in relation to memory and personality.

There is good reason to believe that the records of memory are not all preserved within the body, and that something has been noted down in the place or thing to which the records refer. This appears, in great measure, from our own experience in relation to persons with whom we have associated, and with whose thoughts and actions we are familiar. These thoughts and actions remain with us, and become a part of our being, and not only are we ourselves conscious of the addition, but they with whom the thoughts and actions had their origin, they know that our memory is furnished in this manner, - they know that we keep a faithful register of what they have said or done. In like manner, also, these persons remember our words and deeds, and we know that this is the case.

The knowledge of identity which attaches to things we have once seen is also an argument that these 
thing retain some impress which we have placed upon them, and which we are able to recognise at a future time; for, unless this were the case, the knowledge of identity is completely obliterated, and every fresh impression of the same thing must strike upon the mind as new and distinct.

In this way (as it seems to me) we may fix some of the seats of memory away from the body; for, whatever images there may be within, we are obliged to admit an unsevered connexion between them and the extraneous phenomena to which they refer for their origin.

Personality, also, as well as memory, appears a growing energy, which continually unfolds and includes a wider circle, without in any way losing its own proper difference and distinction. Thus, in marriage, man experiences a communion and extension of being, by which he becomes one with his wife, in the strictest sense of the word. In time his children possess a share in his being; then his country gains his regard, and patriotic feelings are mixed with the paternal and conjugal; and lastly, he passes beyond the bounds of country, and humanity is included in his own proper individuality. This connexion of household love, of patriotism, of humanity, is no imaginary delusion, but there are a thousand things, which, acting and reacting, convince him of the contrary. 
Viewing memory and personality in relation to each other, the one confirms and explains the other. Both argue in mind an extra-corporeal presencean undefined ubiquity, (if we dare use such a term and comparison,) which may be supposed to be the faint shadow of the omnipresence of the Divine Essence, of which mind is the offspring. In relation to what has preceded, we may also regard imagination to be the shadow of the creative energy, as the absence of decay and the superiority over time is of the eternity of its original; and endowed in this manner with the germs of eternity, creative power, and ubiquity, we may suppose each mental act, whether conscious or unconscious, and whether in the body or out of it, to be a fiat, by which something is created out of nothing, or some new arrangement impressed upon that which already exists. And as the essence is imperishable, so we may suppose that these fiats retain their life and existence; so that memory instead of being a mysterious phenomenon is the necessary attribute of the living essence to which it belongs. Be this as it may, however, both memory and personality afford arguments that the mind is not confined within the limits of the bodily part of man, (which is our present purpose to know,) and these arguments harmonize with those that have preceded. Extracorporeal existence, therefore, is a third property of mind. 
Mind-we may conclude from the foregoing considerations-is not a principle confined to the body or to any part of the body, which changes with every wind, and holds its existence at a precarious tenure; but it is a spiritual essence, in which there is no evidence of decay, and which is superior to time and place in the ordinary sense of the words. It is absolutely necessary to understand these high qualities of mind at the commencement of our inquiry; for if our notions on this subject are low and sensational, we shall strive in vain to obtain any light upon the connexion which exists between mind and body.

II.

The relation of mind to corporeity is a question of great difficulty, and in order to find any answer it is necessary to consult revelation, as well as to examine nature; for unless we avail ourselves of this double means, the end of the search is more perplexed and uncertain than the beginning. What, then, we may ask, is the relation of mind to corporeity? Is it a connexion which is necessary and inseparable, or is it one that is dissolved at any time? These are the questions which present themselves to our notice, and which indicate the objects we must keep in view.

In this inquiry we are very prone to anticipate the verdict of reason, by saying that the union of 
mind and body is separable, and to point to death for the proof; and yet, in making this statement, there are some considerations which occur to us as involving certain doubts and qualifications, so that if we are called upon to repeat it, we do so in a more guarded manner. We find, indeed, that we may continue to entertain all the opinions which wrap themselves around the human heart, and believe in all the realities of a future state as we now believe them, without supposing the being to be dissevered on death. It is imagined, indeed, that the spirit hovers within the neighbourhood, without losing all interest, or even influence, in human affairs; and that it lingers in a more peculiar and special sense about the grave in which the body has been deposited: and it may be asked if this idea is not somewhat at variance with the belief that the spirit has departed altogether from its former companion? Nor is this departure necessary for the realization of the verities of a future state; indeed, it is no more necessary that the scene of future existence should be in a region infinitely remote from our present abode, than that Deity should be so remote. Heaven, we are told by an infallible authority, is not afar, but within, - as if the earth itself, when the mists cleared away from the vision, was still a garden in which Deity walked in a visible form; and, on the other hand, there is some ground for supposing that the spirit despairs in his ancient haunts, 
and not in a distant prison. If the mind of man, moreover, is such as we have attempted to show in the first part of this chapter,-namely, an essence continually extending throughout creation in an instinctive search after ubiquity, and including with each succeeding moment a wider circle; and if every word and act is imperishable, it may be as impossible to withdraw from a place which has once been occupied, as to annihilate a word or idea. An essence like this may become happier by being nearer to Deity, or be rendered miserable by remaining apart, but these changes may take place-as Deity is omnipresent-not only without leaving the body with which it was associated at death, but also without leaving the other bodies, which it had occupied at earlier periods, and which seemed to have been laid aside by degrees.

There are other considerations, also, which lead us to entertain this opinion. The term sleep, indeed, which is so often used to express death, is applied, as it would seem, to the condition of the entire being; indeed, it is admitted by all, that the interval between death and resurrection is one of imperfection when compared with the state which follows-imperfection, that is to say, in the whole being, and not merely in the bodily part. We arrive, also, at the same conclusion from the history of those persons who have been raised from the dead, as Lazarus, the widow's son of 
Nain, and others; for if in these cases there had been a separate state of existence of the intelligent principle, and this a higher one, we may argue that some of the secrets of this state would have transpired, or human nature must have been less curious in those days than in our own. And as tradition preserves a total silence on these matters, there is some reason to believe that death in these persons was a state of sleep not confined to the body. On the other hand we arrive by another mode at the same conclusion, from the history of the two mortals who have evidenced their active existence by appearing at the Transfiguration; for we find that, in the one, death was replaced by translation, and, in the other, that death, though it took place, was not ordinary death; indeed, in the manner of his end, Moses must be said to be almost as much exempted from the common lot of mortals as Elijah.

And if the mind participates in the sleep of the body, this must be an argument that the two are not disjoined from their present companionship by death. We would not contend, indeed, that this is a sleep which is always or ever devoid of consciousness; for there is the most incontrovertible evidence that this is not the case,-as, for example, in the parable of the rich man and Lazarus. We do contend, however, that as yet we have not met with sufficient reason to suppose that this consciousness is exercised in a region 
far removed from our present abode, or in a state apart from embodiment; indeed, in the parable which has just been mentioned, there is nothing in the wording to lead us to suppose that one disembodied spirit was speaking to another, but the contrary.

There is more light, however, if we continue to investigate the history of man, and to compare it with that of a still higher order of intelligences. Tracing beyond the resurrection, mind and body are found in communion, but with all traces of mortality removed from each. The communion, indeed, is infinitely more perfect than at present. There is diversity, but a diversity which merges in unity, and in which the bodily and mental parts of our being are essentially one; for we are told that the body has become like unto that of our Saviour Christ, after his resurrection. At this time, therefore, the human body must be supposed to be realizable to the senses, and yet susceptible of a spiritual transformation by which it is removable from the senses; so that in this transformability of the one into the other, the absolute distinction between the body and the supersensuous principle we have called mind, is lost.

It is the same, also, with angels, who, like ourselves, are created beings; and in this way we may have boldness to believe that the capacity of change seen in the body of our Saviour at the close of His earthly history, and which has just been men- 
tioned, is applicable to our own perfected corporeity. In these intelligences we find the possession of true and sensible bodies. They were visible in the dawn, at broad day, in the evening, and at night; they conversed with man; they ate and drank the food prepared for them. And yet, if we continue to study the history, we find a marked difference between this corporeity and our own, inasmuch as it could vanish away at any moment, and appear again with the same facility. There is, indeed, the very capacity of change which is seen in the divine humanity of Christ after his resurrection; and as in this case we have to do with created beings, we may argue that the human body after its resurrection, will be transformed in such a manner as to be assimilated to the angelic body, and to that in which Deity was incarnated.

When, therefore, we examine the perfected state of man, and find that, as at present, the mental or spiritual essence is associated with a distinct bodily form, we obtain a strong argument in favour of our previous position-that this communion is not dis. solved in the interval between death and resurrection. Indeed, upon the high grounds which have just been taken, it is scarcely possible to entertain the thought of mind existing as a naked essence apart from corporeity, nor of body as a foreign addition to mind. So far, indeed, from body being distinct and independent, it would seem to be mind incarnated in 
mind, and holding a similar relation to this essence, (only at an infinite and unapproachable distance,) as the body of our Saviour Christ did to his Divinitythat is, Divinity incarnated in Divinity.

To the reception of views like these, there are great and wellnigh insurmountable obstacles, arising chiefly in the notions of inferiority which we apply to the body, and which we reiterate so often. But, notwithstanding this, if we attend to what is said in Holy Writ, and study nature with a philosophical spirit, we shall find fewer real difficulties than we might anticipate. It will undoubtedly be admitted by all that the present state of being is imperfect, and in process of evolution to a higher; and therefore it is no more necessary that we should possess at present the entire faculties of a future condition, than that the caterpillar should have all the energies of the butterfly. At the same time, we would contend that there is sufficient evidence to show that the present body is capable of being altered as we have said. The bodily attributes of our Saviour which we may assume without irreverence for ourselves-inasmuch as they belong also to angels, form the grand fact upon which this opinion rests. Here, then, was a human form, living upon earth for thirty years, and confounded by the multitude with ordinary men, suffering death, being raised again, appearing for some time in familiar intercourse with his friends, eating and 
drinking with them, satisfying the incredulity of the most sceptical, and yet this body, which was composed of true blood, and flesh, and bones, and these the very same which were possessed before the crucifixion, was, nevertheless, capable of becoming transfigured so as to pass away from human senses. We trace, indeed, a body which we are taught to believe was perfect man, "of a reasonable soul and human flesh subsisting," as well as perfect God, through the successive phases of development to perfection; and from the similarity which may be detected in our own metamorphosis, we may ask if there is not reason to expect the completion of what remains to be effected. Is the body so imperfect and inglorious that we need doubt on his account? Is the soul so devoid of impulses and aspirations that we need fear on hers?

And further: A philosophical investigation of nature, if it be properly carried out, will alike prevent us from assigning too much or too little importance to the body. It will deter us from holding those notions which are too prevalent in the present day - that the body, or a part of the body, is the source and fountain of the mind. If, for example, we examine the nervous system, we find it to be composed of a common archetype with the other systems of the body, - as the osseous, the vascular, the mus- 
cular.* It originates in the same way, is developed upon the same plan, and formed from the same nutrient plasm; and for these reasons, therefore, we should be disposed to think that the nervous system is not exclusively related to mind. We find, also, that the archetype which is inherent in organic bodies is the same as that which rules the inorganic world: and hence another reason, so far as form is concerned, why the nervous system is not in exclusive relation to mind. It is found, also, in the chapter immediately preceding, and in the chapters on vital movement, that the nervous influence may be regarded as a modification of cosmical force, so that in relation to function as well as to form, we cannot consider the nervous system as exclusively related to mind.

That this is the case, we may also reason from other considerations. We know, indeed, that the condition of the circulation in a sentient organ is of infinite importance to the proper exercise of the function of that organ, or, in other words, the condition of the circulation has greatly to do with the receiving of impressions from surrounding objects; and it is not less true that the greater number of changes in the cerebral and other centres are secondary, and manifestly so, to alterations in the circulation in these centres,- - so that the blood is concerned in receiving

* See Proteus; or, the Law of Nature, chap. i. 
impressions from the inherent life of the individual, as well as from foreign sources. Nerve and blood, therefore, are inseparably united in the economy, and the one reacts upon the other; and where both are necessary, it is idle to say that one is more important than the other. Indeed, we must not forget that the seat of life is assigned by Scripture to the blood.

All the arguments which show that the nervous system cannot be regarded as the exclusive seat of mind, apply equally to the other systems of the organism, and thus we are led to imagine that there may be something in corporeity which more closely conforms to the ubiquity of the mind than we might at first believe. Considerations like these do not harmonize with the prejudice that the body is the source and fountain of the mind-a notion savouring of the proneness to idolatry which has infected all our faculties, and which is as fatal to the discovery of truth in science as in religion. In teaching us the existence of an archetypal unity in the works of nature, philosophy enables the reason to comprehend how the body is transformable into unity, which, if we may so speak, is but a single step from spirit; and at one and the same time to conquer the erroneous ideas that the body is the cause or parent of the mind, or that it is an inferior and degraded companion to be got rid of as soon as possible. Philosophy elucidates what, in a certain sense, may be said to be 
the doctrine of Scripture on the subject-that body and mind are correlative-for she demonstrates a unity in body, which, in its absolute and comprehensive perfection, is an idea so transcendental that we lose all distinction between it and spirit. Philosophy, indeed, enables us to look far into that mystical change which affects the body in its perfected state, and thus, so far as our present knowledge extends, we are able to understand that nature harmonizes with revelation in what relates to the being of man.

It is not our intention, however, to pursue this theme any further than to show that the bodily and mental parts of our being are indissolubly united, and not to penetrate into the consequences as they affect physiology or morality. In attaining to this end our arguments have been negative rather than positive, and much remains to be said before ancient prejudices can be uprooted or a candid reason satisfied; but, at the same time, we may conclude that there are some grounds for the belief that the mental and bodily parts of our being are correlative-that while they are distinct and not to be confounded, neither are they to be disjoined, there being a perfect diversity, but yet diversity in unity. 
There is now but a short step to the conclusion of our argument, and that is to ascertain how this bi-une essence of body and mind can become the seat and centre of active movements. This is done by showing that men are images of their Maker in a far fuller sense than what relates to mere bodily form, as we have attempted to do in the work to which frequent reference has been made, - namely, in "Proteus; or, the Law of Nature:"-and hence we may conclude that the faculties of movement, intelligence and life, form a triune gift which is immediately derived from "Him in whom we live, and move, and have our being."

THE END. 
BY THE SAME AUTHOR,

\section{PROTEUS; OR, THE LAW OF NATURE.}

Price 6s.

London: J. Churchill, Princes Street, Soho.

WILL BE SHORTLY POBLISHED,

ME D I C A L C O M M N T A R I E S

First Series: On Convulsive Diseases. 



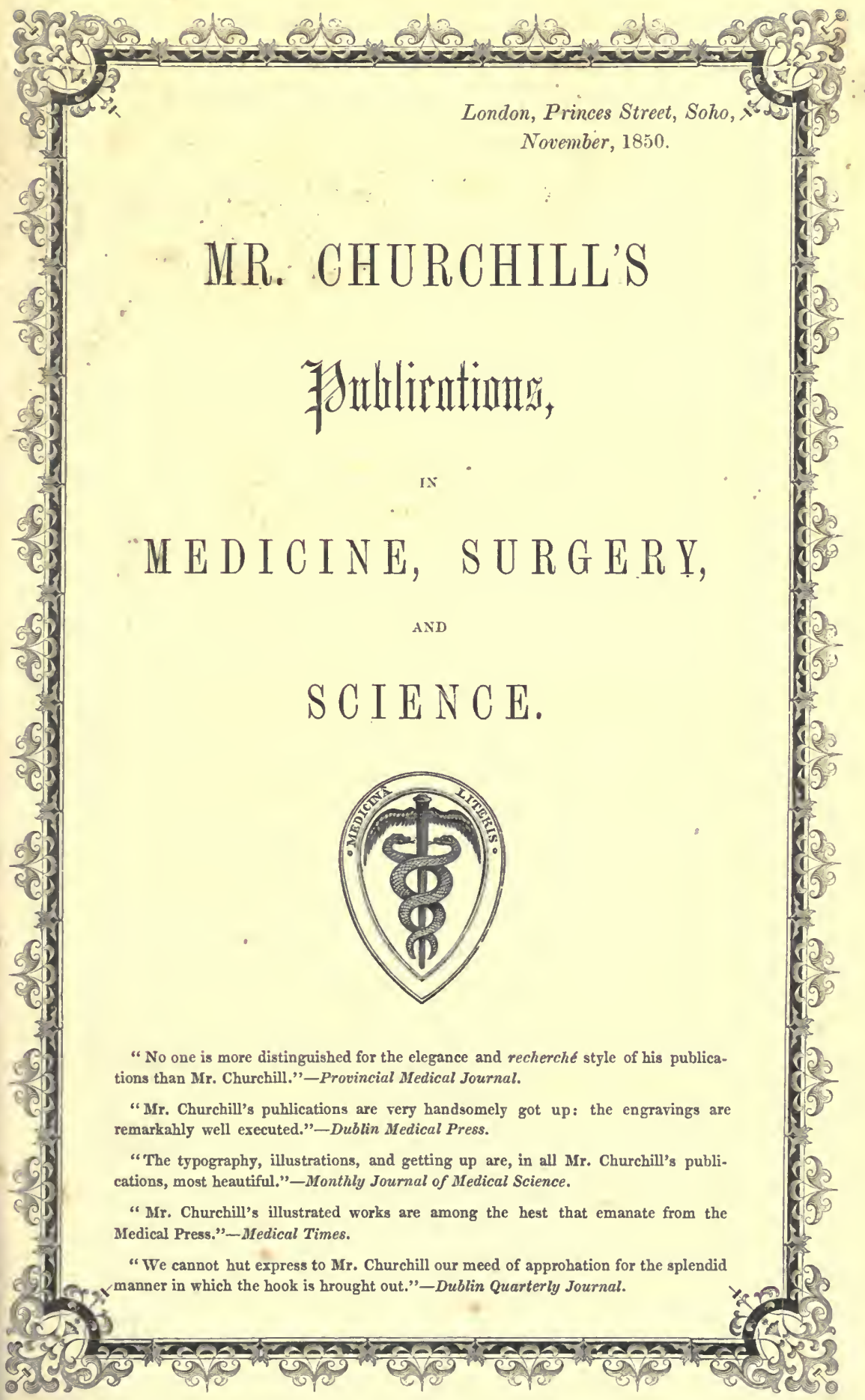


Mr. Churchils is the Publisher of the following Periodicals, offering to Authors a wide extent of Literary Announcement, and a Medium of Advertisement, addressed to all Classes of the Profession. Communications, Books for Review, addressed to the respective Editors, are received and duly forwarded by Mr. Churchill.

\section{THE BRITISH AND FOREIGN MEDICO-CHIRURGIGAL REVIEW; OR,}

QUARTERLY JOURNAL OF PRACTICAL MEDICINE.

Price Six Shillings. Nos. 1 to 12.

\section{THE MEDICAL TIMES.}

Published Weekly, price Sevenpence, or Stamped, Eightpence.

Annual Subscription, if pre-paid, $£ 1$. $5 s$.; or Stamped, $£ 1.10$ s., and regularly forwarded to all parts of the Kingdom.

Rew SErifs, commencing lst July 1850.

This Journal occupies an influential position in the Profession; its circulation, both as to extent and respectability, renders it a highly desirable medium for Advertisers.

\section{THE HALF.yEARLY ABSTRACT OF THE MEDICAL SCIENCES.}

Being a Digest of the Contents of the principal British and Continental Medical Works; together with a Critical Report of the Progress of Medicine and the Collateral Sciences. Edited by W. H. Ranking, M.D., Cantab. Post 8vo. cloth, 6s.6d. Vols. 1 to 11 .

\section{THE JOURNAL OF PSYCHOLOGICAL MEDICINE} AND MENTAL PATHOLOGY.

Being a Quarterly Review of Medical Jurisprudence and Insanity. Edited by Forbes Winslow, M.D. Price $3 s .6 d$. Nos. 1 to 12 .

THE PHARMACEUTICAL JOURNAL. EDITED BY JACOB BELL, F.L.S., M.R.I.

Published Monthly, price One Shilling.

Under the sanction of the Pharmaceutical Society, whose Transactions form a distinct portion of each Number.

* * Vols. 1 to 9 , bound in cloth, price 12s. $6 d$. each.

MONTHLY JOURNAL OF MEDICAL SCIENCE.

Price Two Shillings.

THE PROVINCIAL MEDICAL \& SURGICAL JOURNAL.

Published Fortnightly, Stamped, price Ninepence.

THE DUBLIN MEDICAL PRESS.

Published Weekly, Stamped, price Sixpence, free to any part of the Empire.

THE LONDON AND PROVINCIAL MEDICAL DIRECTORY. Published Annually. 12mo. cloth, 7s. $6 d$. 


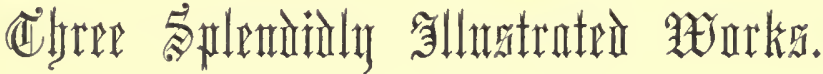

\section{PATHOLOGY OF THE HUMAN EYE.}

\section{Illustrated in a Series of Coloured Plates, from Original Drawings.}

By JOHN DALRYMPLE, F.R.S., F.R.C.S.

Fasciculi I. to VI. Imperial Quarto, 20s. each. To be completed in Nine Numbers.

"The fidelity of the delineations is only equalled by the exquisite beauty of the execution. The value of the plates is greatly enhanced by the excellent instructions for treatment, which are laid down with simplicity and clearness; and the work, when completed, will, in our judgment, be the noblest contribution to ophthalmic science which this country has ever produced."-London Journal of Medicine.

"The value of this work can scarcely be over estimated. We shall recur to it, and point out more in detail its peculiar features, - it realizes all that we believe it possible for art to effect in the imitation of nature."-British and Foreign Medico-Chirurgical Review.

\section{SURGICAL ANATOMY.}

A Series of Dissections, illustrating the Principal Regions of the Human Body.

By JOSEPH MACLISE, F.R.O.S.

Fasciculi I. to VII. Imperial Folio, 5 s. each. To be completed in Eight Numbers.

"As a surgical anatomist, Mr. Maclise has probably no superior. This work bids fair to redeem our country from the stigma of possessing no original work on surgical anatomy." -British and Foreign Medico-Chirurgicul Review.

"It is impossible to glance at this publication without some feeling of surprise. The work will certainly be the cheapest in the way of anatomical illustration that has appeared in this country." Medical Gazette.

"One of the cheapest works we have ever known issued from the medical press. It will be of great value to the student engaged in dissecting, and to the surgeon at a distance from the means of keeping up his anatomical knowledge."-Medical Times.

\section{PORTRAITS OF SKIN DISEASES.}

\author{
By ERASMUS WILSON, F.R.S. \\ Fasciculi I. to VIII., 20s. each.
}

"May be truly designated a splendid performance. We can scarcely speak too strongly of the merits of tbis work."-British and Foreign Medico-Chirurgical Review.

"We have never before seen a work more beautifully got up-they excel all other plates of diseases of the skin that have ever been published."-Lancet.

"It is impossible to speak too highly of the beauty of these portraits-they constitute an undoubted proof of the superiority of British art." -Monthly Medical Journal.

"Admirably fitted to assist diagnosis, and to familiarise the practitioner with the special characters of diseases of the skin."-Medical Gazette.

Mr. Churchill feels it an honorable distinction to be engaged on three Works, which, in Pictorial Illustration and Typographical excellence, must command the admiration of the Profession, and reflect credit on the Country producing them. Avare of the objection (too justly entertained) to subscribe for Works published in Fasciculi, from an apprehension of their non-completion, or of a falling off in the "getting up," Mr. Churchill trusts his assurance will be received, that no Subscriber shall have to accuse him of not completing these Works, and that in every respect equal to the first Numbers. 
MR. CHURCHILL'S PUBLICATIONS.

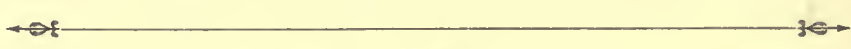

\section{Brford Eritions. \\ EDITED BY DR. GREENHILL.}

I.

ADDRESS TO A MEDICAL STUDENT. 18mo. cloth, $3 s .6 d$.

II.

PRAYERS FOR THE USE OF THE MEDICAL PROFESSION. Cloth, $1 s .6 d$. III.

LTEE OF SIR JAMES STONHOUSE, BART., M.D. Cloth, $4 s .6 d$. IV.

ANECDOTA SYDENHAMIANA. Second Edition. 18mo. $2 s$.

LIFE OF THOMAS HARRISON BURDER, M.D. 18mo. cloth, $4 s$.

VI.

BURDER'S LETTERS FROM A SENIOR TO A JUNIOR PHYSICIAN,

PRomoting the religious welfare of His Patients. 18mo. sewed, $6 d$.

LIFE OF GEORGE CHEYNE, M.D. 18mo. sewed, $2 s .6 d$.

vIII.

HUEELAND ON THE RELATIONS OF THE PHISICIAN TO THE SICK,

TO THE PUBLIC, AND TO HIS COLLEAGUES. 18mo. sewed, $9 d$.

Ix.

GISBORNE ON THE DUTIES OF PHYSICIANS. 18mo. sewed, $1 s$.

$\mathrm{x}$.

LIFE OF CHARLES BRANDON TRYE. 18mo. sewed, $1 s$.

$\mathrm{xI}$.

PERCIVAL'S MEDICAL ETHICS. Third Edition. 18mo. cloth, $3 s$.

XII.

CODE OF ETHICS OF THE AMERICAN MEDICAL ASSOCIATION. $8 d$. XIII.

WARE ON THE DUTIES AND QUALIFICATIONS OF PHYSICIANS. $8 d$. xIv.

MAURICE ON THE RESPONSIBILITIES OF MEDICAL STUDENTS. $9 d$. $\mathrm{x} \nabla$.

FRASER'S QUERIES IN MEDICAL ETHICS. $9 d$.

DR. WILLIAM ADDISON, F.R.S., F.L.S.

ON HEALTHY AND DISEASED STRUCTURE, and tine True

Principles of Treatment for the Cure of Disease, especially Coniumption and Scrofula, founded on Microscopical Axalisis. 8vo. cloth, 12s.

"A work deserving the perusal of every one intercsted in the late rapid advance of physiology and pathology."-Medico-Chirurgical Review.

"It is incumbent upon us to express our decided sense of the value of this work, and to assure those readers who are willing to follow Dr. Addison through his somewhat profound and difficult microscopic and pathological studies, that they will find this volume replete with observations of great interest." Monthly Medical Journal.

"Conscious that we have scarcely done justice to the talents and industry displayed in this work, we do not doubt that those best qualified to judge of its merits will give it the high rank in the litcrature of our profession which it so richly deserves."-Medical Gazette. 
MR. CHURCHILL'S PUBLICATIONS.

$+\infty \mathrm{i}+30$

MR. ANDERSON, F.R.C.S.

ECCENTRIC NERVOUS AFFECTIONS; their Causes, Symptoms, and Treatment. 8ro, cloth, 5 s.

\section{DR. JAMES ARNOTT.}

ON INDIGESTION; its Pathology and its Treatment, by the Local Application of Uniform and Continuous Heat and Moisture. With an Account of an improved Mode of applying Heat and Moisture in Irritative and Inflammatory Diseases. With a Plate. 8vo. 5s.

II.

PRACTICAL ILLUSTRATIONS OF THE TREATMENT OF OBSTRUCTIONS IN THE URETHRA, AND OTHFR CANALS, BY THE DILATATION OF FLUID PRESSURE. 8ro. boards, 3s.

MR. ATKINSON.

MEDICAL BIBLIOGRAPHY. Vol. I. Royal 8vo. $16 s$.

"We have never encountered so singular and remarkable a book. It unites the German research of a Plouquet with the ravings of Rabelais, - the humour of Sterne with the satire of Democritus, - the learning of Burton with the wit of Pindar." -Dr. Johnson's Review.

"In Mr. Atkinson, I have found a gentleman, and a man of varied talent, ardent and active, and of the most overflowing goodness of heart. In his retirement from an honourable profession (Medicine and Surgery), he knows not what the slightest approximation to ennui is. The heartiest of all the octogenarians I ever saw, he scorns a stretch, and abhors a gape. It is 'up and be doing' with him from sunrising to sunset. His library is suffocated with Koburgers, Frobens, the Ascensii, and the Stephens.' -Dibdin's Northern Tour.

\section{MR. BATEMAN.}

MAGNACOPIA : A Practical Library of Profitable Knowledge, communicating the general Minutiæ of Chemical and Pharmaceutic Routine, together with the generality of Secret Forms of Preparations; including Concentrated Solutions of Camphor and Copaiba in Water, Mineral Succedaneum, Marmoratum, Silicia, Terro-Metallicum, Pharmaceutic Condensions, Prismatic Crystallization, Crystallized Aromatic Salt of Vinegar, Soda, Seltzer and all Spa Waters; for Bottling without the Use of Machinery; newly-invented Writing Fluids ; Etching on Steel or Iron; with an extensive Variety of et ccetera. Third Edition. 18mo. $6 s$.

\section{MR. BEASLEY.}

I.

THE DRUGGISTS' GENERAL RECEIPT-B00K: comprising a copious Veterinary Formulary and Table of Veterinary Materia Medica ; Patent and Proprietary Medicines, Druggists' Nostrums, \&c.; Perfumery, Skin Cosmetics, Hair Cosmetics, and Teeth Cosmetics; Beverages, Dietetic Articles, and Condiments; Trade Chemicals, Miscellaneous Preparations and Compounds used in the Arts, \&c.; with useful Memoranda and Tables. 18mo. cloth, $6 s$.

II.

\section{THE POCKET FORMULARY AND SYNOPSIS OF THE}

BRITISH AND FOREIGN PHARMACOPGIAS; comprising standard and approved Formulæ for the Preparations and Compounds employed in Medical Practice. Fourth Edition, corrected and enlarged. 18mo, cloth, $6 s$.

"Extremely useful as an adjunct to the shop library ; a pocket Pharmacopœia Universalis, containing, in addition to the officinal formulæ, those magistral preparations which are so continually requircd at the hands of the dispenser."-Annals of Chemistry and Pharmacy. 
MR. CHURCHILL'S PUBLICATIONS.

$\rightarrow t$

DR. BLAKISTON, F.R.S.

LATE PHYSICIAN TO THE BIRMINGHAM GENERAL HOSPITAL.

PRACTICAL OBSERVATIONS ON CERTAIN DISEASES OF

THE CHEST; and on the Principles of Auscultation. 8vo. cloth, $12 s$.

"The importance of the subjects treated of must plead our excuse for so lengthened an analysis of the work. We have derived much pleasure and instruction from its perusal, and we warmly recommend it to the notice of the profession." -Dublin Medical Journal.

MR. JOHN E. BOWMAN,

DEMONSTRATOR OF CHEMISTRY IN KING'S COLLEGE, LONDON.

I.

AN INTRODUCTION TO CHEMISTRY; with numerous Illustrations

on Wood. Foolscap 8vo. cloth, 6s.6d.

"One of the most complete manuals that has for a long time been given to the chemical student. Every process is indicated with clearness, and the manipulatory details are assisted by an extensive series of woodcuts."-Athenaum.

"The best introductory work on the subject with which we are acquainted. The definitions contained in it are unusually happy."-Monthly Medical Journal.

II.

A PRACTICAL HAND-BOOK OF MEDICAL CHEMISTRY; with

Illustrations on Wood. Foolscap 8vo. cloth, 6s. $6 d$.

"We have examined this treatise, and we can recommend it to the student as a useful elementary guide. The illustrations are numerous and accurate, and well calculated to aid diagnosis." $-M$ Medical Gazette.

DR. JAMES BRIGHT.

\section{ON DISEASES OF THE CHEST AND AIR PASSAGES ;} with a Review of the several Climates recommended in these Affections. Post 8vo. cloth, $6 s$.

MR. ISAAC B. BROWN.

\section{ON SCARLATINA; AND ITS SUCCESSFUL TREATMENT.}

Post 8ro. cloth, $4 s$.

DR. BUDD, F.R.S.

PBOFESSOB OF MENICINE IN KING'S COLLEGE, LONDON.

ON DISEASES OF THE LIVER.

Illustrated with Coloured Plates and Engravings on Wood. 8vo. cloth, 14s.

"We cannot too strongly recommend the diligent study" of this volume. The work cannot fail to rank the name of its author atnong the most enlightened pathologists and soundest practitioners of the day." -Medico-Chirurgical Reriew.

MR. H. T. CHAPMAN, F.R.C.S.

ON THE TREATMENT OF ULCERS OF THE LEG WITHOUT CONFINEMENT; with an Inquiry into the best Mode of effecting the Permanent

Cure of Varicose Veins. Post 8 ro. cloth, $5 s$.

"Mr. Chapman has done much by directing the attention of the profession to the advantages of this combined treatment. We have read his work with much pleasure, and have used the compress, straps of linen, and roller, as directed, and have found them to answer admirably well." -Dublin Quarterly Medical Journal. 


\section{MR. CHURCHILL'S PUBLICATIONS.}

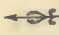

DR. CARPENTER, F.R.S.

I.

PRINCIPLES OF HUMAN PHYSIOLOGY, with their chief Applications to PATHOLOGY, HYGIENE, and FORENSIC MEDICINE. With numerous Illustrations on Steel and Wood. Fourth Edition. Preparing.

“'The 'Principles of General and Comparative Physiology' of Dr. Carpenter, which have just entered upon a new edition, and which we have had occasion to mention with commendation in our last volume, had already opened the path to the extension of the labours of that author into the more important department of Human Physiology. The able manner in which the suhject of Comparative Physiology was handled, the enlarged and elevated views entertained hy the author, at once pointed to Dr. Carpenter as the writer hy whom the obvious want in the field of Human Physiology was to be supplied ... In concluding our notice of this volume, we do so by recommending it most strongly to our readers, and especially to our young friends who are preparing a foundation upon which to huild their reputation and future success in life. The volume is beautifully got up; it will form an ornamental addition to the study and library." - Lancet.

II.

\section{PRINCIPLES OF GENERAL AND COMPARATTVE PHYSI-}

OLOGY ; intended as an Introduction to the Study of Human Physiology, and as a Guide to the Philosophical Pursuit of Natural History. Illustrated with numerous Engravings on Wood. Third Edition. In the Press.

"I recommend to your perusal a work recently puhlished hy Dr. Carpenter. It has this advantage, it is very much up to the present state of knowledge on the subject. It is written in a clear style, and is well illustrated." - Professor Sharpey's Introductory Lecture.

"In Dr. Carpenter's work will be found the hest exposition we possess of all that is furnished hy comparative anatomy to our knowledge of the nervous system, as well as to the more general principles of life and organization."-Dr. Holland's Medical Notes and Reflections.

"See Dr. Carpenter's 'Principles of General and Comparative Physiology,'-a work which makes me proud to think he was once my pupil."-Dr. Elliotson's Physiology.

III.

A MANUAL OF PHYSIOLOGY, including Physiological Anatomy, for the use of the Medical Student. With numerous Illustrations on Steel and Wood. Foolscap 8vo. cloth, 12s. $6 d$.

"Without question, the best manual or short treatise on Physiology extant."-British and Foreign Medical Review.

"A highly scientific and philosophical treatise; rich in novel and valuable facts."-Medical Guzette.

\section{SIR ASTLEY COOPER, BART., F.R.S.}

\section{A TREATISE ON DISLOCATIONS AND FRACTURES OF}

THE JOINTS. New Edition, much enlarged. Edited by BRANSBY B. COOPER, F.R.S. With 126 Engravings on Wood, by BAGG. 8vo. cloth, 20 s.

"In this work we find the last, the most matured views of its venerahle author, who, with unexampled zeal, continued to almost the last moment of his life to accumulate materials for perfecting his works. Every practical surgeon must add the present volume to his lihrary. Its commodious and portable form - no mean consideration, - the graphic, the almost speaking force of the unequalled illustrations, the copious addition of valuahle and instructive cases, and the great improvement in clearness and precision which has heen gained hy the judicious arrangement of the materials, all combine to render the present edition indispensahle." -British and Foreign Medical Review.

II.

\section{ON THE STRUCTURE AND DISEASES OF THE TESIIS.}

Illustrated with 24 highly-finished Coloured Plates. Second Edition. Royal 4 to.

Reduced from £3. 3 s. to £1. 10 s.

"The republication of this splendid volume supplies a want that has been very severely felt from the exhaustion of the first edition of it... The practical surgeon who is not master of its contents cannot he fully aware of the imperfection of his own knowledge on the subject of diseases of the testicle."British and Foreign Medical Review. 
MR. CHURCHILL'S PUBLICATIONS.

$\rightarrow$

MR. COOPER.

PBOFESOR OP SURGEY IN THE UNIVERITY COLLEge, LONDON.

I.

THE FIRST LINES OF THE PRACTICE OF SURGERY; designed as an Introduction for Students, and a Concise Book of Reference for Practitioners. Sixth Edition, considerably improved. 8vo. cloth, $13 s$.

II.

A DICTIONARY OF PRACTICAL SURGERY; comprehending all the most interesting Improvements, from the Earliest Times down to the Present Period. Seventh Edition. One very thick volume, 8vo. $1 l .10 s$.

MR. COOLEY.

COMPREHENSIVE SUPPLEMENT TO THE PHARMAACOPGIAS.

THE CYCLOP EDIA OF PRACTICAL RECEIPTS, AND COLLATERAL INFORMATION IN THE ARTS, MANUFACTURES, AND TRADES, INCLUDING MEDICINE, PHARMACY, AND DOMESTIC ECONOMY; designed as a Compendious Book of Reference for the Manufacturer, Tradesman, Amateur, and Heads of Families. Second Edition, in one thick volume of 800 pages. $8 \mathrm{vo}$. cloth, $14 s$.

MR. CRITCHETT, F.R.C.S.

ON THE CAUSES AND TREATMENT OF ULCERS OF THE LOWER EXTREMITY. 8vo. cloth, $5 s$.

DR. CRISP, M.R.C.S.

A TREATISE ON THE STRUCTURE, DISEASES, AND INJURIES OF THE BLOOD VESSELS; with Statistical Deductions. Being the JaCksonian Prize Essay, 1844. 8vo. cloth, $7 s$.

"The work is a valuable contribution to surgery-one of which the general practitioners have reason to be proud."-Medico-Chirurgical Review.

"We have great pleasure in recommending to the notice of the members of the Provincial Association this excellent work of one of our associates."-Provincial Medical and Surgical Journal.

"We regard Mr. Crisp's work as a valuable addition to our surgical literature."-British and Foreign Medical Review.

“The Committee strongly recommend the study of Mr. Crisp's work to those who desire to be prepared for more than the "ordinary emergencies" of practice." -South-Eastern Branch of the Provincial Medical and Surgical Association.

DR. DA VEY, M.R.C.S.

CONTRIBUTIONS TO MENTAL PATHOLOGY, with Introductory Observations, containing the past and present state of the Insane in Ceylon, \&c. Post 8vo. cloth, $6 s$.

"The author of this really valuable work is a staunch follower of the system of Conolly."-Lancet.

"Highly interesting and worthy of perusal,"-Monthly Medical Journal. 


\section{MR. CHURCHILL'S PUBLICATIONS.}

\section{DR. TOOGOOD DOWNING.}

ON TIC DOULOUREUX AND OTHER PAINFUL AFFECTIONS

OF THE NERVES, with Suggestions for a New Plan of Treatment by means of the Axecralgicos. Illustrated by numerous Cases and an Engraving of the Apparatus. $3 s$. "We would certainly advise a trial of Dr. Downing's Aneuralgicon."-London Journal of Medicine.

MR. DRUITT, F.R.C.S.

THE SURGEON'S VADE-MECUM; with numerous Engravings on

Wood. Fifth Edition. Foolscap 8vo. cloth, 12s.6d.

“... But while we thus enlarge upon the merits of the work as suitable to the wants of the student, we feel equally warranted in recommending it to the perusal of the practitioncr, as fulfilling the intention of the author, in being ' a short, but complete account of modern surgery ;' containing everything that is essential to the right understanding of its principles, and embodying the experience of the highest authorities as to the best rules of practice." - Lancet.

MR. FERGUSSON, F.R.S.

PBOFESSOR OF SURGERY IN KING'S COLLEGE, LONDON.

A SYSTEM OF PRACTICAL SURGERY; with numerous Illustrations on Wood. Second Edition. Foolscap 8vo. cloth, 12s.6d.

"Professor Fergusson's work, we feel persuaded, will be as great a favourite as it deserves, for it combines the powerful recommendations of cheapness and elegance with a clear, sound, and practical treatment of every subject in surgical science. The illustrations, by Bagg, are adnirable-in his very best style."-Edinburgh Journal of Medical Science.

\section{REMIGIUS FRESENIUS.}

\section{ELENENTARY INSTRUCTION IN CHENICAL ANALYSIS,} AS PRACTISED IN THE LABORATORY OF GIESSEN. Edited by LLOYD BULLOCK, late Student at Giessen.

Qualitative; Third Edition. 8vo. cloth, $9 s$.

Quantitative; 8vo. cloth, $14 s$.

"I can confidently recommend this work, from my own personal experience, to all who are desirous of obtaining instruction in analysis, for its simplicity and usefulness, and the facility with which it may be apprehended."-Baron Liebig.

\section{DR. FLEMING.}

\section{AN INQUIRY INTO THE PHYSIOLOGICAL AND MEDICINAL} PROPERTIES OF THE ACONITUM NAPELLUS; to which are added Observations on several other Species of Aconitum : being a Thesis to which a Gold Medal was awarded by the Faculty of Medicine of the University of Edinburgh, at the Graduation of 1844. $8 \mathrm{vo}$. cloth, 5 s.

\section{DR. FORBES, F.R.S}

A PHYSICIAN'S HOLIDAY; or, A Month in Switzerland in the Summer of 1848. With a Map and Illustrations. Second Edition. Post 8vo. cloth, 8s, $6 d$. 
MR. CHURCHILL'S PUBLICATIONS.

$\rightarrow-\xi$

\section{MR. FOWNES, PH. D., F.R.S.}

I.

A MANUAL OF CHEMISTRY; with numerous Mlustrations on Wood. Third Edition. Fcap. 8ro. cloth, $12 s, 6 d$.

"The author of this Manual has made a valuable addition to the existing works on chemistry, by offering the student an accurate compendium of the state of chemical science, well illustrated by appropriate and neatly executed wood engravings."-Medico-Chivurgical Review.

"An admirable exposition of the present state of chemical science, simply and clearly written, and displaying a thorough practical knowledge of its details, as well as a profound acquaintance with its principles. The illustrations, and the whole getting-up of the book, merit our highest praise." - British and Foreign Medical Review.

II.

THE ACTONIAN PRIZE ESSAY OF 100 GUINEAS, AWARDER BY THE COMMITEE OF THE ROXAL INSTITUTION OF GREAT BRITAIN.

\section{CHEMISTRY, AS EXEMPLIFYING THE WISDOM AND}

BENEFICENCE OF GOD. Second Edition. Foolscap 8ro. cloth, 4s.6d.

"The field which the author has gone orer is one of the utmost interest. He has embraced all the leading facts of the subject, and made them to bear upon his principal argument. One great merit of the book, and full of promise as far as the author is concerned as a man of science, is, that although dealing with facts which might have tempted ium inco nasty and striking generalizations, he has preferred treading cautiously along the path of inductive science." -Athencum.

III.

INTRODUCTION TC QUATITATIVE ANALYSIS. Post 8ro. cloth, $2 s$.

IV.

DR. GAIRDNER.

ON GOUT; its History, its Canses, and its Cure. Post 8ro. cloth, $6 s$.

"No one can rise from the pcrusal of Dr. Gairdner's treatise without the conviction that it contains a trustworthy history of the disease,--that it convers sound directions for treatment, - and that it is the work of a physician who, amid the wearying toil of a large and successful practice, keeps himself thoroughly conversant with all the recent advances in physiological science, both at home and abroad." -Medical Times.

MR. GALLOWAY,

LECTURER ON CBEMISTRY, QUERNWOON COLLEGE.

A MANUAL OF QUALITATIVE ANALYSIS. Post 8vo. cloth, $4 s$.

"The Author, having had ample opportunities of ascertaining the difficulties which oppose the student's progress in the study of Analysis, has endeavoured in the present work to obriate these, as much as possible, by simplifying the course of study."

\section{DR. GAVIN.}

* ON FEIGNED AND FICTITIOUS DISEASES, chicfly of Soldiers and Senmen; on the means used to simulate or produce them, and on the best Modes of discovering Impostors; being the Prize Essay in the Class of Military Surgery in the University of Edinburgh. 8vo. cloth, $9 s$. 
MR. CHURCHILL'S PUBLICATIONS.

$\leftarrow \boldsymbol{t}$

DR. GLOVER.

\section{ON THE PATHOLOGY AND TREATMENT OF SCROFULA;}

being the Forthergillian Prize Essay for 1846. With Plates. 8vo. cloth, 10s. 6d.

MR. GRANTHAM.

\section{FACTS AND OBSERVATIONS IN MEDICINE AND SURGERY;}

with additional Memoirs. 8vo. cloth, $7 s, 6 d$.

"We recommend this work to the perusal of our readers, and feel sure they will derive instruction from its pages." - Lancet.

"We recommend this volume to writers on medicine and surgery who desire to compare their own experience with that of others." -Medical Gazette.

MR. GRAY, M.R.C.S.

PRESERVATION OF THE TEETH indispensable to Comfort and

Appearance, Health, and Longerity. $18 \mathrm{mo}$. cloth, $3 s$.

"This small volume will be found interesting and useful to every medical practitioner, the heads of families, and those who have the care of children; while persons who have lost tceth will be made aware of the cause, and enabled to judge for themselves of the rationale of the principles pointed out for their replacement, and preservation of the remainder."

MR. GRIFFITHS,

PROPESSOR OF CHEMISTRY IN THE MEDICAL COLLEGE OF ST. BARTHOLOMEW'S HOSPITAL. CHEMISTRY OF THE FOUR SEASONS - Spring, summer, Autumn, Winter. Illustrated with Engravings on Wood. Post 8vo. cloth, 10s. 6d.

"This volume combines, in an eminent degree, amusement with instruction. The laws and properties of those wonderful and mysterious agents-heat, light, electricity, galvanism, and nuagnetism, are appropriately discussed, and their influence on vegetation noticed. We would especially recommend it to youths commencing the study of medicine, hoth as an incentive to their natural curiosity, and an introduction to several of those hranches of science which will necessarily soon occupy their attention."British and Foreign Medicul Review.

DR. GULLY.

I.

THE WATER CURE IN CHRONIC DISEASE: an Exposition of the Causes, Progress, and Terminations of various Chronic Diseases of the Viscera, Nervous System, and Limbs, and of their Treatment by Water and other Hygienic Means. Third Edition. Foolscap 8vo. sewed, 2s. 6d.

II.

THE SIMPLE TREATMENT OF DISEASE; deduced from the

Methods of Expectancy and Revulsion. 18mo. cloth, $4 s .6 d$.

III.

\section{AN EXPOSITION OF THE SYMPTOMS, ESSENTIAL NATURE,}

AND TREATMENT OF NERVOUSNESS. Sccond Edition. 8vo. $6 s$.

"This volume is written in a lucid style, and deserves the attention of every medical practitioner." Edinburgh Medical and Surgical Journal. 


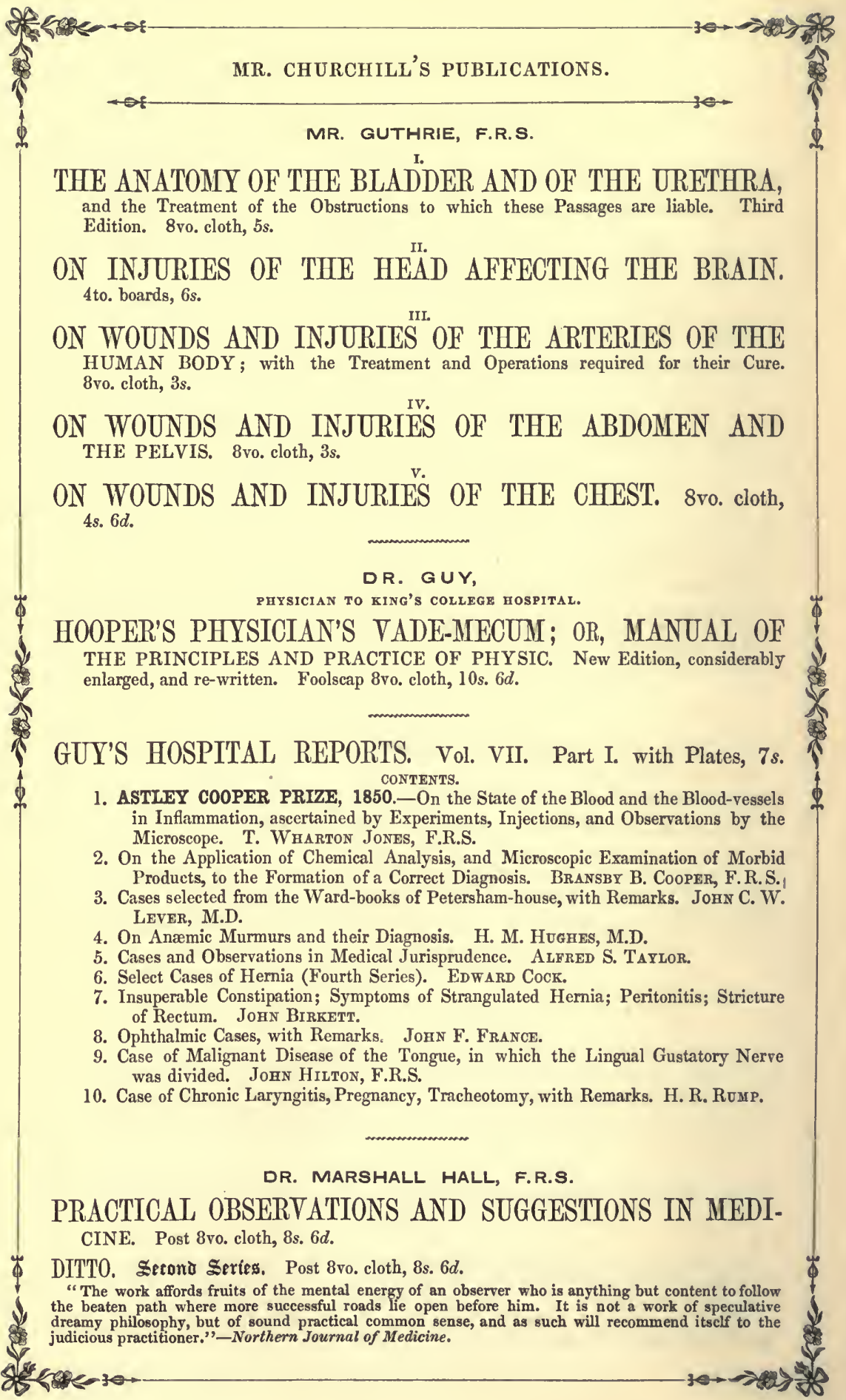


MR. CHURCHILL'S PUBLICATIONS.

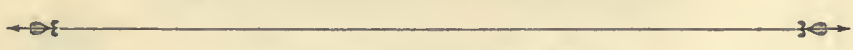

MR. HANCOCK, F.R.C.S.E.

SURGEON AND LECTURER ON SURGERY, CBARING-CROSS HOSPITAL.

ON THE OPERATION FOR STRANGULATED HERNIA. 8 ro. cloth, $4 s$.

"We feel convinced that the already high reputation of the author will be increased by this contribution to practical surgery, and we earnestly recommend 'Hancock on Hernia' to the consideration both of the senior and junior members of our profession." - Lancet.

"We confidently recommend the examination of these opinions to our readers as those of a talented practical surgeon, and we think that few authors of late years have come before the medical public with such claims to an attentive perusal of their labours." - Provincial Medical Journal.

MR. HARE, M.R.C.S.

PRACTICAL OBSERVATIONS ON THE PREVENTION, CAUSES, AND TREATMENT OF CURVATURES OF THE SPINE; with Engravings. Third Edition. 8vo. cloth, 6s.

\section{DR. HENNEN, F.R.S.}

PRINCIPLES OF MILITARY SURGERY; comprising Observations on the Arrangement, Police, and Practice of Hospitals, and on the History, Treatment, and Anomalies of Variola and Syphilis. Illustrated with Cases and Dissections. Third Edition. With Life of the Author, by his Son, Dr. John Hennen. 8vo. boards, $16 s$.

MR. HOGG, M.R.C.S.

ON THE MANAGEMENT OF INFANCY: with Remarks on the Influence of Diet and Regimen; on Bathing; and the Treatment of Ringworm, Leprosy, Scrofula, Affections of the Liver, \&c, Post 8vo. cloth, 4s. 6d.

DR. G. CALVERT HOLLAND.

I.

THE PHILOSOPHY OF ANIMATED NATURE; OR, THE LAWS AND ACTION OF THE NERVOUS SYSTEM. 8vo. cloth, $12 s$.

II.

THE PHILOSOPHY OF THE MOVING POWERS OF THE BLOOD. 8vo. cloth, 8 s.

\section{DISEASES OF THE LUNGS FROM MECHANICAL CAUSES,} and Inquiries into the Condition of the Artisans exposed to the Inhalation of Dust. 8 ro. cloth, $4 s .6 d$.

\section{MR. HOOD.}

ON THE DISEASES MOST FATAL TO CHILDREN, with Reference to the Propriety of Treating them as proceeding from Irritation, and not from Inflammation. Post 8vo. cloth, 6s.

" The views of Mr. Hood are, to a greater extent than is usually imagined, borne out by all the best late writers who have seen much practice among children. The work is purely a practical one, and is a valuable contribution to our knowledge."-Edinburgh Medical and Surgical Journal. 
MR. CHURCHILL'S PUBLICATIONS.

$+\infty$

DR. JAMES HOPE, F.R.S.

\section{ON DISEASES OF THE HEART AND GREAT VESSELS.}

Fourth Edition. Post 8vo. cloth, 10s.6d.

"This is a new edition of the late Dr. Hope's well known treatise, reduced in size and price. To those who are desirous of possessing this truly standard work, we would strongly recommend the present edition."-Provincial Medical Journal.

DR. HOSKINS, F.R.S.

\section{SCHARLING ON THE CHEMICAL DISCRIMINATION OF}

VESICAL CALCULI. Translated, with an Appendix containing Practical Directions for the Recognition of Calculi. With Plates of Fifty Calculi, accurately coloured. 12mo. cloth, 7s. $6 d$.

MR. HOWARD, M.R.C.S.

\section{THE ANATOMY, PHYSIOLOGY, AND PATHOLOGY OF THE}

EYE. 8vo. cloth, $15 s$.

"This work is evidently the production of a man thoroughly acquainted with the subject of which he treats."-The Lancet.

MR. THOMAS HUNT, M.R.C.S.

\section{THE PATHOLOGY AND TREATMENT OF CERTAIN DIS.}

EASES OF THE SKIN, generally pronounced Intractable. Illustrated by upwards of Forty Cases. 8vo. cloth, $6 s$.

"We have found Mr. Hunt's practice exceedingly successful in severe obstinate cases" - Braithwaite's Retrospect of Medicine.

"The facts and views he brings forward eminently merit attention."-British and Foreign Medical Review.

DR. ARTHUR JACOB, F.R.C.S.,

PROFESSOR OP ANATOMY AND PHYSIOLOGY IN THE ROYAL COLLEGE OF SURGRONS IN IRELAND.

\section{A TREATISE 0N THE INFLAMMATIONS OF THE EYE-BALL.}

Foolscap 8vo. cloth, 5 s.

It includes the Description and Treatment of the Idiopathic, Scrofulous, Rheumatic, Arthritic, Syphilitic, Gonorrhoeal, Post-febrile, and Neuralgic Species; as well as the circumscribed Inflammations of the Cornea, Membrane of the Aqueous Humour, Choroid, Crystalline Lens and Retina; and also Inflammation from Injury, with the Sympathetic and Phlebitic varieties.

MR. WHARTON JONES, F.R.S.

\section{A MANUAL OF THE PRINCIPLES AND PRACTICE OF} OPHTHALMIC MEDICINE AND SURGERY; illustrated with 102 Engravings, plain and coloured. Foolscap 8vo. cloth, 12s.6d.

"The execution of the work sustains in every point the already high reputation of the author as an ophthalmic surgeon, as well as a physiologist and pathologist. We entertain little doubt that this book will become a manual for daily reference and consultation by the student and the general practi. tioner."-British and Foreign Medical Review. 


\section{MR. CHURCHILL'S PUBLICATIONS.}

DR. BENCE JONES, F.R.S.

ON ANIMAL CHEMISTRY, in its relation to STOMACH and RENAL DISEASES. 8 vo. cloth, $6 s$.

\section{MR. LAWRENCE, F.R.S.}

\section{A TREATISE ON RUPTURES. The Fifth Edition, considerably enlarged. 8 vo. cloth, $16 s$.}

"The peculiar advantagc of the treatise of Mr. Lawrence is, that he explains his views on the anatomy of hernia and the different varieties of the disease in a manner which renders his book peculiarly useful to the student. It must be superfluous to express our opinion of its value to the surgical practitioner. As a treatise on hernia, presenting a complete view of the literature of the subject, it stands in the first rank." - Edinburgh Medical and Surgical Journal.

\section{DR. HUNTER LANE, F.L.S.}

\section{A COMPENDIUM OF MATERIA MEDICA AND PHARMACY;} adapted to the London Pharmacopoia, embodying all the new French, American, and Indian Medicines, and also comprising a Summary of Practical Toxicology. One neat pocket volume. Cloth, 5 s.

"Dr. Lane's volume is on the same general plan as Dr. Thompson's long-known Conspectus; but it is much fuller in its details, more especially in the chemical department. It seems carefully compiled, is well suited for its purpose, and cannot fail to be useful."-British and Foreign Medical Review.

\section{MR. EDWIN LEE.}

\section{I.}

\section{THE BATHS OF RHENISH GERMANY; with Notices of the} adjacent Towns. Post 8vo. cloth, 4s.

\section{OBSERVATIONS ON THE MEDICAL INSTITUTIONS AND}

PRACTICE OF FRANCE, ITALY, AND GERMANY; with Notices of the

Universities and Climates, and a Parallel View of English and Foreign Medicine and Surgery. Second Edition, $7 s .6 d$.

\section{PRACTICAL OBSERVATIONS ON MINERAL WATERS AND}

BATHS. Post 8vo. cloth, 3s.

\section{DR. ROBERT LEE, F.R.S.}

I.

CLINICAL MIDWIFERY : comprising the Histories of 545 Cases of Difficult, Preternatural, and Complicated Labour, with Commentaries. Second Edition. Foolscap 8vo. cloth, 5 s.

"There is no better way of teaching than that of furnishing reports of cases which have fallen under the notice of one competent to observe and record facts. The work will be found a most serviceable guide to the young accoucheur; for while it lays before him the difficulties which he may have to encounter in practice, it shows him how those difficulties are to be overcome." -Medical Gazette.

II.

\section{PRACTICAL OBSERVATIONS ON DISEASES OF THE}

UTERUS. With coloured Plates. Two Parts. Imperial 4to., 7 s. 6d. each Part. 


\section{MR. CHURCHILL'S PUBLICATIONS.}

M. LALLEMAND.

ON THE CAUSES, SYMPTOMS, AND TREATMENT OF SPER-

MATORRHGA. Translated from the French. By Henry J. M'Dodgall, M.R.C.S., late House-Surgeon to University College Hospital. 8vo. cloth. Second Edition. In the Press.

"The volume is copiously illustrated by cases, which show all the Protean effects that have been observed to follow spermatorrhoea. The translation is creditable to Mr. MI'Dougall; he has carefully avoided anything like empiricism, and has treated the subject as it should be treated by a professional man desirous of improving surgical practice."-Medical Gazelte.

"WV express our opinion, that Mr. M'Dougall's translation of so useful a work will prove of great service to the profession of this country, by recalling attention to a too-neglected subject." $-M e d i c o-$ Chirurgical Review.

MR. LISTON, F.R.S.

SURGEON TO THE NORTH LONDON HOSPITAL.

\section{PRACTICAL SURGERY. Fourth Edition. 8vo. cloth, $22 s$.}

"In conclusion, it is scarcely necessary to repeat our earnest recommendation of Mr. Liston's work. Having on a former occasion expressed ourselves strongly on the subject, we can only add that the present edition is, as it should be, even more worthy of our praise than its predecessors. It is a guide to the advanced student, and, as suggesting practical observations of the highest value to the practitioner, it is unsurpassed."-British and Foreign Medical Review.

“ His Practical Surgery, being a record of his own pcculiar experience, obtained a rapid sale. It embodies his plans and modes of procedure, more especially in operations; and is undoubtedly one of the most important contributions to the literature of practical surgery in the English language." Memoir of Liston.-Athenæum.

MR. EDWARD F. LONSDALE,

ASSISTANT-SUBGEON TO THE BOYAL ORTHOPGDIC HOSPITAL.

OBSERVATIONS ON THE TREATMENT OF LATERAL CUR-

VATURE OF THE SPINE; pointing ont the Advantages to be gained by placing the

Body in a position to produce Lateral Flexion of the Vertebral Column, combined with the after application of Firm Mechanical Support. 8vo. cloth, 6s.

"We would wish that this treatise on lateral curvature of the spine were generally read, since much ignorance prevails concerning the subject, and, consequently, it presents an ample field for the quack, and an opprobrium to the profession."-Lancet.

\section{A PRACTICAL TREATISE ON FRACTURES. Illustrated with}

Sixty Woodcuts. 8vo. boards, $16 s$.

M. LUGOL.

ON SCROFULOUS DISEASES, Translated from the French, with Additions by W. H. RANKING, M.D., Physician to the Suffolk General Hospital. 8vo. cloth, 10 s. $6 d$.

"One of the most valuable works presented to the public for many a year, and calculated to deeply modify the views of the profession with regard to the pathology of scrofula." -Lancet.

\section{DR. MACREIGHT.}

A MANUAL OF BRITISH BOTANY; with a Series of Analytical Tables for the Assistance of the Student in the Examination of the Plants indigenous to, or commonly cultivated in, Great Britain. Small 8vo. cloth, $7 s .6 d$.

"There is a prodigious mass of elementary matter and useful information in this pocket rolume." Aledico-Chirurgical Review. 
MR. CHURCHILL'S PUBLICATIONS.

$\rightarrow f-3 \Leftrightarrow$

DR. MACKNESS,

CONSULTING PHYSICIAN TO THE HASTINGS DISPENSARY.

HASTINGS CONSIDERED AS A RESORT FOR INVALIDS, with Tables illustrative of its Temperature, Salubrity, and Climate, showing its suitability in Pulmonary and other Diseases; also Directions for the Choice of a Residence, and Hints as to Diet, Regimen, Bathing, \&c. Second Edition. 8vo. cloth, $4 s$.

THE MORAL ASPECTS OF MEDICAL LIFE; containing the "Akesios" of PROFESSOR MARX. 12mo. cloth, $7 s .6 d$.

"Dr. Mackness has done a decided service to the profession in compiling this work." - Britisk and Foreign Medical Review.

"We cordially recommend this work as replete with interest and instruction."-Provincial Medical Journal.

"We shall pursue the subject of the Akesios in an early number; one more interesting can rarely be placed before the profession." - Lancet.

MR. MACILWWAIN,

CONSULTING SURGEON TO THE FINSBURY DISPENSARY, ETC.

ON TUMOURS, THEIR GENERAL NATURE AND TREATMENT. 8vo. cloth, $5 s$.

DR. WM. H. MADDEN.

THOUGHTS ON PULMONARY GONSUMPTION; with an Appendix on the Climate of Torquay. Post 8vo. cloth, 5 s.

DR. MARTIN.

THE UNDERCLIFF, ISLE OF WIGHT: its Climate, History, and Natural Productions. Post 8vo. cloth, 10s, 6d.

MR. ALFRED MARKWICK,

SURGEON TO THE WESTERY GERMAN DISPENSARY, ETC.

A GUIDE TO THE EXAMINATION OF THE URINE IN HEALTH AND DISEASE. For the Use of Students. 18mo. cloth, $4 s$.

"Although addressed especially to students, it contains almost all the information upon these matters which the practitioner requires." -Dublin Medical Press.

"The author must be admitted to have attained his object, in presenting a convenient bedside companion."-Dr. Runking's Abstract.

DR. MASON,

INVENTOR OF MASON'S HYDROMETER.

ON THE CLIMATE AND MFTEOROLOGY OF MADEIRA : Edited by JAMrS SHERIDAN KNowles; to which are attached a Review of the State of Agriculture and of the Tenure of Land, by George PeAcock, D.D., F.R.S.; and an Historical and Descriptive Account of the Island, and Guide to Visitors, by JoHN DrIvEr, Consul for Greece, Madeira. 8vo. cloth, 18s.; royal 8vo. $£ 1$. 11s. $6 d$.

DR. MILLINGEN.

ON THE TREATMENT AND MANAGEMENT OF THE IN-

SANE; with Considerations on Public and Private Lunatic Asylums, 18mo. cloth, 4s. $6 d$.

"Dr. Millingen, in one small pocket volume, has compressed more real solid matter than could be gleaned out of any dozen of octavos on the same subject. We recommend this vade-mecum as the best thing of the kind we ever perused." $-D r . J o h n s o n ' s ~ R e v i e w$. 
MR. CHURCHILL'S PUBLICATIONS.

$-f$

MR. PAGET,

LECTURER ON PHYSIOLOGY AT ST. BARTHOLOMEW'S HOSPITAL.

I.

RECORDS OF HARVEY, in Extracts from the Journals of the Royal Hospital of St. Bartholomew. 8vo. 2s.6d.

II.

A DESCRIPTIVE CATALOGUE OF THE ANATOMICAL MUSEUM OF ST. BARTHOLOMEW'S HOSPITAL. Vol. I. Morbid Anatomy. 8ro. cloth, $5 s$.

DR. E. A. PARKES,

ASSISTANT-PHYSICIAN TO UNIVERSITY COLLEGE HOSPITAL.

ON ASIATIC CHOLERA: Researches into its Pathology and Treatment. 8vo. cloth, $6 s$.

"We cannot recommend a better guide in that practical investigation of the disease to which we shall prohably he, ere long, called upon to return, than Dr. Parkes has thus seasonably placed hefore us."Medico-Chirurgicul Review.

"It remains but to express our most farourable opinion of Dr. Parkes's production. It is truly a practical work, written with much ahility and judgment."-The Luncet.

DR. THOMAS B. PEACOCK, M.D.,

PHYSICIAN TO ST. THOMAS's HOSPITAL, ETC.

\section{ON THE INFLUENZA, OR EPIDEMIC CATARRHAL FEVER}

OF 1847-8. 8vo, cloth, 5s. 6d.

"We know of no work which contains a more complete description of the disease, and its complications."-Lancet.

DR. PROUT, F.R.S.

I.

ON THE NATURE AND TREATMEN'T OF STOMACH AND

RENAL DISEASES; being an Inquiry into the Connection of Diabetes, Calculus, and other Affections of the Kidney and Bladder with Indigestion. Fifth Edition. With

Seven Engravings on Steel. 8vo. cloth, $20 s$.

"We acknowledge and have pride in hearing testimony to the high qualifications of our countryman in the branch of pathological inquiry based upon chemical facts; we recognise the comprehensive sagacity of his speculations, and respect the patient zeal with which he has toiled to erect upon these a stable system, - the important connection hetween a large number of disordered states of the urinary secretion and disordered states of the process of digestion and assimilation. . . W We have only to repeat our conviction that no student or practitioner can he regarded as even tolerably acquainted with the subject who has not read and re-read them."-British and Foreign Medical Review.

II.

CHEMISTRY, METEOROLOGY, AND THE FUNCTION OF

DIGESTION, considered with reference to NATURAL THEOLOGY. Being a

Third Edition, with much new matter, of the "Bridgewater Treatise." 8vo. cloth, 15s.

"Those who have been benefited by the labours and researches of Dr. Prout will be delighted to see the announcement of the third edition, so much enlarged as to he almost a new work. ... This tahle of contents will show the great extent of our author's inquiries, and we need hardly assure our readers that the subjects are treated with consummate ability."-Dublin Journal of Medical Science. 


\section{MR. CHURCHILL'S PUBLICATIONS.}

\section{TRANSACTIONS OF THE PROVINCIAL MEDICAL AND SUR-}

GICAL ASSOCIATION; containing valuable Communications on Medicine and Surgery, Medical Topography, Infirmary Reports, and Medical Statistics. With Plates, 8vo. cloth.

Vols. I. to XVI.

MR. PETTIGREW, F.R.S.

ON SUPERSTITIONS connected with the History and Practice of

Medicine and Surgery. 8vo. cloth, $7 \mathrm{~s}$.

"The anecdotal character of this work cannot fail to render it generally acceptable; while the good sense that pervades it, as distant from empty declamation as from absurd credulity, stamps it with true historic value."-Gentleman's Magazine.

SIR WM. PYM, K.C.H. INSPECTOR-GENERAL OF ARMT HOSPITALS.

OBSERVATIONS UPON YELLOW FEVER, with a Review of "A Report upon the Diseases of the African Coast, by Sir WM. BunNeTr and Dr. BRrson," proving its highly Contagious Powers. Post 8vo. 6s.

THE PRESCRIBER'S PHARMACOPCEIA; containing all the Medicines in the London Pharmacopeia, arranged in Classes according to their Action, with their Composition and Doses. By a Practising Physician. Third Edition. 32mo. cloth, 2s. 6d.; roan tuck (for the pocket), 3s. 6d.

"Never was half-a-crown better spent than in the purchase of this 'Thesnuris Medicaminum." This little work, with our visiting-book and stethoscope, are our daily companions in the carriage." Dr. Johnson's Review.

DR. RADCLIFFE.

PROTEUS; OR, THE LAW OF NATURE. 8vo. cloth, $6 s$.

\section{DR. RANKING.}

\section{THE HALF-YEARLY ABSTRACT OF THE MEDICAL SCIENCES;}

being a Practical and Analytical Digest of the Contents of the Principal British and Continental Medical Works published in the preceding Half-Year; together with a Critical Report of the Progress of Medicine and the Collateral Sciences during the same period.

\section{Volumes I. to XI., 6s. 6d. each.}

" "The sifting which the journals and other medical works undergo, and the judicious selection from their pages of points of practical interest, and of discoveries of importance in the collateral sciences, form an important part of the duty of the editor; and, after a careful examination of Dr. Ranking's volumes, we are hound to state that the duty has been most ably performed."-Provincial Medical Journal.

"Useful in a high degree, by concentrating into one volume a large amount of scientific information. The work is well conceived and executed with ability, and, we doubt not, will be useful to those who feel it their duty to keep up with the knowledge of the day." Edinburgh Medical and Surgical Journal.

\section{DR. RAMSBOTHAM,}

CONSULTING PHYSICIAN TO THE ROTAL MATERNITY CHARITY.

PRACTICAL OBSERVATIONS ON MIDWIFERY, with a Selection of Cases. Second Edition. 8ro. cloth, $12 s$.

Dr. Dewes states, in his advertisement to the American edition, " that he was so much pleased with Dr. Ramshotham's work on Midwifery, that he thought he would be doing an acceptable office to the medical community in America, should he cause it to be re-published. He believes he does not say too much when he declares it to be, in his opinion, one of the best practical works extant." 
MR. CHURCHILL'S PUBLICATIONS.

$+\boldsymbol{t}$

DR. F. H. RAMSBOTHAM,

PHYSICIAN TO THE BOYAL MATERITY CHARITY, ETC.

\section{THE PRINCIPLES AND PRACTICE OF OBSTETRIC NEDI-}

CINE AND SURGERY, IN REFERENCE TO THE PROCESS OF PAR-

TURITION. Illustrated with One Hundred and Ten Plates on Steel and Wood; forming one thick handsome volume. Sccond Edition. 8ro. cloth, 22s.

" The work of Dr. Ramsbotham may be described as a complete system of the principles and practice of midwifery ; and the author has been at very great pains indeed to present a just and useful view of the present state of obstetrical knowledge. The illustrations are numerous, well selected, and appropriate, and engraved with great accuracy and ability. In short, we regard this work, between accurate descriptions and useful illustrations, as by far the most able work on the principles and practice of midwifery that has appeared for a long time. Dr. Ramsbotham has contrived to infuse a larger portion of common sense and plain unpretending practical knowledge into his work than is commonly found in works on this subject; and as such we have great pleasure in recommending it to the attention of obstetrical practitioners." -Edinburgh Medicul and Surgical Journal.

DR. JAMES REID.

I.

A MANUAL OF PRACTICAL MIDTIFERY. Intended chicfly as a Book of Reference for Students and Medical Practitioners. With Engravings on Wood. $24 \mathrm{mo}$. cloth, $5 s .6 d$.

"The relative diameters of the pelvis and the foctal head, and the different presentations of the child, are all usefully represented by wood engravings among the letter-press, and the book is thus particularly well calculated to effect the objects of such a work."-Luncet.

II.

ON INFANTILE LARYNGISMUS; with Observations on Artificial Feeding, as a frequent Cause of this Complaint, and of other Convulsive Diseascs of Infants. Post 8 vo. cloth, 5s.6d.

MR. ROBERTSON,

FORMERLT SENIOB SURGEON TO THE MANCHESTER AND SALFORD LYING-IN-HOSPITAL.

ESSAYS ON SUBJECTS CONNECTED CHIEFLY WITH THE PHYSIOLOGY AND DISEASES OF FEMALES AND WITH PRACTICAL MIDWIFFRY. In the Press.

DR. ROWE, F.S.A.

J.

NERVOUS DISEASES, LIVER AN STOMACH COMPLAINTS, LOW SPIRITS, INDIGESTION, GOUT, ASTHMA, AND DI\$ORDERS PRODUCED BY TROPICAL CLIMATES. With Cases. Twelfth

Edition. 8vo. 5s. 6d.

"Dr. Rowe, the first edition of whose work appeared in 1820, claims, with justice, a priority of authorship over many other writers in this field of inquiry."-Lancet.

"We have no hesitation in placing this work among the first ranks of those which have succeeded, for very few preceded it." - Medical Times.

II.

ON SOME OF THE MOST IMPORTANT DISEASES OF WOMEN. 8vo. $5 s, 6 d$. 
MR. CHURCHILL'S PUBLICATIONS.

$\rightarrow$

DR. W. H. ROBERTSON,

PHYSICZAN TO THE BUXTON BATH CHARITY.

I.

\title{
THE NATURE AND TREATMENT OF GOUT.
}

\author{
8vo. cloth, 10s. $6 d$.
}

"We cannot conclude this notice of Dr. Robertson's treatise without cordially recommending it as a sound and practical work, fitted for reference, both as a work of information on the subject and as a guide to practice."-Provincial Medical Journal.

II.

\section{A TREATISE ON DIET AND REGIMEN.}

Fourth Edition. 2 vols. post 8vo. cloth, 12 .

"It is scarcely necessary that we should add our hearty recommendation of Dr. Robertson's treatise, not merely to our medical readers, hut to the public, over whom they have an influence. It is one of the few hooks which is legitimately adapted, both in subject and manner of treatment, to both classes." British and Foreign Medico-Chirurgical Review.

DR. ROYLE, F.R.S.

\section{A MANUAL OF MATERIA MEDICA AND THERAPEUTICS,}

including the Preparations of the Pharmacopœias of London, Edinburgh, and Dublin, with many New Medicines. With numerous Engravings on Wood, foolscap 8vo. cloth, $12 s, 6 d$.

“Dr. Royle's Manual, while it has the convenience of being in a portable form, contains as much matter as would fill two other volumes in large type."-Medical Gazette.

"This work is ably done-the botanical part with grcat skill, and the chemical, natural history, and therapeutic department most perfect and complete."-Edinburgh Medical Journal.

" This is another of that beautiful and cheap series of Manuals puhlished by Mr. Churchill. The execution of the wood-cuts of plants, flowers, and fruits is admirable. The work is indeed a most valuable one."-British and Foreign Medical Review.

\section{DR. SEARLE, M.R.O.S.E.}

I.

THE WHY AND THE WHEREFORE; 0R, THE PHILOSOPHY

OF LIFE, HEALTH, AND DISEASE: New and Original Views explanatory of their Nature, Causes, and Connexion, and of the Treatment of Disease upon a few General Principles based upon the Laws of Nature and Common Sense, the Fruit of Thirty Years? Professional Experience. 8vo. cloth, 8s.

II.

CHOLERA, DYSENTERY, AND FEVER; explaining, in a way that may be comprehended by all persons, the Nature of these Affections, their Causes, Means of Prevention, and Treatment; the fruit of thirty years' professional experience. 12mo. cloth, $5 s$.

MR. SHAW.

\section{THE MEDICAL REMEMBRANCER; 0R, BOOK OF EMER-}

GENCIES : in which are concisely pointed out the Immediate Remedies to be adopted in the First Moments of Danger from Poisoning, Drowning, A poplexy, Burns, and other Accidents; with the Tests for the Principal Poisons, and other useful Information. Third Edition. 32mo. cloth, 2s. $6 d$.

"The plan of this little book is well conceived, and the execution corrcsponds thereunto. It costs little money, and will occupy littlc room; and we think no practitioner will regret being the possessor of what cannot fail, sooner or later, to he useful to him."-British and Fortign Medical Review. 
MR. CHURCHILL'S PUBLICATIONS.

$\rightarrow t \rightarrow-3 \rightarrow$

DR. SHEARMAN.

AN ESSAY ON THE PROPERTIES OF ANIMAL AND

VEGETABLE LIFE; their Dependence on the Atmosphere, and Connection with each other, in Relation to the Functions of Health and Disease. Post 8vo. cloth, 5s. $6 d$.

DR. SIMPSON,

PHYSICIAN TO YORK COUNTY HOSPITAL.

OBSERVATIONS ON ASIATIC CHOLERA; and Facts regarding the Mode of its Diffusion. 12mo. cloth, $4 s .6 d$.

DR. W. TYLER SMITH.

I.

ON PARTURITION; AND THE PRINCIPLLS AND PRACTICE OF OBSTETRICS. Foolscap 8vo. cloth, $9 s$.

II.

THE PERIODOSCOPE, a new Instrument for determining the Date of Labour, and other Obstetric Calculations, with an Explanation of its Uses, and an Essay on the Periodic Phenomena attending Pregnancy and Parturition. 8vo. cloth, $4 s$.

"We anticipate for the work that which it deserves for its novelty, incenuity, and utility-a wide circulation. It should be in the hands of all medical men who practise midwifery."-Medical Gazette.

III.

SCROFULA : its Causes and Treatment, and the Prevention and Eradication of the Strumous Temperament. 8vo. cloth, $7 s$.

"This treatise is a great improvement on those by which it has been preceded. The part of Dr. Smith's work with which we are most pleased is that devoted to the treatment of this formidable discase and to the management of scrofulous children." - Lancet.

\section{J. STEPHENSON, M.D., \& J. M. CHURCHILL, F.L.S.}

\section{MEDICAL BOTANY; OR, ILLUSTRATIONS AND DESCRIP.} TIONS OF THE MEDICINAL PLANTS OF THE PHARMACOPGIAS; comprising a popular and scientific Account of Poisonous Vegetables indigenous to Great Britain. New Edition, edited by GILBERT BURNETT, F.L.S., Professor of Botany in King's College.

In three handsome royal 8vo. volumes, illustrated by Two Hundred Engravings, beautifully drawn and coloured from nature, cloth lettered.

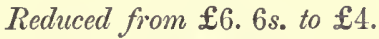

"The most complete and comprehensive work on Medical Botany."-Pharmaceutical Journal.

"So high is our opinion of this work, that we recommend cvery student at college, and evcry surgeon who goes abroad, to have a copy, as one of the essential constituents of his library."Dr.Johnson's Medico-Chirurgical Review.

MR. SMITH.

\& FRUITS AND FARINACEA THE PROPER FOOD OF MAN; being an Attempt to prove, from History, Anatomy, Physiology, and Chemistry, that the Original, Natural, and Best Diet of Man is derived from the Vegetable Kingdom. Second Edition. Foolscap 8vo., 3s. 6 d. 
$-2 \mathrm{e}+\ldots$

\section{DR. SHAPTER.}

THE CLIMATE OF THE SOUTH OF DEVON, AND ITS IN-

FLUENCE UPON HEALTH. With short Accounts of Exeter, Torquay, Teignmouth, Dawlish, Exmouth, Sidmouth, \&c. Illustrated with a Map geologically coloured.

Post 8vo. cloth, 7s. $6 d$.

"This volume is far more than a guide-book. It contains much statistical information, with very minute local details, that may be advantageously consulted by the medical man before he recommends any specific residence in Devonshire to his patient." - Alhenaum.

II.

\section{THE HISTORY OF THE CHOLERA IN EXETER IN 1832.}

Illustrated with Map and Woodcuts. 8vo. cloth, $12 s$.

DR. ALFRED TAYLOR, F.R.S.

LECTURER ON MEDICAL JURISPEUDENCE AND CHEMISTRY AT GUY'S MOSPITAL.

\section{1.}

\section{A MANUAL OF MEDICAL JURISPRUDENCE. Third Edition.}

Foolscap 8vo, cloth, 12s. $6 d$.

CONTENTS.

Poisoning - Wounds - Infanticide - Drowning-Hanging - Strangulation - SuffocationLightning-Cold-Starvation-Rape-Pregnancy-Delivery-Birth-Inheritance-Legitimacy-Insanity, \&c. \&c.

"We recommend Mr. Taylor's work as the ablest, most comprehensive, and, above all, the most practical useful book which exists on the subject of legal medicine. Any man of sound judgment, who has mastered the contents of Taylor's 'Medical Jurisprudence,' may go into a Court of Law with the most perfect eonfidence of being able to acquit himself creditably." -Nedico-Chirurgical Review.

"Mr. Taylor possesses the happy art of expressing himself on a scientific topic in intelligible language. The size of his Manual fits it to be a circuit companion. It is one of the most beautiful specimens of typography we ever had the pleasure-and it is a pleasure-of perusing." - Law Times.

II.

\section{ON POISONS, in relation to MEDICAL JURISPRUDENCE AND} MEDICINE. Foolscap 8vo. cloth, 12s. 6d.

"Mr. Taylor's volume needs no praise of ours; its extraordinary cheapness, its beautiful typography, its portalility, all speak for themselves. We feel confident that it will ere long be the table-book of every medical practitioner who has the least regard for his own reputation, and be found in the circuitbag of the barrister." - Dublin Medical Journal.

"An excellent and valuable manual. We predict for it a vcry favourable rcception by the profession. It contains all that kind of information which a medical man will be glad to have access to when he has the prospect of appearing in the witness-box." - Edinburgh MIedical Journal.

MR. WILLIAM TAYLOR, M.R.C.S.

\section{ON A NET AND SUCCESSFUL TREATMENT FOR FEBRILE}

AND OTHER DISEASES, including Inflammatory Fever, Typhus, Scarlatinn, Measles, Dropsy, Incipient Phthisis, and Insanity, through the medium of the Cutaneous Surface. Illustrated with Cases. Post 8vo. cloth, 58.

DR. TILT.

\section{ON DISEASES OF MENSTRUATION AND OVARIAN} INFLAMMATION IN CONNECTION WITH STERILITY AND AFFECTIONS OF THE WOMB. Post 8vo. cloth, 6 s.

"We recommend the work of Dr. Tilt, both on account of the practical importance of the subject on which it treats, and the lucid and logical nanner in which the novel doctrines adranced in it are deduccd from premises that are certainly undeniable." - Lancet. 
MR. CHURCHILL'S PUBLICATIONS.

\section{DR. TUNSTALL.}

THE BATH WATERS; their Use and Effects in the Cure and Relief of various Chronic Diseases. 8ro. cloth, 5 s.

MR. TUSON, F.R.S.

SURGEON TO THE MIDDLESEX HOSPITAL.

I.

MYOLOGY. Illustrated by Plates on a Peculiar Construction; containing the Muscles of the Human Body, in Layers, as they appear on Dissection. Second Edition. . Large folio, $3 l .12 s$.

II.

A SUPPLEMENT TO MYOLOGY, Containing the Arteries, Veins, Nerves, and Lymphatics, the Abdominal and Thoracic Viscera, the Brain, the Ear, the Eye, \&c. \&c. Reduced from $4 l .12 s$. to $2 l$. $6 s$.

III.

THE ANATOMY AND SURGERY OF INGUINAL AND FEMORAL HERNIA. Illustrated by Plates coloured from Nature, and interspersed with Practical Remarks. Large folio, reduced from $2 l$. $2 s$. to $1 l$. $1 s$.

IV.

THE CAUSE AND TREATMENT OF CURVATURE OF THE SPINE, AND DISEASES OF THE VERTEBRAL COLUMN, with Cases. Plates. 8vo. cloth, $10 s$. v.

THE STRUCTURE AND FUNCTIONS OF THE FEMLALE BREAST, AS THEY RELATE TO ITS HEALTH, DERANGEMENT, OR DISEASE. 8ro. cloth, 10s. $6 d$.

DR. TURNBULL,

PHYSICIAN TO THE LIVERPOL NORTHERN HOSPITAL.

I.

A TABULAR VIEW AND SYNOPSIS OF THE PHYSICAL SIGNS AND DIAGNOSIS OF THE' DISEASES OF THE LUNGS. With Woodcuts, mounted on cloth, $5 s$. boards.

"This tabular view, affording a coup d'œil of the various auscultatory \&c. phenomena discoverable in health and disease, will prove useful to many practitioners, as well as students, in their investigation of thoracic maladies."-Medica-Chirurgical Review.

\section{II.}

AN INQUIRY HOW FAR CONSUMPTION IS GURABLE; WITH OBSERVATIONS ON THE TREATMENT AND ON THE USE OF COD-LIVER OIL AND OTHER REMEDIES. 8ro. cloth, $4 s$.

MR. TUKE.

DR. JACOBI ON THE CONSTRUCTION AND MANAGENENT OF HOSPITALS FOR THE INSANE. Translated from the German. With Introductory Observations by the Editor. With Plates. 8ro. cloth, 9s. 


\section{MR. CHURCHILL'S PUBLICATIONS.}

\section{DR. SPENCER THOMSON.}

I.

TEMPERANCE AND TOTAL ABSTINENCE; 0R, THE USE AND ABUSE OF ALCOHOLIC LIQUORS IN HEALTH AND DISEASE. Being the Second Essay of the Temperance Prize, and recommended for publication by the Adjudicators. Post 8vo., 2s. 6d.

II.

BRITISH CHOLERA : its Nature and Causes considered in connection with Sanitary Improvement, and in comparison with Asiatic Cholera. Post 8vo. cloth, $4 s$.

"The work is sensible and well written, and bears on every page the results of a personal investigation of the subject under treatment."-Lancet.

DR. UNDERWOOD.

TREATISE ON THE DISEASES OF CHILDREN. Tenth Edition, with Additions and Corrections by HENRY DAVIES, M.D. 8vo. cloth, 15s.

VESTIGES OF THE NATURAL HISTORY OF CREATION. People's Edition. Foolscap 8vo. sewed, 2s. $6 d$. BY THE SAME AUTHOR.

EXPLANATIONS : A SEQUEL TO "VESTIGES." Second Edition. Post 8vo. cloth, $5 s$.

MR. WALKER.

INTERMARRIAGE; OR, THE NATURAL LAWS BY WHICH BEAUTY, HEALTH, AND INTELLECT RESULT FROM CERTAIN UNIONS, AND DEFORMITY, DISEASE, AND INSANITY FROM OTHERS. With Delineations of the Functions and Capacities which each Parent bestows on Children, and an Account of Corresponding Effects in the Breeding of Animals. With Plates. Second Edition. 8vo. cloth, $14 s$.

DR. WALLER, LECTURER ON MIDWIFERT AT ST. THOMAS'S HOSPITAL.

A PRACTICAL TREATISE ON THE FUNCTION AND DISEASES OF THE UNIMPREGNATED WOMB. With a Chapter on Leucorrhoea, Fluor Albus, or Weakness. Illustrated by Plates. 8vo. cloth, 9s.

DR. SETH B. WATSON.

THE CHOLERA AT MALTA IN 183\%. From the Italian of Dr. Stilon. To which is prefixed, a LETTER from SIR JOHN STODDART, LL.D., then Chief Justice at Malta. 18mo. cloth, price $5 s$.

DR. WRIGHT,

PHYSICIAN TO QUERN'S HOSPITAL, BIRMINGHAM.

PATHOLOGICAL RESEARCHES ON DEATH FROM SUFFOCATION AND FROM SYNCOPE, AND ON VITAL AND POST-MORTEM BURNING: suggested by the Case of the alleged Bridgnorth Matricide. 4to. with plates, $3 s, 6 d$. 
MR. CHURCHILL'S PUBLICA'TIONS.

ERASMUS WILSON, F.R.S.

I.

\section{THE ANATOMIST'S VADE-MECUM: A SYSTEM OF HUMAN}

ANATOMY. With numerous Illustrations on Wood. Fourth Edition. Foolscap 8ro.

cloth, 12s. 6d.

"As a satisfactory proof tbat the praise we bestowed on the first edition of this work was not unmerited, we may obserre it bas been equally well thought of in foreign countries, haring been reprinted in the United States and in Germany. In every respect, tbis work, as an anatomical guide for the student and the practitioner, merits our warmest and most decided praise." -Medical Gazette.

11.

DISEASES OF THE SKIN: A Practical and Theoretical Treatise on the DIAGNOSIS, PATHOLOGY, and TREATMENT OF CUTANEOUS DISEASES, arranged according to a Natural System of Classification, and preceded by an Outline of the Anatomy and Physiology of the Skiı. Second Edition. 8vo, cloth, 12s.

The SAME WORK; illustrated with Eight finely-executed Engravings on Steel $_{2}$ accurately coloured. 8vo. cloth, $28 s$.

"The work is very considerably improved in tbe present edition, and is, for tbe first time, illustrated witb plates. Of these plates it is impossible to speak too highly. Tbe representations of tbe various forms of cutaneous disease are singularly accurate, and the colouring excecds almost anything we bave met with in point of delicacy and finish." - British and Foreign Medical Review.

\section{III.}

HEALTHY SKIN : A Treatise on the Management of the Skin and Hair in relation to Health. Third Edition. Foolscap 8vo. 2s.6d.

"'The student will be delighted to find his labours so mucb facilitated; and a few bours of agreeable society with a most pleasantly-written book will do more to make him acquainted witb a class of obscure diseases than all tbat has been previously written on tbe subject."-Lancet.

iv.

ON RINGWORM, ITS CAUSES, PATHOLOGY, AND TREATMENT. Illustrated with a Steel Plate. Post 8vo. cloth, $5 s$.

V.

PORTRAITS OF DISEASES OF THE SKIN. Folio. Fasciculi I.

to VIII. Containing Four highly-finished Coloured Plates. 20s, each.

"May be truly designated a splendid performance, surpassing, in the artistic beauty of its delineations, and fully equalling in tbeir fidelity to nature, any tbing whicb bas yet been brought out in tbis country or on the continent. We can scarcely speak too strongly of the merits of this work."-British and Foreign Medical Review.

"The drawings appear to us to be executed with great care, and admirably fitted to assist diagnosis, and to familiarize the practitioner with the special characters of diseases of the skin."-Medical Gazette.

"We bave never before seen a work more beautifully got up, botb as regards tbe typograpby and tbe execution and colouring of the plates. Even Alibert's grand work sinks into tbe shade when placed by tbe side of that of Mr. Wilson's."-Laneet. 


\section{MR. CHURCHILL'S PUBLICATIONS.}

$-\infty$

DR. WILLIAMS, F.R.S.

PROFESSOR OF THE PRACTICE OF MEDICINe, EXIVERSITY COLLEGE, LONDON.

PRINCIPLES OF MEDICINE; comprehending General Pathology and

Therapeutics. Second Edition. 8ro. cloth, $14 s$.

“Thanks are due to Dr. Williams for publishing a work like the present: to the student of medicine, sincerely anxious to study and understand the great principles of the science, he has rendered a very useful service; while the practitioner will be all the better for having his knowledge made clear, orderly, and precise by the aid of a work like the present."-Edinburgh Medical Journal.

"We hail its appearance, not only on account of the value we are ready to attach to any production from the pen of its accomplished author, but also as the indication of a vast improvement in medical teaching, which must operate most favourably, at no distant date, on medical practice. The detailed examination on which we now enter will show that our anticipations are not too high and that the work possesses the strongest claims to attention."-British and Foreign Medical Review.

\section{DR. J. WILLIAMS.}

I.

\section{AN ESSAY ON THE USE OF NARCOTICS AND OTHER} REMEDIAL AGENTS CALCULATED TO PRODUCE SLEEP IN THE TREATMENT OF INSANITY, for which the Author obtained the Lord Chan-cellor's Prize in Ireland. Post 8vo, cloth, $4 s$.

\section{II.}

\section{ON THE ANATOMI, PHYSIOLOGY, AND PATHOLOGY OF} THE EAR; being the Prize Essay in the University of Edinburgh. With Plates. 8vo. cloth, 10s. $6 d$.

MR. WHITEHEAD, F.R.C.S.

SORGEON TO THE MANCHESTER AND SALFORD LYING-IN HOSPITAL.

\section{THE CAUSES AND TREATMENT OF ABORTION AND}

STERILITY : being the result of an extended Practical Inquiry into the Physiological and Morbid Conditions of the Uterus, with reference especially to Leucorrhoal Affections, and the Diseases of Menstruation. 8vo. cloth, $12 s$.

"The work is valuable and instructive, and one that reflects much credit alike on the industry and practical skill of the author."-Medico-Chirurgical Review.

DR. FORBES WINSLOW.

A SYNOPSIS OF THE LAT OF LUNACY; as far as it relates to the Organization and Management of Private Asylums for the Care and Trentment of the Insane. In the form of a Chart, varnished, mounted on canvass and rollers, price $6 s$.

MR. YEARSLEY.

DEAFNESS PRACTICALLY ILLUSTRATED; being an Exposition of Original Views as to the Causes and Treatment of Diseases of the Ear. Third Edition. Post 8vo. cloth, 5 s.

II.

ON THE ENLARGED TONSIL AND ELONGATED UVULA, and other Morbid Conditions of the Throat. Third Edition. 8vo. cloth, 5s. 


\title{
CHURCHILL'S SERIES OF MANUALS.
}

"We here give Mr. Churchill public thanks for the positive benefit conferred on the Medical Profession, by the series of beautiful and cheap Manuals which bear his imprint."British and Foreign Medical Review.

\section{AGGREGATE SAIE 41,000 corIES.}

DR. GOLDING BIRD, F.R.S.

\section{ELEMENTS OF NATURAL PHILOSOPHY;}

Being an Experimental Introduction to the Study of the Physical Sciences, with numerous Illustrations on Wood. Third Edition. Fcap. 8vo. cloth; $12 s, 6 d$.

DR. CARPENTER, F.R.S.

\section{A MANUAL OF PHYSIOLOGY.}

With numerous Illustrations on Steel and Wood. Fcap. 8vo. cloth, $12 s_{.} 6 d$.

\author{
MR. FERGUSSON, F.R.S.E.
}

\section{A SYSTEM OF PRACTICAL SURGERY.}

With numerous' Illustrations on Wood. Second Edition. Fcap. 8ro. clòth, 





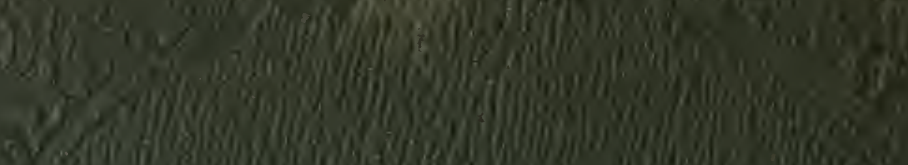

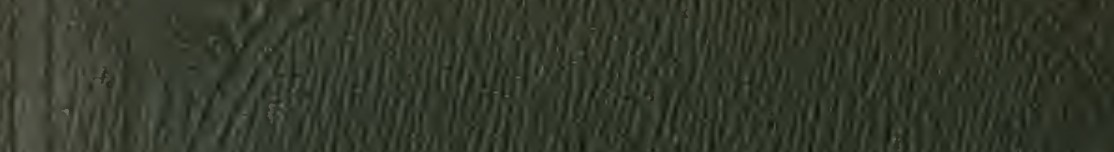

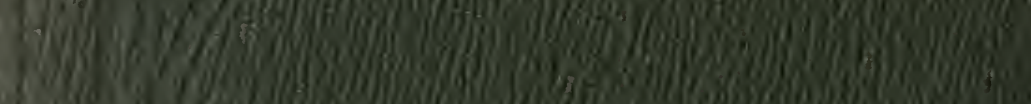

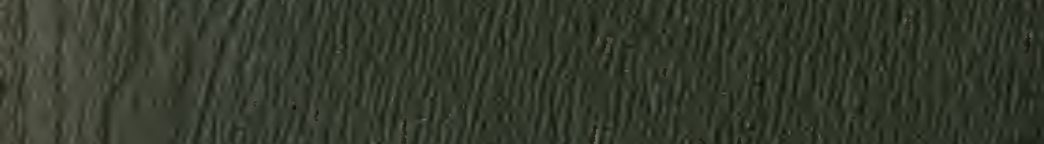

$10(1)$

W.

19.6.

Whis 1 is

40 (1)

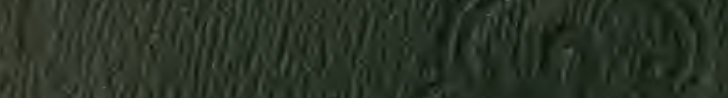

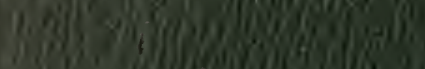

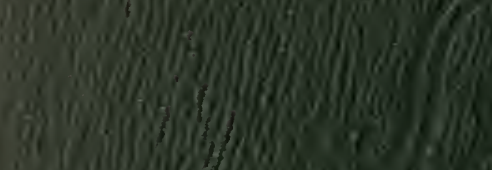

(6)

1)

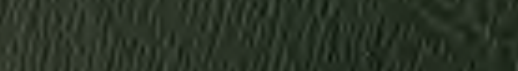

1).

achery

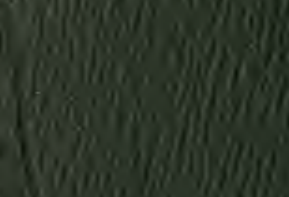

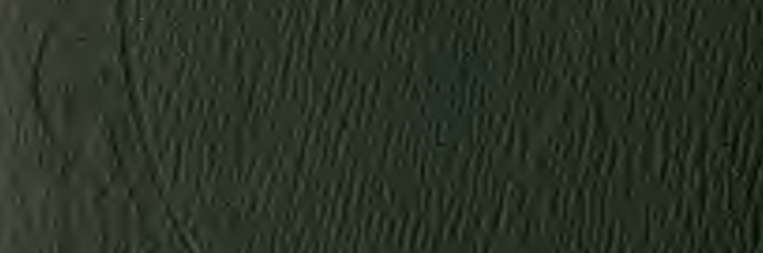

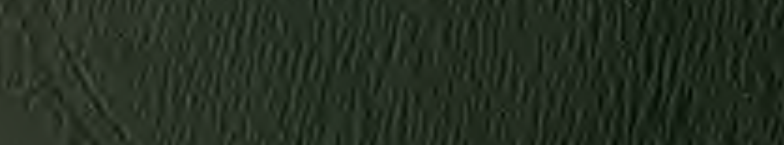

